\title{
THIAGO PIRES
}

\section{CONFIGURAÇÃO DE UMA REDE DE DISTRIBUIÇÃO}

\section{CAPACITADA COM RESTRIÇÃO DE COBERTURA}

Dissertação apresentada à Escola Politécnica da Universidade de São Paulo, para obtenção do título de Mestre em Engenharia de Sistemas Logísticos.

São Paulo

2006 


\section{THIAGO PIRES}

\section{CONFIGURAÇÃO DE UMA REDE DE DISTRIBUIÇÃO}

\section{CAPACITADA COM RESTRIÇÃO DE COBERTURA}

Dissertação apresentada à Escola Politécnica da Universidade de São Paulo, para obtenção do título de Mestre em Engenharia de Sistemas Logísticos.

Área de Concentração:

Engenharia de Transportes

Orientador:

Prof. Dr. Nicolau Dionísio Fares Gualda

São Paulo

2006 


\section{DEDICATÓRIA}

A Tatiana Henrique Garé Pires, minha esposa, com todo meu amor, pela sua paciência, compreensão e apoio durante o período do mestrado. 


\section{AGRADECIMENTOS}

Ao Prof. Dr. Nicolau Gualda, pela atenção e dedicação ao longo de todo o mestrado, especialmente no período de orientação do trabalho.

À minha família, pelo incondicional apoio desde o início do mestrado.

Aos amigos, que torceram por mim e me incentivaram durante a realização do curso. 


\section{RESUMO}

O presente estudo trata da configuração de uma rede de distribuição capacitada com restrição de cobertura. $\mathrm{O}$ objetivo é determinar quais cidades, dentre um conjunto de candidatas, devem atuar como centrais de desconsolidação de carga, de forma a minimizar o custo total de transporte (transferência e distribuição) para uma determinada demanda, atendendo às restrições operacionais e de distância de cobertura.

A partir da pesquisa na literatura sobre o assunto, foi preparado um modelo de programação linear inteira para encontrar a solução ótima para o problema. Esse modelo é baseado nos clássicos problemas de localização, com modificação na função objetivo para retratar melhor a estrutura de custos de transporte, além da inclusão de restrições de cobertura e restrições de atendimento mínimas e máximas em cada central. O modelo foi implementado utilizando o suplemento Solver da planilha eletrônica Excel.

Um outro enfoque de solução baseado na metaheurística Busca Tabu (Tabu Search) foi elaborado, com dois objetivos: permitir a análise de problemas quando não se tem disponível uma ferramenta para solução de modelos de programação linear; e analisar o comportamento da metaheurística quando utilizada na solução desse tipo de problema. O procedimento foi implementado a partir da construção de macros em linguagem Visual Basic for Application (VBA), também em Excel.

O modelo de programação linear e a metaheurística Busca Tabu foram aplicados a alguns cenários de um problema real. Resultados, comparações e conclusões dessas aplicações são apresentados neste trabalho. 


\begin{abstract}
The present study deals with configuring a capacitated distribution network with coverage constraint. The objective consists of determining which cities, among a set of candidates, should act as load deconsolidation centers, aiming to minimize transportation total costs to attend a given demand, and obeying all operational constraints and coverage distances.

Based on a literature review, an integer linear programming model was formulated to find the problem optimal solution. The model is based on classical location problems, but includes changes in the objective function to incorporate the transportation costs structure, besides coverage constraints and minimum and maximum central capacity constraints. The model was implemented using Excel's Solver add-in.
\end{abstract}

Another solution approach based on the Tabu Search metaheuristic was proposed, with two objectives: to permit problem analysis when linear programming tools are not available; and to learn on metaheuristic behavior when used to solve this type of problem. The Tabu Search procedure was implemented using Excel macro language in Visual Basic for Applications (VBA).

Both integer linear programming and metaheuristic models were applied to some scenarios of a real-world problem. Applications results, comparisons and conclusions are presented in this work. 


\section{LISTA DE FIGURAS}

Figura 2.1 - Caracterização da rede de distribuição objeto do estudo ................................... 14

Figura 2.2 - Relação entre distância de cobertura, custo total e número de representantes .... 15

Figura 2.3 - Padrão rota real versus rota equivalente para custo de rodagem ...................... 17

Figura 4.1 - Etapas da metodologia de solução .......................................................... 46

Figura 4.2 - Refinamento da alocação de cidades da solução original do procedimento ....... 55

Figura 4.3 - Fluxograma da Fase 1 da Busca Tabu............................................................ 56

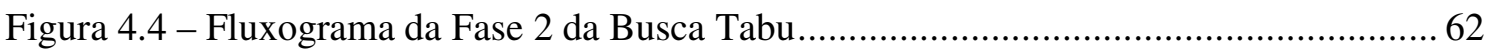

Figura 4.5 - Encaminhamento da metodologia de solução............................................. 67

Figura 5.1 - Gráfico de correlação entre distância real e teórica ......................................... 74

Figura 5.2 - Gráfico de relação entre cobertura, custo e representantes no cenário 1 ........... 77

Figura 5.3 - Gráfico de relação entre cobertura e custos dos cenários 1 e 2 ........................ 80

Figura 5.4 - Rede do problema real estudado, com destaque as candidatas às centrais.......... 84

Figura 5.5 - Relação entre cobertura, custos e representantes ............................................ 89

Figura 5.6 - Solução para 300 km de cobertura, sem restrições operacionais........................ 90

Figura 5.7 - Solução para 300 km de cobertura, com restrições operacionais ...................... 90

Figura 5.8 - Solução para 150 km de cobertura, sem restrições operacionais....................... 94

Figura 5.9 - Solução da PL para 400 km de cobertura, com restrições operacionais ............. 97

Figura 5.10 - Solução da BT para 400 km de cobertura, com restrições operacionais ........... 97

Figura A.1 - Tela de parâmetros do PSP ................................................................ 107

Figura A.2 - Tela de opções do PSP .................................................................... 107

Figura A.3 - Trecho da macro Refinamento codificada em VBA .................................... 108

Figura A.4 - Planilha de registro dos resultados intermediários da Busca Tabu .................. 109

Figura A.5 - Planilha de acompanhamento das iterações do procedimento........................ 109

Figura A.6 - Planilha com parte da matriz de alocação (variáveis de decisão) ..................... 110

Figura A.7 - Exemplo de mapa de alocação gerado através de gráfico no Excel................. 111 


\section{LISTA DE TABELAS}

Tabela 5.1 - Cidades que compõem a rede do problema preliminar................................. 70

Tabela 5.2 - Latitude, longitude e demanda dos nós da rede do problema preliminar ........... 70

Tabela 5.3 - Custos de transporte de cada nó da rede do problema preliminar (continua) ..... 71

Tabela 5.3 - Custos de transporte de cada nó da rede do problema preliminar (conclusão) ... 72

Tabela 5.4 - Matriz de distância teórica $(\mathrm{em} \mathrm{km})$ para o problema preliminar ...................... 72

Tabela 5.5 - Matriz de distância real (em km) para o problema preliminar.......................... 73

Tabela 5.6 - Resultado da aplicação do modelo ao cenário 1 do problema preliminar .......... 76

Tabela 5.7 - Restrições operacionais dos nós do problema preliminar............................... 78

Tabela 5.8 - Resultados da aplicação do modelo para o cenário 2 ….................................. 79

Tabela 5.9 - Dados da rede do problema real (continua) ............................................. 81

Tabela 5.9 - Dados da rede do problema real (continuação) ............................................. 82

Tabela 5.9 - Dados da rede do problema real (conclusão) ….......................................... 83

Tabela 5.10 - Dados das cidades candidatas a central de desconsolidação (representantes) .. 84

Tabela 5.11 - Matriz de distâncias reais para o problema real (continua)............................. 85

Tabela 5.11 - Matriz de distâncias reais para o problema real (continuação) ....................... 86

Tabela 5.11 - Matriz de distâncias reais para o problema real (conclusão) .......................... 87

Tabela 5.12 - Resultados do modelo de programação linear para o problema real ................ 88

Tabela 5.13 - Resultados do procedimento Busca Tabu para o problema real......................93

Tabela 5.14 - Comparação entre os resultados da programação linear e da Busca Tabu ....... 95

Tabela 5.15 - Desempenho da Busca Tabu para os diferentes cenários do problema real ..... 96 


\section{SUMÁRIO}

1 INTRODUÇÃO

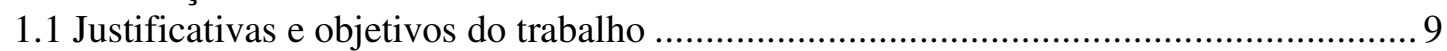

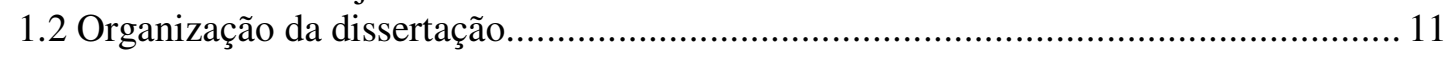

2 CARACTERIZAÇÃO DO PROBLEMA EM QUESTÃO …………………………....... 12

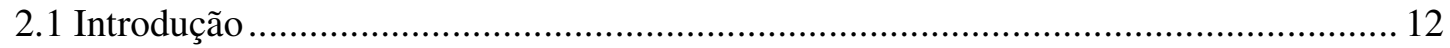

2.2 Descrição geral do problema ................................................................................... 13

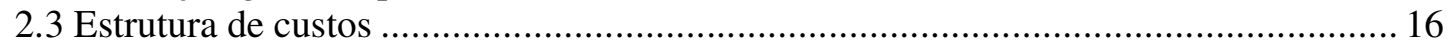

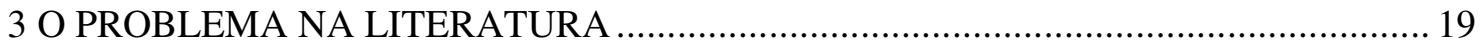

3.1 Histórico da teoria de localização de instalações...………………………………….... 19

3.2 Classificação dos problemas e modelos de localização .............................................. 20

3.3 Modelos Clássicos de Localização............................................................................ 23

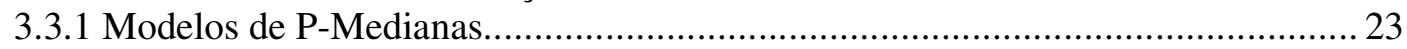

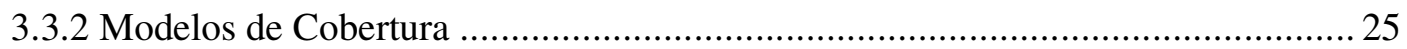

3.3.3 Modelos de Centro ………........................................................................ 30

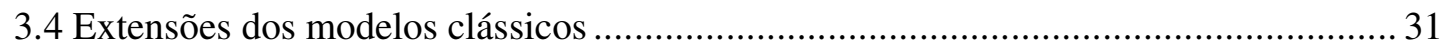

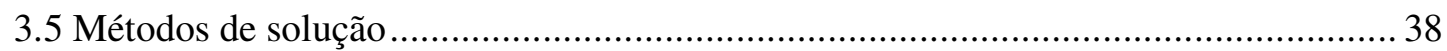

3.5.1 A metaheurística Busca Tabu............................................................................ 41

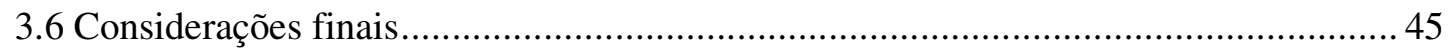

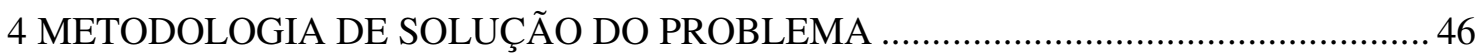

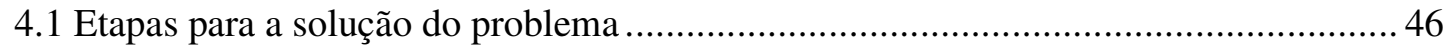

4.2 Especificação do modelo de programação linear selecionado ………………………... 49

$4.3 \mathrm{O}$ procedimento baseado na metaheurística Busca Tabu .............................................52

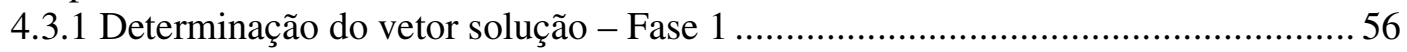

4.3.2 Refinamento da solução de alocação - Fase 2 ………………………………........ 61

4.4 Encaminhamento da aplicação de metodologia proposta................................................. 64

5 APLICAÇÃO DA METODOLOGIA AO PROBLEMA EM QUESTÃO ............................69

5.1 Aplicação da metodologia com o modelo de programação linear ....................................69

5.1.1 Estudo preliminar - utilização do Solver padrão ……………………………….... 70

5.1.2 Estudo de caso - utilização do Premium Solver Platform..................................... 80

5.2 Aplicação da metodologia com o procedimento baseado em Busca Tabu .................... 91

5.3 Comparação entre os resultados da programação linear e da Busca Tabu ..................... 93

5.4 Considerações finais sobre a aplicação da metodologia .............................................. 98

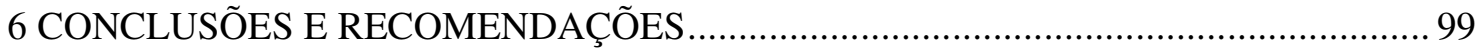

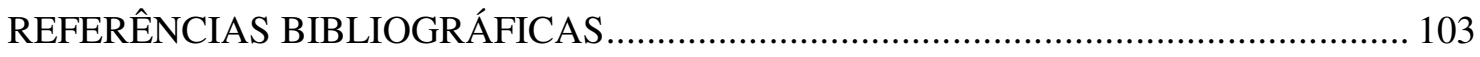

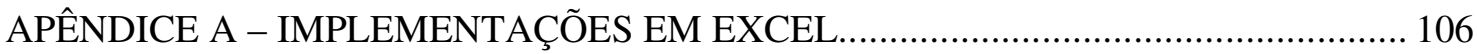

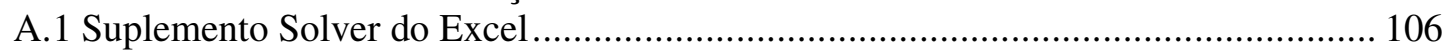

A.2 Codificação da Busca Tabu em Visual Basic for Application ……………………..... 107

A.3 Geração de mapas de alocação............................................................................... 110 


\section{INTRODUÇÃO}

\subsection{Justificativas e objetivos do trabalho}

O problema de determinar o local para instalações fixas ao longo de uma rede logística é uma das mais importantes decisões de planejamento de nível estratégico a ser tomada pelos profissionais de logística. Sua importância provém geralmente dos altos investimentos envolvidos e do grande impacto que essas decisões têm sobre os custos logísticos.

As decisões de localização estão ligadas à determinação do número, do tamanho e da própria localização geográfica das instalações a serem usadas. Essas instalações são conhecidas como pontos ou nós da rede logística e podem ser fábricas, portos, fornecedores, armazéns, filiais, centros de serviço e terminais de transporte, que possuem a característica de servir de ponto de parada temporária no fluxo de entrega do bem ou serviço ao consumidor final.

Por outro lado, a importância de otimizar os custos de transporte e atender a níveis de serviço cada dia mais exigentes, está na essência das empresas do setor de logística e transporte. O presente estudo visa a justamente disponibilizar uma ferramenta prática para a avaliação e configuração de uma rede de distribuição, com ênfase na minimização dos custos relacionados à operação de transporte de carga fracionada.

A partir da adaptação do modelo clássico de localização, aliado ao conceito de cobertura da classe de problemas com essa característica presente na literatura, foi proposta uma modelagem para a solução do problema da rede de distribuição. 
Na modelagem tradicional, normalmente os nós a serem localizados referem-se às instalações de médio ou grande porte, tais como fábricas e armazéns, com alto custo fixo relacionado à sua abertura e fechamento. A modelagem aqui apresentada visa à localização ótima de centrais de desconsolidação de carga que se caracterizam por pontos estratégicos para os quais são transferidas, de forma consolidada, as cargas a serem entregues na região de alcance da central. Geralmente são locais que requerem um investimento bem menor para sua abertura ou fechamento.

Essa diferença pode ser também compreendida do ponto de vista de planejamento. Enquanto a localização de fábricas e armazéns assume um caráter mais estratégico, em função dos altos valores envolvidos e da maior dificuldade em alterar a solução após sua implantação, a localização das centrais pode ser considerada uma ferramenta de planejamento tático, uma vez que sua decisão influencia a rede logística de distribuição, mas pode ser modificada com maior facilidade.

Além da modelagem para solucionar o problema de localização de forma ótima, uma outra estratégia baseada na metaheurística Busca Tabu (Tabu Search) foi avaliada como método alternativo de solução. Seu desenvolvimento e implementação também são discutidos neste trabalho, juntamente com a comparação entre as soluções obtidas tanto pela modelagem tradicional quanto pelo procedimento.

No encaminhamento da metodologia adotada, que contempla as etapas para análise do problema, destaca-se a implementação computacional - em planilha eletrônica Excel - dos modelos estudados. 
Como resultado da aplicação dessa metodologia, está a configuração de uma rede de distribuição, com a seleção das melhores centrais de desconsolidação de carga do ponto de vista de mínimo custo de transporte. Essa configuração, além de atender às restrições operacionais inerentes ao problema, garantirá o nível de serviço desejado a partir da alocação das cidades às centrais respeitando a distância de cobertura determinada.

\subsection{Organização da dissertação}

No próximo capítulo é caracterizado o problema objeto do estudo e a hipótese a ser desenvolvida ao longo da dissertação. No capítulo três é apresentado o resultado da revisão bibliográfica realizada sobre o tema modelos matemáticos de localização, desde as primeiras formulações até os atuais métodos de solução, incluindo aqueles baseados na metaheurística busca tabu. A metodologia de solução do problema, a descrição do modelo a ser implementado e a constituição do procedimento baseado em Busca Tabu, constituem o quarto capítulo desse texto. O capítulo cinco é dedicado à aplicação da metodologia de solução ao problema particular de um operador logístico. No mesmo capítulo, os resultados são apresentados juntamente com a análise crítica e comparativa das soluções encontradas por ambos os métodos. As conclusões e recomendações do estudo são relatadas no sexto e último capítulo da dissertação. 


\section{CARACTERIZAÇÃO DO PROBLEMA EM QUESTÃO}

\subsection{Introdução}

O problema estudado é o de configuração de uma rede de distribuição de carga fracionada de um operador logístico. O objetivo é determinar quais cidades, dentre um conjunto de candidatas, devem atuar como centrais de desconsolidação de carga, de forma a minimizar o custo total de transporte (transferência e distribuição) para uma determinada demanda.

Trata-se de uma rede de fluxo unidirecional, ou seja, toda carga parte de uma mesma origem com diferentes destinos e não há movimentação de carga entre as cidades da rede.

A natureza da carga a ser distribuída é material promocional, principalmente brindes (camisetas, canetas, bonés, etc.) e impressos em geral (folders, cartazes, banners, displays, etc.)

Cada conjunto de entregas corresponde a uma Campanha para o problema em questão. Uma Campanha se caracteriza pelo fato de concentrar em um curto espaço de tempo normalmente uma semana - uma grande quantidade de materiais a ser distribuída em diversos pontos de venda. Outra característica importante de uma Campanha está no fato de que preferencialmente os pontos de venda devem receber suas remessas com a mínima variação possível de prazo, ou seja, no mesmo dia.

Esse fato determina o aspecto tático do estudo, à medida que a solução encontrada tem suas condições de validade restritas às características daquela particular distribuição. 
Esse tipo de abordagem consiste numa forma de estruturação de uma rede "volátil" de distribuição, uma vez que a escolha das centrais de desconsolidação pode mudar diariamente, dependendo da distribuição geográfica e nível de demanda das Campanhas a serem realizadas.

\subsection{Descrição geral do problema}

Os locais de entrega, chamados de nós da rede, são agrupados e representados pelas cidades nas quais estão localizados, e têm sua demanda determinada sobre dois aspectos: quantidade de carga a ser entregue (em quilogramas $(\mathrm{kg})$ ) e quantidade de entregas a serem feitas, que corresponde ao número de locais a serem visitados (diferentes endereços). Isso quer dizer que em uma mesma cidade, podem ter diversos locais de entrega que juntos correspondem à demanda total de peso associada a essa cidade.

Um subconjunto da rede são as cidades candidatas a sediar uma central para desconsolidação e distribuição de carga. No problema em estudo, as cidades candidatas são aquelas que possuem representantes locais capacitados à realização da distribuição regional. Os critérios para definição desses locais candidatos estão relacionados principalmente à posição geográfica do município, facilidade de acesso através de rodovias, presença de aeroportos, nível de demanda, entre outros, e constituem dados de entrada do problema.

Um aspecto importante é o fato de que esses representantes já existem nesses locais, independente de serem ou não utilizados em todas as distribuições. Trata-se, em sua maioria, de empresas que prestam o mesmo tipo de serviço a outros operadores logísticos e transportadores. 
Por essa razão, o problema é tratado do ponto de vista de "escolha" de centrais, e não de sua abertura ou instalação, objetivo de grande parte dos modelos de localização. Por outro lado, a análise das soluções obtidas com a aplicação do modelo selecionado, pode identificar a carência de centrais em determinada região, servindo como ponto de partida para a seleção e contratação de novos representantes.

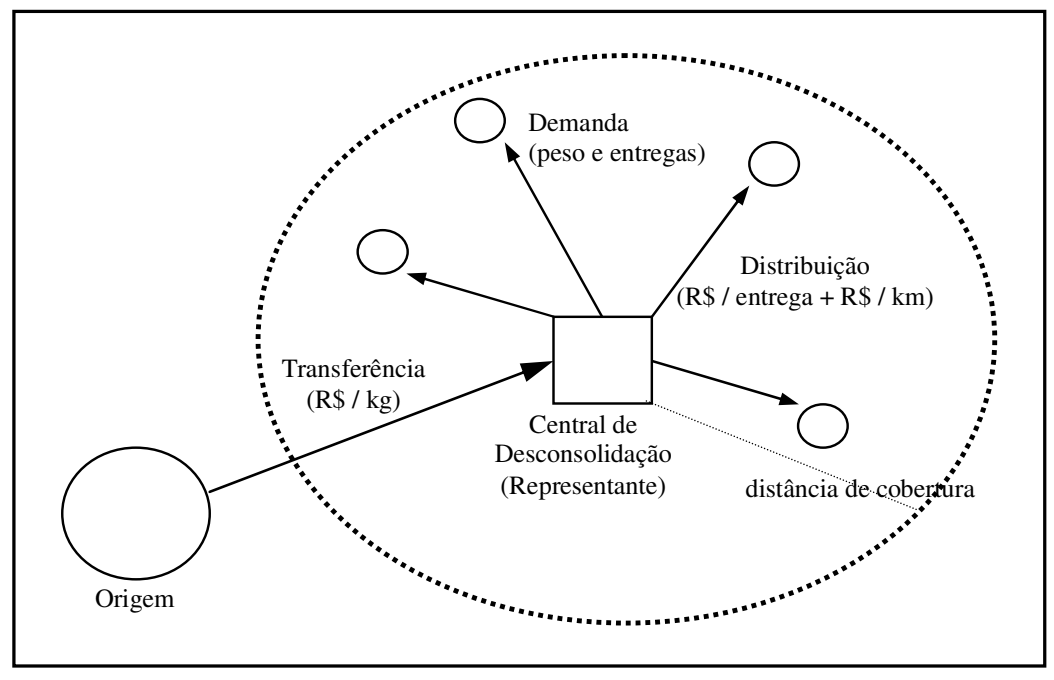

Figura 2.1 - Caracterização da rede de distribuição objeto do estudo

Podemos caracterizar o problema a partir de algumas questões de planejamento:

1. Quantos representantes devem fazer parte da rede de distribuição?

2. Qual será a demanda que cada um precisará comportar?

3. Onde devem estar localizados?

4. Quais cidades devem estar designadas a cada representante, de forma a se cumprir o nível de serviço estabelecido para a campanha?

Nesse problema, o conceito de nível de serviço está associado à distância de cobertura (medida em quilômetros, $\mathrm{km}$ ), isto é, a proximidade da cidade a ser atendida do representante 
selecionado, é considerada fator de garantia para que as entregas sejam realizadas dentro dos prazos estabelecidos (ver figura 2.1).

Portanto, a escolha dos representantes é diretamente influenciada pelo nível de serviço que se deseja oferecer ao cliente. Quanto melhor esse nível, menor a distância de cobertura e, provavelmente, maior a quantidade de representantes que será preciso dispor, resultando em maiores custos de transporte, conforme ilustrado na figura 2.2 abaixo.

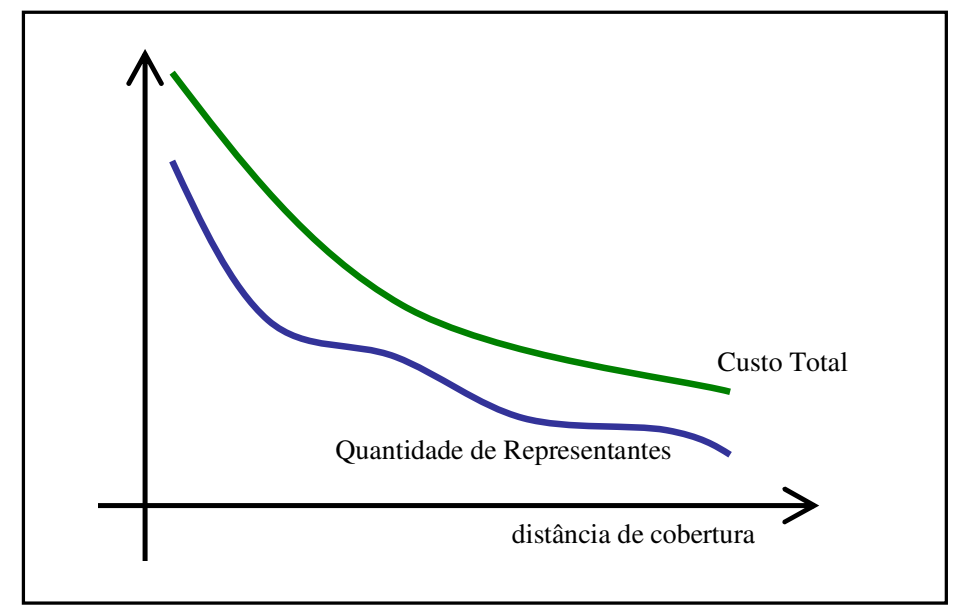

Figura 2.2 - Relação entre distância de cobertura, custo total e número de representantes

Outra restrição inerente ao problema diz respeito à capacidade de entrega dos representantes locais. Para cada um deles, existe um limite superior em peso $(\mathrm{kg})$ a partir do qual a distribuição é prejudicada por restrições operacionais principalmente relacionadas à alocação de frota. Essa restrição corresponde à capacidade total $(\mathrm{em} \mathrm{kg})$ que a frota disponível em cada representante é capaz de transportar em caso de uma Campanha, ou seja, num curto intervalo de tempo. 
Analogamente, a cada um dos representantes candidatos à rede de distribuição, também está associada uma quantidade mínima de entregas a partir da qual esses representantes podem ser "acionados", de forma a garantir a mínima remuneração necessária para a viabilidade da distribuição.

Para o transporte de transferência, ou seja, aquele desde a origem até as centrais selecionadas, normalmente são utilizadas transportadoras que possuem freqüência constante de embarques para os locais selecionados. Não oferecem restrição de capacidade, à medida que a estrutura que dispõem para realização do transporte é bem superior em comparação às demandas de distribuição a serem tratadas no problema.

\subsection{Estrutura de custos}

A estrutura de custos do problema em questão está relacionada à terceirização do transporte por parte dos operadores logísticos. Considera-se que, tanto a etapa de transferência até as centrais selecionadas, quanto a distribuição dentro da área de cobertura dessas centrais, será feita a partir da contratação de transportadoras e representantes locais, constituindo uma rede de distribuição terceirizada. Dessa forma, os custos retratados nesse trabalho, correspondem aos valores a serem pagos pelo operador logístico a esses prestadores de serviço.

O objetivo do estudo em questão é minimizar os custos de distribuição utilizando representantes locais. Conforme já explicado anteriormente, esses representantes não precisam ser "instalados", isto é, eles já estão estabelecidos e se trata de uma questão de escolha de quais serão utilizados, respeitando as restrições de capacidade e também as de nível de serviço. 
Pelo fato de serem locais utilizados esporadicamente, não existe um custo fixo associado a essa utilização. Todas as despesas existentes, por parte dos representantes, em relação às entregas a serem realizadas são traduzidas no valor por entrega cobrado por cada um deles.

Pela realização do serviço de distribuição na cidade em que estão localizados, esses representantes cobram uma taxa fixa por entrega realizada. Isso é válido desde que conhecidas as propriedades de peso e volume das entregas. Para a distribuição nas demais cidades de sua região, é acrescida ao valor da entrega uma taxa por $\mathrm{km}$ rodado (custo de rodagem) até a cidade destino (normalmente essa distância é assumida de centro a centro das cidades, obtida em guias rodoviários).

Uma consideração implícita ao cálculo da taxa de rodagem é a de que um veículo exclusivo será destacado para cada cidade a ser atendida dentro da distância de cobertura. Isso significa que para efeito do custo de rodagem, sempre será considerado um veículo partindo da central direto à cidade destino, sem atender a nenhuma outra cidade. $\mathrm{Na}$ prática, dependendo do porte, um mesmo veículo pode realizar as entregas de mais de uma cidade, seguindo uma roteirização pré-estabelecida (ver figura 2.3).

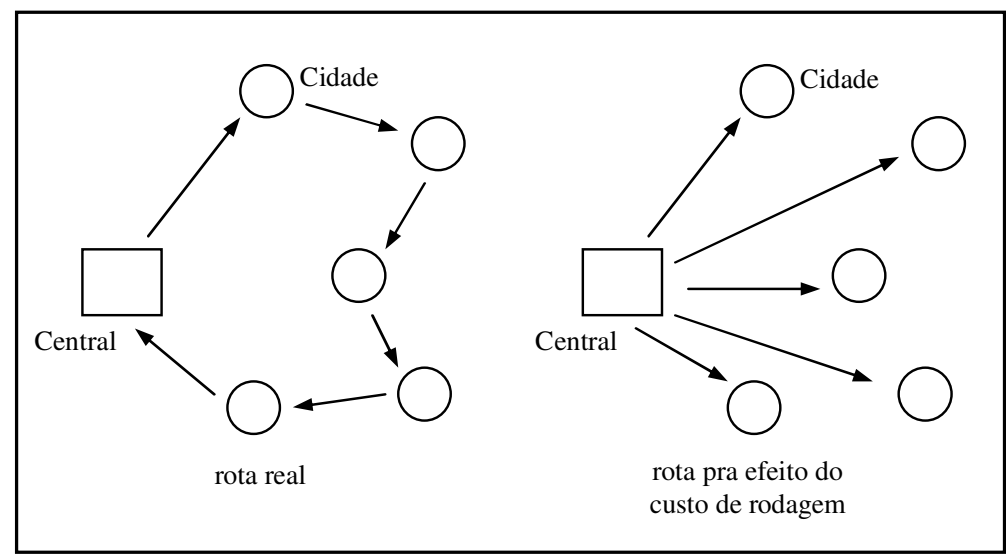

Figura 2.3 - Padrão rota real versus rota equivalente para custo de rodagem 
Por serem utilizadas transportadoras na transferência de carga da origem até os representantes escolhidos, os custos relacionados ao transporte de transferência são no formato tradicional das tabelas de fretes das transportadoras, isto é, valores unitários por quilograma transportado, variando conforme a faixa de peso e a cidade destino. Devido a essa estrutura de custo, é possível identificar oportunidades de economia de escala ao se concentrar uma maior quantidade de peso transferido para um mesmo representante, desde que respeitadas as restrições operacionais e de nível de serviço.

O fato de serem utilizadas transportadoras e representantes (estes atuando como centrais de desconsolidação) confere à rede de distribuição a possibilidade de obtenção de melhores níveis de serviço. Isso porque a transportadora fica responsável pelo transporte de transferência, desde a origem até as centrais (dado que normalmente são utilizadas rotas já estabelecidas e com freqüência conhecida), enquanto a distribuição local é tratada de forma cuidadosa com cada um dos representantes selecionados, especialistas nas entregas em suas regiões de atuação.

Não é foco do trabalho o aprofundamento na discussão ou cálculo dos valores unitários cobrados em cada uma das etapas do transporte. A proposta é a elaboração de um modelo no qual esses valores sejam dados de entrada, cabendo ao operador logístico sua melhor apuração.

Uma vez caracterizado o problema objeto do estudo, buscou-se a partir da revisão bibliográfica (principalmente relacionada ao tema de localização) quais seriam os modelos e as estratégias de solução possíveis para esse tipo de problema. O resultado é apresentado no próximo capítulo. 


\section{O PROBLEMA NA LITERATURA}

Este capítulo trata da revisão bibliográfica relacionada à modelagem matemática dos problemas de localização. Inicialmente é apresentado um breve histórico sobre o tema; em seguida, são discutidos alguns critérios de classificação. Três modelos considerados clássicos na literatura são descritos, bem como suas extensões. Os possíveis métodos de solução e as considerações finais encerram o capítulo.

\subsection{Histórico da teoria de localização de instalações}

A formulação de teorias de localização data da segunda metade do século XIX, com a publicação do estudo do economista alemão Johann Von Thunen, que identificou a tendência de localização das atividades econômicas de maior valor agregado ao redor do centro da cidade e ao longo das vias de transporte (Ballou, 2001).

No entanto, o trabalho de Alfred Weber, em 1909, é considerado por alguns autores como o marco inicial do estudo da teoria da localização (Brandeau e Chiu, 1989; Owen e Daskin, 1998). Weber analisou a importância da matéria-prima em relação ao produto acabado para diferentes processos de produção e concluiu que, para minimizar os custos de transporte, as instalações devem estar mais próximas das fontes de matéria-prima para os mercados cujo processo de produção implica perda de peso e mais próximas dos mercados consumidores, quando esse processo gera aumento de peso no produto acabado (Ballou, 2001).

Edgar Hoover (1957), citado por Ballou (2001), destacou o comportamento de crescimento das taxas de transporte de acordo com a distância percorrida e concluiu que, para os 
problemas nos quais esse tipo de custo é dominante, os menores custos de transporte serão alcançados se a instalação estiver posicionada ou na fonte de matéria-prima ou no próprio mercado consumidor.

Uma característica comum a todos esses trabalhos e que permanece até hoje presente nos estudos de localização é a importância atribuída aos custos de transporte na determinação da localização das instalações consideradas.

O estudo da teoria de localização teve um grande impulso em 1964, com a publicação do artigo de Hakimi, no qual o autor buscava localizar centrais em redes de comunicação e postos policiais em rodovias, com o objetivo de minimizar a distância total entre usuários e a instalação mais próxima de cada um, ou para minimizar essa máxima distância (Owen e Daskin, 1998).

\subsection{Classificação dos problemas e modelos de localização}

A partir dos anos 60, o interesse por parte dos pesquisadores em relação ao assunto pode ser observado pelo grande número de trabalhos publicados (Vallim, 2004). Aliado a isso, o fato dos problemas de localização poderem ser explorados de vários pontos de vista, e serem aplicáveis em vários setores de atividade, alguns autores se propuseram a estabelecer classificações a esses problemas (e aos modelos utilizados para resolvê-los), com o objetivo de agregar maior transparência às discussões científicas e eliminar possíveis ambigüidades.

De acordo com Giannikos e Nickel (1998), propostas de esquema de classificação para modelos de localização surgiram em 1979 com Handler e Mirchandani. Estes autores 
sugeriram um esquema de quatro posições para classificar os modelos de localização, com funções objetivo do tipo centro, aplicado somente a problemas de rede.

Outro tipo de classificação, criado por Brandeau e Chiu (1989), distingue os modelos de localização com base em três critérios: objetivo, variáveis de decisão e parâmetros do sistema.

Daskin (1995), com base na taxonomia descrita acima e em outra semelhante apresentada por Krarup e Pruzan (1990), define uma estrutura de classificação para os modelos e problemas de localização da qual os principais elementos são descritos abaixo:

a) Topografia dos modelos: planares, de rede ou discretos. Nos modelos planares, a demanda e as instalações podem acontecer em qualquer lugar do plano. Em se tratando de modelos de rede, demanda, instalações e as viagens entre eles estão contidas em um grafo formado por nós e ligações. A diferença entre esse modelo e o discreto é que neste último a distância entre nós não está relacionada a uma rede pré-determinada e, portanto, é arbitrada a partir de métricas de distância conhecidas (Manhattan, Euclidiana, etc.) ou algoritmos.

b) Número de instalações a serem localizadas: única ou múltiplas instalações. Dependendo do modelo a ser utilizado, a determinação do número de instalações é especificada endógena ou exogenamente, ou seja, respectivamente como variável do problema ou dado de entrada. Para ambos os casos, os problemas podem ser de localização de uma única ou de várias instalações.

c) Tipo de objetivo: único ou múltiplos. Embora a maioria dos problemas seja modelada com uma única função objetivo, na prática muitas situações implicam na análise de mais de um 
objetivo, geralmente conflitantes. Para esses casos, são necessários modelos multiobjetivos.

d) Capacidade das instalações a serem localizadas: fixa ou ilimitada. Dependendo da aplicação, o modelo utilizado pode ter, como uma classe de restrições, características que limitam o tamanho das instalações ou sua capacidade de processamento de determinado serviço. Em outras situações, restrições dessa natureza são relaxadas, se tratando, pois, de modelos de capacidade ilimitada.

e) Natureza do problema: estática ou dinâmica. No caso dos problemas estáticos, os dados de entrada não dependem do tempo. A solução encontrada é válida somente para aquele conjunto de dados naquele período considerado. Muitas das pesquisas publicadas sobre teoria de localização buscam soluções para essa classe de problemas (Owen e Daskin, 1998). No entanto, o aspecto estratégico inerente ao problema de localização sugere que os modelos empregados considerem algumas características relativas à incerteza futura. Com esse objetivo, nos problemas de localização de natureza dinâmica são realizadas análises em múltiplos períodos, buscando a solução ótima no horizonte de tempo determinado. Esses diferentes períodos visam a capturar as principais possíveis variações nos dados que podem influenciar a solução, tais como demanda e custos.

f) Natureza dos dados de entrada: determinística ou probabilística. Quando os dados de entrada do modelo não estão sujeitos à incerteza, o problema é de natureza determinística. Em oposição, alguns dados (tempos de viagem e demandas, por exemplo) podem ter comportamento estocástico, e assim, precisarem ser representados por funções de probabilidade. 
O foco do presente estudo está nos problemas estáticos e determinísticos que representam a grande maioria das aplicações práticas e são classificados em três grandes grupos considerados clássicos na literatura (Tondo, 1992; Daskin, 1995; Owen e Daskin, 1998; Vallim, 2004): problema das p-medianas, problema de cobertura e problema de centro.

\subsection{Modelos Clássicos de Localização}

\subsubsection{Modelos de P-Medianas}

O problema das p-medianas foi introduzido por Hakimi (1964) e tem como objetivo encontrar a localização ótima de $\mathrm{p}$ instalações de forma a minimizar a distância total ponderada pela demanda entre cada nó de demanda e sua instalação mais próxima.

Daskin (1995) apresenta a seguinte formulação matemática para o problema das p-medianas:

Dados de entrada:

$h_{i}=$ demanda no ponto $i$

$d_{i j}=$ distância entre o nó $i$ e o local candidato $j$

$P=$ número de instalações a localizar

Variáveis de decisão:

$\mathrm{X}_{\mathrm{j}}=\left\{\begin{array}{l}1 \text { se houver uma instalação em } j \\ 0 \text { caso contrário }\end{array}\right.$

$\mathrm{Y}_{\mathrm{ij}}=\left\{\begin{array}{l}1 \text { se o nó } \text { i for atendido por uma instalação em } j \\ 0 \text { caso contrário }\end{array}\right.$

Função objetivo: 
$\operatorname{Minimizar} \sum_{\mathrm{i}} \sum_{j} \mathrm{~h}_{\mathrm{i}} \mathrm{d}_{\mathrm{ij}} \mathrm{Y}_{\mathrm{ij}}$

Restrições:

$\sum_{\mathrm{j}} \mathrm{Y}_{\mathrm{ij}}=1 \quad \forall \mathrm{i}$

$\sum_{j} X_{j}=p$

$\mathrm{Y}_{\mathrm{ij}}-\mathrm{X}_{\mathrm{j}} \leq 0 \quad \forall \mathrm{i}, \mathrm{j}$

$\mathrm{X}_{\mathrm{j}}=0,1 \quad \forall \mathrm{j}$

$\mathrm{Y}_{\mathrm{ij}}=0,1 \quad \forall \mathrm{i}, \mathrm{j}$

A função objetivo (3.1) minimiza a distância total ponderada pela demanda entre os nós de demanda e sua instalação mais próxima. A restrição (3.2) garante que cada nó i será atendido somente por uma instalação em j. O número p de instalações é assegurado pela restrição (3.3). Em (3.4) é feita a ligação entre as variáveis de decisão $\mathrm{X}$ e $\mathrm{Y}$, de forma a garantir que a demanda do nó i só pode ser atendida por uma instalação em j se houver uma instalação em j, ou seja, $\mathrm{Y}_{\mathrm{ij}}=1$ somente se $\mathrm{X}_{\mathrm{j}}=1$. As restrições (3.5) e (3.6) são as que determinam a natureza binária das variáveis de decisão.

Conforme observado por Vallim (2004), utilizando-se da programação inteira com variáveis binárias, esse modelo é capaz de definir as instalações em nós de uma rede e também quais pontos serão atendidos por quais localizações.

Owen e Daskin (1998) atentam para uma característica importante dessa formulação: a de que para qualquer número $\mathrm{p}$ há pelo menos uma solução ótima que localiza as instalações apenas em nós da rede. 


\subsubsection{Modelos de Cobertura}

Para o estudo dos problemas desse grupo, é preciso antes entender o conceito de "cobertura". A demanda de um determinado nó é dita "coberta" se a menor distância entre esse nó e a instalação mais próxima a ele é menor ou igual à distância de cobertura definida (Daskin, 1995). Ou, de forma semelhante, a demanda está "coberta" se puder ser atendida por uma instalação dentro de um tempo especificado (Owen e Daskin, 1998; Vallim, 2004). Distância e tempo de cobertura nesses casos possuem uma estreita relação.

Os problemas de cobertura têm sua aplicação em situações de localização de instalações nas quais a natureza do serviço prestado é crítica, tais como corpo de bombeiros e ambulâncias para atendimento emergencial (Owen e Daskin, 1998).

São dois os principais tipos de problemas de cobertura encontrados na literatura (Daskin, 1995; Owen e Daskin, 1998; Vallim, 2004): "set covering problem" e o problema de cobertura máxima.

O primeiro tipo é considerado por Daskin (1995) como o mais simples entre os modelos de localização. Consiste em minimizar o número de instalações localizadas dentre um conjunto de "locais candidatos" de tal forma que cada nó de demanda seja coberto no mínimo por uma instalação. A formulação matemática apresentada abaixo é discutida pelo mesmo autor.

Dados de entrada:

$\mathrm{a}_{\mathrm{ij}}=\left\{\begin{array}{l}1 \text { se o local candidato j pode "cobrir" a demanda do nó } i \\ 0 \text { caso contrário }\end{array}\right.$

Variáveis de decisão: 
$\mathrm{X}_{\mathrm{j}}=\left\{\begin{array}{l}1 \text { se houver uma instalação em } j \\ 0 \text { caso contrário }\end{array}\right.$

Função objetivo:

$\operatorname{Minimizar} \sum_{\mathrm{j}} \mathrm{X}_{\mathrm{j}}$

Restrições:

$\sum_{\mathrm{j}} \mathrm{a}_{\mathrm{ij}} \mathrm{X}_{\mathrm{j}} \geq 1 \quad \forall \mathrm{i}$

$\mathrm{X}_{\mathrm{j}}=0,1 \quad \forall \mathrm{j}$

Os dados de entrada consistem na matriz binária de cobertura com os valores baseados na comparação entre dois valores: a distância (ou tempo) entre os nós de demanda i e cada um dos $\mathrm{j}$ locais candidatos às instalações, e a distância (ou tempo) de cobertura estabelecido previamente.

A função objetivo (3.7) minimiza o número de instalações a serem localizadas. O conjunto de restrições em (3.8) estipula que cada nó de demanda i precisa estar coberto por no mínimo uma instalação. As restrições em (3.9) referem-se à característica binária das variáveis de decisão.

Essa formulação tem uma consideração extra que, independente do local selecionado, as instalações possuem o mesmo custo de implantação, e que, portanto, essa variável pode ser omitida do modelo. Caso essa afirmação não seja verdadeira, o modelo pode ser facilmente adaptado com a seguinte modificação na função objetivo:

$\operatorname{Minimizar} \sum_{j} c_{j} X_{j}$ 
Com $c_{j}$ sendo o custo de localizar uma instalação no local candidato $\mathrm{j}$.

Geralmente a solução para o problema de cobertura não é única. Na tentativa de restringir esse número de soluções, algumas variações na função objetivo são propostas (Daskin, 1995).

Uma delas é a de privilegiar os locais candidatos que já apresentam instalações posicionadas como pertencentes ao conjunto de locais selecionados. A função objetivo modificada é apresentada abaixo:

$\operatorname{Minimizar} \sum_{j \in E} X_{j}+(1+q) \sum_{j \in N} X_{j}$

Os seguintes dados de entrada adicionais são necessários:

$E=$ conjunto de instalações existentes

$N=$ conjunto de novos locais candidatos

$q=$ número muito pequeno (menor que 1 dividido pelo soma do número de locais existentes)

Outra possível variação é aquela que leva em consideração a cobertura "reserva", ou seja, a solução privilegiada para o modelo é a que maximiza o número de pontos de demanda cobertos por mais de uma instalação (Daskin, 1995).

Uma limitação do modelo de cobertura ocorre quando a distância de cobertura for muito pequena. A restrição de cobertura pode levar a um grande número de instalações a serem localizadas. Do ponto de vista econômico, soluções inviáveis podem ser alcançadas (Owen e Daskin, 1998; Vallim, 2004). 
Os problemas de máxima cobertura visam a resolver essa situação a partir do conceito de nível de cobertura. O objetivo é maximizar a quantidade de demanda coberta - dentro de uma aceitável distância de cobertura - localizando um número fixo de instalações (Owen e Daskin, 1998). Nesses problemas, a restrição de que toda a demanda deve ser atendida é relaxada. O modelo originalmente proposto por Church e ReVelle (1974), é apresentado por Daskin (1995):

Dados de entrada:

$\mathrm{a}_{\mathrm{ij}}=\left\{\begin{array}{l}1 \text { se o local candidato j pode "cobrir" a demanda do nó } i \\ 0 \text { caso contrário }\end{array}\right.$

$h_{i}=$ demanda no ponto $i$

$P=$ número de instalações a localizar

Variáveis de decisão:

$\mathrm{X}_{\mathrm{j}}=\left\{\begin{array}{l}1 \text { se houver uma instalação em } \mathrm{j} \\ 0 \text { caso contrário }\end{array}\right.$

$\mathrm{Z}_{\mathrm{i}}=\left\{\begin{array}{l}1 \text { se o nó i é coberto } \\ 0 \text { caso contrário }\end{array}\right.$

Função objetivo:

$\operatorname{Maximizar} \sum_{\mathrm{i}} \mathrm{h}_{\mathrm{i}} \mathrm{Z}_{\mathrm{i}}$

Restrições:

$\mathrm{Z}_{\mathrm{i}} \leq \sum_{\mathrm{j}} \mathrm{a}_{\mathrm{ij}} \mathrm{X}_{\mathrm{j}} \quad \forall \mathrm{i}$

$\sum_{j} X_{j} \leq P$

$\mathrm{X}_{\mathrm{j}}=0,1 \quad \forall \mathrm{j}$

$\mathrm{Z}_{\mathrm{i}}=0,1 \quad \forall \mathrm{i}$ 
A função objetivo em (3.12) maximiza o número de demandas cobertas. O grupo de restrições em (3.13) garante que cada demanda do nó i só pode ser coberta se pelo menos uma das instalações que cobrem essa demanda for selecionada. Em (3.14), é restrito o número de instalações a serem localizadas. As restrições (3.15) e (3.16) garantem a integralidade e a característica binária das variáveis de decisão.

Daskin (1995) e Owen e Daskin (1998), observaram que ambos os modelos de cobertura e máxima cobertura assumem um conjunto finito de candidatos às instalações e que, ainda, normalmente esse conjunto é formado por alguns dos nós de demanda. Esse fato pode resultar em uma solução inferior àquela obtida se as instalações tivessem como locais candidatos qualquer ponto da rede em estudo.

No entanto, através da identificação de um número finito de pontos adicionais, conhecidos como pontos de interseção da rede (Church e Meadows, 1979), pelo menos uma solução ótima para o problema consiste em localizar as instalações apenas nos nós da rede.

Church e ReVelle (1974), citados por Owen e Daskin (1998), examinaram a relação entre os modelos p-mediana e cobertura. Os autores mostraram que a partir de uma transformação de distâncias, o problema de máxima cobertura pode ser visto como um caso especial do problema de p-mediana. Considerando a distância $d_{i j}$ do problema de p-mediana, a transformação consiste em considerar uma nova distância $d_{i j}^{\prime}$, onde

$$
\mathrm{d}_{\mathrm{ij}}^{\prime}=\left\{\begin{array}{ll}
0 & \text { se } d_{i j} \leq S \\
1 & \text { se } d_{i j}>S
\end{array} \quad \text { onde } \mathrm{S}=\right.\text { distância máxima de cobertura }
$$




\subsubsection{Modelos de Centro}

O terceiro grupo de modelos clássicos de localização é aquele relacionado à solução dos problemas de centro.

O problema de centro consiste em minimizar a distância de cobertura, tal que cada nó de demanda seja coberto, dentro de uma distância determinada endogenamente por uma das instalações localizadas (Daskin, 1995). Esse problema também é conhecido por minimax, pelo objetivo de minimizar a máxima distância entre a demanda e a instalação mais próxima.

Se a localização das instalações está restrita aos nós da rede em estudo, temos o problema de centro de vértice. Quando é possível a localização em qualquer local da rede, o problema de centro é chamado de absoluto. Geralmente, para um mesmo problema, a solução do modelo absoluto é melhor, ou seja, apresenta um valor menor para a função objetivo em comparação ao modelo de vértice (Owen e Daskin, 1998). Daskin (1995) apresenta a formulação para o problema de vértice:

\section{Dados de entrada:}

$h_{i}=$ demanda no ponto $i$

$P=$ número de instalações a localizar

$d_{i j}=$ distância entre o nó $i$ e o local candidato $j$

Variáveis de decisão:

$\mathrm{X}_{\mathrm{j}}=\left\{\begin{array}{l}1 \text { se houver uma instalação em } j \\ 0 \text { caso contrário }\end{array}\right.$

$\mathrm{Y}_{\mathrm{ij}}=\left\{\begin{array}{l}1 \text { se o nó } \text { i for atendido por uma instalação em } j \\ 0 \text { caso contrário }\end{array}\right.$ 
$W$ = máxima distância entre um nó de demanda e sua instalação mais próxima

Função objetivo:

Minimizar W

Restrições:

$\sum_{\mathrm{j}} \mathrm{Y}_{\mathrm{ij}}=1 \quad \forall \mathrm{i}$

$\sum_{j} X_{j}=P$

$\mathrm{Y}_{\mathrm{ij}}-\mathrm{X}_{\mathrm{j}} \leq 0 \quad \forall \mathrm{i}, \mathrm{j}$

$\mathrm{W} \geq \sum_{\mathrm{j}} \mathrm{d}_{\mathrm{ij}} \mathrm{Y}_{\mathrm{ij}} \quad \forall \mathrm{i}$

$\mathrm{X}_{\mathrm{j}}=0,1 \quad \forall \mathrm{j}$

$\mathrm{Y}_{\mathrm{ij}}=0,1 \quad \forall \mathrm{i}, \mathrm{j}$

A função objetivo em (3.17) minimiza a máxima distância entre um nó de demanda e a instalação mais próxima a esse nó. As restrições em (3.18) garantem que o total da demanda será atendido. Em (3.19), o número de instalações a serem localizadas é fixo. O grupo de restrições em (3.20) asseguram que a demanda do nó i não pode ser atendida pela instalação em j, há menos que exista uma localização em j. Restrições em (3.21) garantem que a máxima distância W é maior que qualquer outra distância entre nó de demanda i e instalação em j pela qual é atendido. As restrições em (3.22) e (3.23) são de integralidade das variáveis de decisão.

\subsection{Extensões dos modelos clássicos}

Os três problemas clássicos descritos (p-medianas, cobertura e p-centro) são considerados base para a maioria dos estudos em teoria de localização (Owen e Daskin, 1998). A partir de 
suas modelagens, outras análises surgiram e algumas novas classes de problemas de localização foram identificadas.

Uma das principais diz respeito aos problemas que levam em consideração também os custos fixos associados à localização de instalações. São problemas com ou sem restrição de capacidade nas instalações a serem localizadas (na literatura conhecidos como fixed charge facility location problems).

Os problemas de localização sem restrição de capacidade são formulados adicionando uma parcela de custo na função objetivo do modelo p-medianas e removendo a restrição que fixa o número de instalações. O resultado é um modelo que determina endogenamente a quantidade de instalações e minimiza o custo total de instalações e transporte (Owen e Daskin, 1998).

Daskin (1995) descreve a seguinte formulação para o problema:

Dados de entrada:

$h_{i}=$ demanda no ponto $i$

$d_{i j}=$ distância entre o nó $i$ e o local candidato $j$

$f_{j}=$ custo fixo de localização no local candidato $j$

$c=$ custo por unidade de distância por unidade de demanda

Variáveis de decisão:

$\mathrm{X}_{\mathrm{j}}=\left\{\begin{array}{l}1 \text { se houver uma instalação em } \mathrm{j} \\ 0 \text { caso contrário }\end{array}\right.$

$\mathrm{Y}_{\mathrm{ij}}=\left\{\begin{array}{l}1 \text { se o nó i for atendido por uma instalação em } j \\ 0 \text { caso contrário }\end{array}\right.$

Função objetivo: 
$\operatorname{Minimizar} \sum_{\mathrm{j}} \mathrm{f}_{\mathrm{j}} \mathrm{X}_{\mathrm{j}}+\mathrm{c} \sum_{\mathrm{i}} \sum_{j} \mathrm{~h}_{\mathrm{i}} \mathrm{d}_{\mathrm{ij}} \mathrm{Y}_{\mathrm{ij}}$

Restrições:

$\sum_{\mathrm{j}} \mathrm{Y}_{\mathrm{ij}}=1 \quad \forall \mathrm{i}$

$\mathrm{Y}_{\mathrm{ij}}-\mathrm{X}_{\mathrm{j}} \leq 0 \quad \forall \mathrm{i}, \mathrm{j}$

$\mathrm{X}_{\mathrm{j}}=0,1 \quad \forall \mathrm{j}$

$\mathrm{Y}_{\mathrm{ij}}=0,1 \quad \forall \mathrm{i}, \mathrm{j}$

A função objetivo em (3.24) minimiza o custo total, que é a soma da parcela fixa de instalação com o custo variável de transporte associado a cada local. As restrições são as mesmas já discutidas no modelo p-medianas.

A transformação do modelo acima descrito, para atender aos problemas em que existe a capacidade máxima de atendimento definida para cada instalação a ser localizada, é feita com a inclusão da restrição de capacidade abaixo:

$\sum_{\mathrm{i}} \mathrm{h}_{\mathrm{i}} \mathrm{Y}_{\mathrm{ij}} \leq \mathrm{k}_{\mathrm{j}} \mathrm{X}_{\mathrm{j}} \quad \forall \mathrm{j}$

com $\mathrm{k}_{\mathrm{j}}=$ capacidade máxima de uma instalação se ela estiver localizada em $\mathrm{j}$

O conjunto de restrições em (3.29) garante que a soma das demandas a serem atendidas por uma determinada instalação em j, não exceda a capacidade dessa instalação, desde que ela esteja localizada em j.

Muitos problemas de localização envolvem múltiplos e conflitantes objetivos, por exemplo, a minimização de custos e a maximização de cobertura (Owen e Daskin, 1998). São os 
chamados problemas de localização multiobjetivos, para os quais não há uma única solução, mas sim um balanceamento entre as diversas soluções encontradas, buscando a otimização sob diferentes pontos de vista.

Os problemas e modelos apresentados até esse momento assumem que apenas um tipo de instalação está sendo localizado. Em muitas situações, no entanto, essa consideração não é válida. Para lidar com problemas dessa natureza, nos quais é importante a diferenciação entre os tipos de instalações, existem os modelos de localização hierárquicos. Daskin (1995) cita algumas aplicações desse tipo de modelo: planejamento de uma rede de ensino, com a diferenciação entre escolas de ensino fundamental e superior; planejamento da rede de correios, com instalações que vão desde caixas coletoras nas ruas e avenidas até grandes centrais de triagem de correspondências; e sistemas hospitalares, com unidades básicas de serviço, clínicas e hospitais.

Outra consideração implícita aos modelos discutidos anteriormente é a de que todos os pontos da rede têm característica de demanda e não de oferta (produção). Quando as fontes de produção são consideradas na modelagem, temos os chamados problemas de produção distribuição. Geralmente os modelos são baseados na formulação clássica de localização e têm como objetivos localizar armazéns (ou centros de distribuição) e definir os fluxos entre as fábricas - centros de distribuição - mercado consumidor (demanda).

O modelo proposto por Geoffrion e Graves em 1974, obtido a partir da extensão dos modelos de custo fixo, é citado por diversos autores (Daskin, 1995; Ballou, 2001; Daskin et. al, 2003; Vallim, 2004) como um dos mais importantes dentro dessa categoria. Abaixo é discutida sua formulação: 
Índices

$i$ : índice para mercado consumidor (demanda)

$j:$ índice para candidatos a armazém

$k$ : índice para plantas (fábricas)

l: índice para produtos

Dados de entrada:

$D_{l i}=$ demanda para o produto l no ponto de demanda $i$

$S_{l k}=$ capacidade de produção do produto l na fábrica $k$

$\underline{V}_{j}, V_{j}=$ mínimo e máximo processamento no armazém candidato $j$

$f_{j}=$ custo fixo do armazém candidato $j$

$v_{j}=$ custo variável de processamento no armazém candidato $j$

$C_{l k j i}=$ custo unitário de produzir e embarcar o produto $l$ da fábrica $k$ para o mercado $i$ passando pelo armazém $j$

Variáveis de Decisão:

$\mathrm{X}_{\mathrm{j}}=\left\{\begin{array}{l}1 \text { se houver uma instalação em } j \\ 0 \text { caso contrário }\end{array}\right.$

$\mathrm{Y}_{\mathrm{ij}}=\left\{\begin{array}{l}1 \text { se o nó i for atendido por uma instalação em } j \\ 0 \text { caso contrário }\end{array}\right.$

$Z_{l k i j}=$ quantidade do produto $l$ produzido na fábrica $k$ entregue no mercado $i$ através do armazém em $j$

Função Objetivo:

$\operatorname{Minimizar} \sum_{\mathrm{j}} \mathrm{f}_{\mathrm{j}} \mathrm{X}_{\mathrm{j}}+\sum_{\mathrm{j}} \mathrm{v}_{\mathrm{j}}\left(\sum_{\mathrm{l}} \sum_{i} \mathrm{D}_{\mathrm{li}} \mathrm{Y}_{\mathrm{ij}}\right)+\sum_{\mathrm{l}} \sum_{k} \sum_{j} \sum_{i} \mathrm{C}_{\mathrm{lkji}} \mathrm{Z}_{\mathrm{lkji}}$

Restrições:

$\sum_{\mathrm{i}} \sum_{j} \mathrm{Z}_{\mathrm{lkji}} \leq \mathrm{S}_{\mathrm{lk}} \quad \forall \mathrm{k}, \mathrm{l}$ 


$$
\begin{array}{ll}
\sum_{\mathrm{k}} \mathrm{Z}_{\mathrm{lkji}}=\mathrm{D}_{\mathrm{li}} \mathrm{Y}_{\mathrm{ij}} & \forall \mathrm{l}, \mathrm{j}, \mathrm{i} \\
\sum_{\mathrm{j}} \mathrm{Y}_{\mathrm{ij}}=1 & \forall \mathrm{i} \\
\underline{\mathrm{V}}_{\mathrm{j}} \mathrm{X}_{\mathrm{j}} \leq \sum_{\mathrm{i}} \sum_{l} \mathrm{D}_{\mathrm{li}} \mathrm{Y}_{\mathrm{ij}} \leq \mathrm{V}_{\mathrm{j}} \mathrm{X}_{\mathrm{j}} & \forall \mathrm{j} \\
\mathrm{X}_{\mathrm{j}}=0,1 & \forall \mathrm{j} \\
\mathrm{Y}_{\mathrm{ij}}=0,1 & \forall \mathrm{i}, \mathrm{j} \\
\mathrm{Z}_{\mathrm{lkji}} \geq 0 & \forall \mathrm{i}, \mathrm{j}, \mathrm{k}, 1
\end{array}
$$

A função objetivo em (3.30) minimiza a somatória dos custos fixos de instalação dos armazéns, os custos variáveis de processamento e os custos de transporte desde as fábricas até os mercados. As restrições em (3.31) garantem que a quantidade total do produto 1, embarcado da fábrica k, não excede a capacidade de produção dessa fábrica. Em (3.32), o conjunto de restrições, além de fazer a ligação entre as variáveis de decisão Z e Y, também assegura que a quantidade de produto 1 , embarcado para o cliente i via armazém $j$, é igual à quantidade desse produto produzido em todas as fábricas que são destinados ao cliente i via armazém j. As restrições (3.33) garantem que o total da demanda será atendido. Os limites de processamento para cada armazém são controlados pelas restrições (3.34). As restrições (3.35) e (3.36) são de integralidade e característica binária das variáveis de decisão.

Daskin et. al. (2003) observam que uma importante limitação dos modelos de custo fixo é a consideração de que os embarques para os pontos de demanda são sempre do tipo lotação. Os pontos são atendidos a partir de embarques diretos da origem, sendo cada rota associada a um único destino. 
No entanto, em algumas situações, os embarques são de carga fracionada e as rotas necessariamente passam por mais de um ponto de demanda. Eilon, Watson-Gandy e Christofides (1971) são citados por Daskin et. al (2003) como os primeiros pesquisadores a anunciarem o possível erro na consideração de embarques fracionados como sendo de lotação.

Daí em diante, intensificou-se o estudo de modelos integrados de localização e roteirização. Vários autores citados por Daskin (1995), têm proposto modelagens que se prestam a responder às perguntas inerentes a esse tipo de problema: quantas instalações localizar e onde elas devem estar localizadas; quais demandas serão atendidas por quais instalações; em qual rota esse ponto de demanda será incluído e qual será a sequiência de atendimento.

Wanke (2001), citado por Vallim (2004), observa que os modelos de custo fixo geralmente levam em consideração os custos de instalação e aqueles relacionados ao transporte, sem muita preocupação com o custo de manutenção de estoque (quando esse existe).

Somente em trabalhos recentes, alguns autores apresentaram modelos (geralmente não lineares) que incorporam decisões de estoque de forma integrada à localização (Daskin et al. (2003), Vallim (2004)).

Mutarelli (2004) estudou o problema de localização de instalações logísticas, envolvendo aspectos de produção e de transporte de uma revista semanal. A modelagem proposta foi além dos tradicionais modelos utilizados na solução de problemas de localização, à medida que abordou aspectos temporais relacionados a níveis de serviço, escolha de modais e capacidade de produção. 


\subsection{Métodos de solução}

Os problemas de localização geralmente envolvem uma quantidade de dados muito grande e uma complexidade alta para a sua resolução. Isso porque a análise a ser realizada envolve um conjunto extenso de variáveis de decisão e o número possível de alternativas a serem consideradas e comparadas normalmente é alto, mesmo para problemas de pequeno porte.

As técnicas utilizadas para solucionar os problemas de localização vão desde os modelos matemáticos exatos, passam pela programação matemática, aplicação de heurísticas e metaheurísticas, uso de simulação e lógica fuzzy (Vallim, 2004).

No entanto, a técnica presente no maior número de trabalhos é a programação linear inteira, na sua forma pura ou mista (Brandeau e Chiu, 1989; Owen e Daskin, 1998; Vallim, 2004).

Uma de suas principais vantagens é a capacidade de modelar os custos fixos e variáveis de uma rede logística. Além disso, por se tratar de uma técnica de otimização, garante que as soluções encontradas são ótimas, ou seja, são as melhores possíveis dentro do conjunto de variáveis e restrições adotadas. Sua principal desvantagem é que, quando trabalhamos com grandes problemas, é necessário um longo tempo de processamento, às vezes até inviabilizando sua resolução.

Mutarelli (2004) resolveu o problema de configuração de uma rede de produção e de transporte de uma revista semanal a partir de uma modelagem de programação linear inteiramista, com função objetivo de minimização do custo total. A modelagem proposta foi 
implementada em planilha eletrônica Excel e resolvida com a utilização do pacote de otimização What's Best.

Os modelos clássicos de localização normalmente utilizam a programação inteira em sua modelagem. Dependendo das dimensões do problema, a complexidade do algoritmo da solução se eleva de forma exponencial o que inviabiliza a obtenção de solução ótima dentro de um tempo razoável. Esses problemas são chamados de NP-completos (Daskin, 1995).

Quando isso ocorre, normalmente são utilizadas heurísticas que, segundo definição de alguns autores citados por Voss (2001), consistem em "uma técnica que procura boas soluções (próximas à ótima) com um tempo computacional razoável, sem garantir que essa solução seja ótima ou viável, ou ainda, em muitos casos, sem garantir tão próxima da solução ótima a solução encontrada está."

A partir dos anos 80, uma nova classe de métodos aproximados - chamada metaheurísticas tem sido utilizada com sucesso na solução de uma variedade de difíceis problemas de otimização combinatória (Osman e Laporte, 1996).

Entre as definições de metaheurística disponíveis na literatura, Osman e Laporte (1996) e Voss (2001) citam a de Osman e Kelly (1996) que definem metaheurística como "um processo de geração iterativo que guia uma heurística subordinada a partir da inteligente combinação de diferentes conceitos para exploração e descoberta dos espaços de busca, usando estratégias de aprendizado para estruturar a informação com o objetivo de obter de forma eficiente soluções próximas do ótimo." 
Alguns trabalhos (Vallim, 2004; Silva, 2004) desenvolvidos no âmbito do Departamento de Engenharia de Transportes da Escola Politécnica da Universidade de São Paulo, tratam do tema de localização de instalações com métodos de solução baseados em metaheurísticas.

Vallim (2004) em seu trabalho apresentou uma metodologia em duas fases para resolver o problema de localização de centros de distribuição de carga: a primeira fase define as localizações ótimas dos CDs, com a utilização de simulated annealing na agregação da demanda em clusters e na seleção de melhores candidatos; na segunda fase, a quantidade ótima de CDs é definida modelando os custos de estoque, armazenagem e vendas perdidas.

Silva (2004) estudou o problema de localização de terminais de consolidação de carga parcelada. A rede de distribuição foi modelada como sendo do tipo hub-and-spoke, em que o tráfego entre dois pontos quaisquer (spokes) é sempre feito via terminais de consolidação (hubs). A modelagem resultou em um problema NP-hard, ao qual foi aplicada uma metaheurística baseada em algoritmos genéticos.

Dentre os vários tipos de metaheurísticas reportadas na literatura, Simulated Annealing, Busca Tabu (Tabu Search) e Algoritmos Genéticos têm sido as mais utilizadas na solução de problemas de localização (Giannikos e Nickel, 1998). Os mesmos autores relatam alguns trabalhos desenvolvidos sobre o tema "problemas de localização" nos quais foram utilizados algoritmos baseados em Busca Tabu e afirmam que essa metaheurística mostrou ser uma técnica eficiente quando utilizada na solução dessa classe de problemas. 


\subsubsection{A metaheurística Busca Tabu}

A metaheurística Busca Tabu, originalmente proposta por Glover em 1986, tem sido utilizada na solução de vários tipos de problema de natureza combinatória (Gendreau, 2002). Essas aplicações incluem: sequenciamento de máquinas, problema de designação quadrática, problemas de localização de hubs, redes neurais, entre outros (Glover e Laguna, 1997).

O método tem como principal característica a habilidade em utilizar a informação obtida durante a busca com o objetivo de evitar a "armadilha" do ótimo local e explorar outras regiões do espaço de solução (Glover, 1989).

De acordo com Glover (1990a), a Busca Tabu está apoiada sobre três principais conceitos: o uso de estrutura de memória flexível, que permite quantificar critérios e armazenar informações do histórico de busca; utilização de mecanismos de controle para restringir e expandir o processo de busca; e incorporação de função de memórias diferentes, de curto a longo prazo, para implementação de estratégias de intensificação e diversificação da busca.

Al-Sultan e Al-Fawzan (1999) definem como elementos básicos da técnica de Busca Tabu os seguintes parâmetros: configuração (uma solução possível para o problema); tipo de movimento (processo de gerar outra solução a partir de uma configuração); conjunto de movimentos candidatos (possíveis movimentos para uma dada configuração); restrições tabu (características do movimento que o tornarão proibido de ser repetido); e critérios de aspiração (regras que prevalecem sobre as restrições tabu). 
Os mesmos autores descrevem, de forma simplificada, o funcionamento da metaheurística: dada uma solução inicial e o valor da função objetivo para essa configuração, o método gera um conjunto de movimentos candidatos a partir da atual configuração; se o melhor desses movimentos não é tabu (não possui os atributos que o tornam proibido de ser realizado), ou se é tabu, mas satisfaz o critério de aspiração (normalmente relacionado ao valor da função objetivo), então o movimento é selecionado e considerado como nova configuração; caso contrário, o método seleciona o melhor movimento que não é tabu e o considera como nova configuração; em ambos os casos, o movimento selecionado é declarado tabu (por algumas iterações não pode ser aplicado); o procedimento é repetido para certo número de iterações; no final, a melhor solução obtida é o resultado do procedimento.

Sun e McKeown (1993) descreveram em seu trabalho uma metaheurística baseada em Busca Tabu para solução do problema de localização com custos fixos de abertura. A Busca Tabu é utilizada na obtenção de um vetor solução, cujo status de seus componentes corresponde à abertura ou não de cada um dos locais candidatos. Os autores utilizaram duas listas tabu para o gerenciamento do processo de busca. Em uma delas é armazenado, durante um número determinado de iterações (que pode ser fixo ou variável), o status das variáveis que já estiveram na solução, para que não voltem a ser consideradas enquanto forem tabu. Na outra lista, as variáveis avaliadas são impedidas de deixarem a solução durante um número determinado de iterações, a menos que esse movimento obtenha uma solução melhor que todas até então encontradas (critério de aspiração). Os autores concluem que a Busca Tabu pode ser aplicada com sucesso a essa classe de problemas, com base nos resultados da aplicação computacional. 
Rolland et al. (1996) apresentaram em seu estudo um novo procedimento baseado em Busca Tabu para a solução do problema de p-medianas. Algumas estratégias específicas foram utilizadas no algoritmo. A cada iteração, a geração de novas configurações de solução foi baseada em movimentos de adição e retirada de nós. Para evitar o ótimo local, adotou-se uma estratégia de oscilação que consistiu em permitir, durante um determinado período de tempo, soluções não viáveis no espaço de busca. Outra característica do método foi a utilização de um tempo aleatório no qual a configuração permaneceu tabu, ou seja, proibida de ser repetida. A metaheurística foi aplicada em 100 problemas teste, variando as dimensões entre 13 e 500 nós. Os resultados foram comparados com as soluções obtidas por duas outras heurísticas e concluiu-se que, tanto em termos de qualidade como em tempo de solução, o desempenho da metaheurística foi superior ao das heurísticas.

Al-Sultan e Al-Fawzan (1999) estudaram o problema de localização de instalações sem restrição de capacidade. $\mathrm{O}$ algoritmo utilizado na solução do problema também se baseou na metaheurística Busca Tabu. Dada uma solução inicial (obtida a partir de uma outra heurística), a configuração tem o seu custo total calculado e é armazenada como sendo a melhor solução. A partir dessa configuração, é gerado um conjunto de soluções vizinhas e para cada uma o custo total é calculado. A solução com o menor custo (desde que não seja tabu ou mesmo que seja tabu, seja a melhor solução obtida até então) é escolhida, e o atributo da configuração é armazenado na lista tabu. O procedimento é repetido até um prédeterminado número de iterações. Em todos os problemas testados, o algoritmo encontrou a solução ótima.

Michel e Van Hentenryck (2004) também estudaram a solução para a classe de problemas de localização de instalações sem limite de capacidade, a partir da implementação da 
metaheurística Busca Tabu. Para determinados problemas benchmark (dos quais já se conhece a solução ótima), o algoritmo implementado encontrou também a solução ótima com alta frequiência. Sua performance foi comparada com a de outra heurística baseada em algoritmo genético, obtendo resultados satisfatórios nessa comparação.

No único trabalho localizado durante a revisão bibliográfica que trata da Busca Tabu em uma rede com restrição de capacidade, Gendron et al. (2003) estudaram o problema de localização de depósitos, com o objetivo de minimizar os custos de transporte de contêineres entre esses depósitos; porém, cada instalação possui restrição em relação à quantidade de contêineres que podem ser armazenados.

O procedimento Busca Tabu é utilizado na determinação de quais depósitos devem ser abertos ou fechados. Para cada configuração proposta, os custos de transporte são obtidos resolvendo um problema de fluxo de rede de mínimo custo associado. Os autores utilizaram dois tipos de movimentos na geração de soluções vizinhas: adição ou subtração de um depósito da solução, e modificação do status de um par de depósitos (abertura e fechamento simultâneos de dois depósitos diferentes). Para reduzir esse número de soluções vizinhas, os autores ordenaram as soluções com base na estimativa de custo associado a cada um dos movimentos executados e selecionavam apenas os melhores.

Após as aplicações computacionais, Gendron et al. (2003) concluíram que a Busca Tabu se mostrou eficiente para os problemas em que os nós de demanda estão relativamente próximos, e os custos fixos de abertura e operação dos depósitos são grandes. 


\subsection{Considerações finais}

A utilização de modelos de localização do ponto de vista de planejamento tático, da forma como proposta nesse trabalho, pode ser considerada diferenciada, uma vez que as aplicações encontradas na literatura, em sua grande maioria, reforçam o aspecto estratégico desses tipos de modelos. Normalmente eles visam a obter localizações ótimas para as instalações desejadas num horizonte de planejamento de longo prazo.

Não foi encontrada na literatura pesquisada uma modelagem que retratasse todas as características do problema objeto do estudo, principalmente em relação à estrutura de custos. No entanto, a combinação do conjunto de restrições de cobertura de alguns modelos, associada à adaptação da função objetivo e à inclusão de restrições de capacidade, constitui a estratégia, descrita no próximo capítulo, para elaboração do modelo a ser utilizado na solução do problema.

Segundo Rolland et al. (1996), heurísticas e/ou metaheurísticas têm sido métodos utilizados na solução de problemas de localização que envolvem um número maior de variáveis e restrições. Nesse sentido, a revisão da literatura mostra a metaheurística Busca Tabu como um possível caminho para solucionar problemas dessa natureza. 


\section{METODOLOGIA DE SOLUÇÃO DO PROBLEMA}

Este capítulo tem como objetivo apresentar a modelagem e a metodologia de solução proposta para o problema em estudo.

\subsection{Etapas para a solução do problema}

A metodologia idealizada para a solução do problema compreende os passos descritos a seguir e pode ser visualizada na figura abaixo.

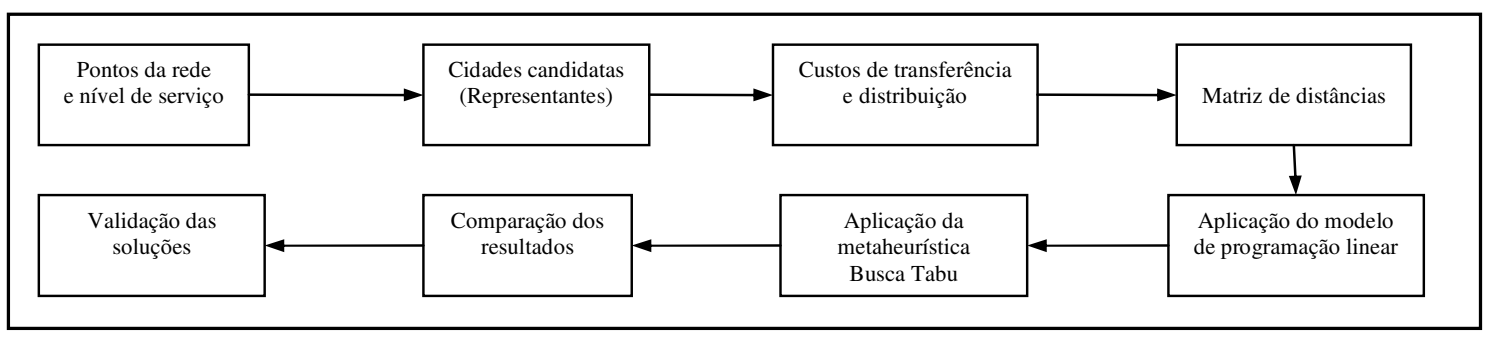

Figura 4.1 - Etapas da metodologia de solução

Passo 1: Pontos da Rede e Nível de Serviço

Levantamento das cidades e suas respectivas demandas em $(\mathrm{kg})$ e em quantidade de entregas; nível de serviço estabelecido para a campanha (distância de cobertura em km).

\section{Passo 2: Cidades Candidatas (Representantes)}

Selecionar quais representantes serão candidatos a fazer parte da rede de distribuição, e quais os limites (mínimo e máximo) de operação relacionados a cada um. 
Passo 3: Custos de Transferência e Distribuição

Determinar, para cada cidade candidata, os valores unitários para o custo de transferência da origem até a central $(\mathrm{R} \$ / \mathrm{kg})$ e o custo de distribuição, formado pelo valor por entrega ( $\mathrm{R} \$ /$ entrega) na cidade, mais o valor por quilômetro rodado $(\mathrm{R} \$ / \mathrm{km})$, a partir da central até a cidade a ser atendida.

\section{Passo 4: Matriz de Distâncias}

Calcular as distâncias entre os vértices da rede, ou seja, a matriz de distâncias entre cada par de pontos formado pela cidade candidata e pela cidade destino. Essas distâncias devem, preferencialmente, ser obtidas diretamente de guias rodoviários.

Quando não estão disponíveis as distâncias reais entre todos os pontos da rede, pode-se lançar mão da distância teórica entre dois nós da rede em estudo, que pode ser calculada a partir da aplicação da fórmula de distância de grande círculo (Ballou, 1995), com os dados de latitude e longitude dos pontos considerados. A fórmula do grande círculo é:

$$
\begin{gathered}
\mathrm{D}_{\mathrm{A}-\mathrm{B}}=6360\left\{\operatorname { a r c c o s } \left[\operatorname{sen}\left(\mathrm{LAT}_{\mathrm{A}}\right) \quad \mathrm{x} \operatorname{sen}\left(\mathrm{LAT}_{\mathrm{B}}\right)+\cos \left(\mathrm{LAT}_{\mathrm{A}}\right) \times \cos \left(\mathrm{LAT}_{\mathrm{B}}\right) \quad \mathrm{x}\right.\right. \\
\left.\left.\cos \left(\mathrm{LONG}_{\mathrm{B}}-\mathrm{LONG}_{\mathrm{A}}\right)\right]\right\}
\end{gathered}
$$

Onde:

$\mathrm{D}_{\mathrm{A}-\mathrm{B}}=$ distância do grande círculo entre os pontos $\mathrm{A}$ e B $(\mathrm{em} \mathrm{km})$

$\mathrm{LAT}_{\mathrm{A}}=$ latitude do ponto A (radianos)

$\mathrm{LAT}_{\mathrm{B}}=$ latitude do ponto $\mathrm{B}$ (radianos)

$\mathrm{LONG}_{\mathrm{A}}=$ longitude do ponto A (radianos)

$\mathrm{LONG}_{\mathrm{B}}=$ longitude do ponto $\mathrm{B}$ (radianos) 
Entre as vantagens da utilização dessa fórmula podemos citar o fato dos dados de latitude e longitude estarem disponíveis em uma grande variedade de fontes e o método apresentar boa acurácia. No entanto, as distâncias computadas sempre subestimam as distâncias reais, uma vez que os veículos não viajam em linha reta. Para ajustar essas distâncias, um fator de circuito (multiplicador) deve ser utilizado. $\mathrm{O}$ valor de 1,17 para rodovias é considerado um bom fator, embora esse número possa ser determinado para a rede em estudo a partir de uma amostra de distâncias reais entre alguns dos pontos. (Ballou, 1995).

Passo 5: Aplicação do modelo selecionado

Nessa fase, o modelo proposto deve ser aplicado de modo a obter a localização ótima das centrais, minimizando o custo total de transporte. Se o problema tiver dimensões muito grandes, pode ser que essa etapa não possa ser aplicada, ou seja, o problema não possa ser resolvido de forma ótima. Nesse caso, a solução será obtida como descrita no próximo passo.

Passo 6: Aplicação da metaheurística baseada em Busca Tabu Nessa etapa, o procedimento desenvolvido a partir da metaheurística Busca Tabu é aplicado ao problema, obtendo também uma solução viável. Em alguns problemas de maior número de variáveis e restrições, esta poderá ser a única solução encontrada.

Passo 7: Comparação dos Resultados

A solução obtida com a metaheurística Busca Tabu é comparada à solução ótima obtida a partir do modelo de programação linear (caso tenha sido possível obtê-la). Os resultados são apresentados em mapas para uma melhor visualização e entendimento da configuração proposta por cada um dos métodos de solução. 
Passo 8: Validação dos Dados

A melhor solução proposta é analisada sob o aspecto de sua viabilidade operacional de implantação, levando em consideração restrições práticas da operação em estudo e possibilidades de economia de escala.

\subsection{Especificação do modelo de programação linear selecionado}

Diante da caracterização do problema a ser resolvido, e com base na revisão bibliográfica apresentada no capítulo anterior, o modelo de solução proposto é baseado na modelagem clássica de localização (descrita em Daskin, 1995), adaptado aos custos de transferência e distribuição de cargas, à consideração da distância de cobertura, além das restrições de mínimo e máxima capacidade nos locais candidatos.

Objetivo: Determinar os centros de desconsolidação de carga (representantes) a serem utilizados de forma a minimizar os custos de transporte a partir da cidade de origem.

Definições:

Distância de Cobertura (DC) = distância máxima $(\mathrm{em} \mathrm{km})$ a partir da central em j que uma cidade i pode distar para que seja atendida por essa central, respeitando o nível de serviço contratado (prazo de entrega).

Custo Total $(\mathrm{CT})=$ Custo de Transferência + Custo de Rodagem dentro do Raio de Cobertura da Central + Custo de Entrega nas Cidades atendidas pela Central.

Custo de Transferência: Total da carga (em kg) a ser transferida para a central em j x Taxa unitária $(\mathrm{R} \$ / \mathrm{kg})$ do frete para a cidade $\mathrm{j}$. 
Custo de Rodagem dentro do Raio de Cobertura da Central: Distância da central em j até a cidade atendida $(\mathrm{em} \mathrm{km}) \times$ Valor por $\mathrm{km}(\mathrm{R} \$ / \mathrm{km})$ para entrega dentro do raio de cobertura.

Custo de Entregas: Total de entregas na cidade atendida pela central em j x Valor unitário por entrega (R\$/entrega).

Índices:

$\mathrm{I}=$ conjunto das cidades i pertencentes à rede a ser estudada

$\mathrm{J}=$ conjunto das cidades $\mathrm{j}$ candidatas à central de desconsolidação de carga

Dados de entrada:

$\mathrm{M}=$ constante igual ao total de nós da rede em estudo

$\mathrm{A}_{\mathrm{i}}=$ quantidade $(\mathrm{em} \mathrm{kg})$ de carga a ser entregue na cidade $\mathrm{i}$

$\mathrm{B}_{\mathrm{i}}=$ quantidade de entregas a serem realizadas na cidade $\mathrm{i}$

$\mathrm{C}_{\mathrm{oj}}=$ valor de transferência $(\mathrm{R} \$ / \mathrm{kg})$ da origem até a cidade $\mathrm{j}$ candidata a central

$C_{j}=$ valor por entrega $(R \$ /$ entrega $)$ realizada pela central em $j$

$\mathrm{KM}_{\mathrm{j}}=$ valor $(\mathrm{R} \$ / \mathrm{km})$ do deslocamento a partir da central em $\mathrm{j}$

$\mathrm{D}_{\mathrm{ji}}=$ distância entre a cidade candidata $\mathrm{j}$ e a cidade $\mathrm{i}$

$\mathrm{DC}_{\mathrm{ji}}=$ matriz de distância de cobertura da central, ou seja, 1 para as cidades cuja $\mathrm{D}_{\mathrm{ji}}$ é menor ou igual à DC e 0 caso contrário.

$\operatorname{Max}_{\mathrm{j}}=$ máximo de peso $(\mathrm{em} \mathrm{kg})$ que a central em j é capaz de atender.

$\operatorname{Min}_{\mathrm{j}}=$ número mínimo de entregas que deve estar designado a uma central j para que ela seja utilizada. 
Variáveis de decisão:

$X_{j}=\left\{\begin{array}{l}1 \text { se existir uma central na cidade candidata } j \\ 0 \quad \text { caso contrário }\end{array}\right.$

$Y_{j i}=\left\{\begin{array}{l}1 \text { se a central } j \text { atende a cidade } i \\ 0 \quad \text { caso contrário }\end{array}\right.$

Função Objetivo:

Minimizar o custo total da operação de transporte CT:

$\operatorname{Min} \mathrm{CT}=\sum_{J} \sum_{I} Y_{j i}\left(A_{i} C_{0 j}+D_{j i} K M_{j}+B_{i} C_{j}\right)$

Restrições:

$$
\begin{array}{ll}
\sum_{I} Y_{j i}-M X_{j} \leq 0 & \forall j \\
\sum_{J} D C_{j i} Y_{j i} \geq 1 & \forall i \\
\sum_{I} D C_{j i} Y_{j i} A_{i} \leq X_{j} \operatorname{Max}_{j} & \forall j \\
\sum_{I} D C_{j i} Y_{j i} B_{i} \geq X_{j} \operatorname{Min}_{j} & \forall j \\
X_{j}=0,1 & \forall j \\
Y_{j i}=0,1 & \forall j, i
\end{array}
$$

A função objetivo (4.2) minimiza o total do custo de distribuição. A primeira parcela dos parênteses representa o custo de transferência; a segunda, o custo de rodagem até as cidades dentro do raio de cobertura e a terceira os custos de entrega. 
Vale observar que para as entregas nas cidades que têm central, o custo de rodagem é zero, pois $\mathrm{i}=\mathrm{j}$ e $\mathrm{D}_{\mathrm{ji}}=0$. Outra consideração implícita à modelagem é a de que um veículo exclusivo será destacado para cada cidade a ser atendida dentro do raio de cobertura. Isso significa que, para efeito do custo de rodagem, sempre será considerado um veículo partindo da central direto à cidade destino, sem atender a nenhuma outra cidade. Na prática, o veículo até pode ser utilizado para atendimento de mais de uma cidade.

A restrição (4.3) faz a ligação entre as variáveis de localização $\mathrm{X}$ e as de alocação $\mathrm{Y}$, garantindo que uma cidade i só pode ser alocada a uma central em j se houver uma central localizada nessa cidade, ou seja, $Y_{j i}=1$ só se $X_{j}=1$. As restrições de (4.4) são as equações de atendimento à demanda, tanto em termos de peso $(\mathrm{kg})$ quanto em número de entregas de cada cidade i da rede, considerando inclusive a questão da cobertura. As restrições (4.5) limitam o peso que cada central é capaz de distribuir e as restrições (4.6) estabelecem o número mínimo de entregas que deve estar associado a uma central aberta. As restrições (4.7) e (4.8) são as de integralidade das variáveis de decisão.

\subsection{O procedimento baseado na metaheurística Busca Tabu}

A razão para a elaboração de um procedimento alternativo à programação linear reside, principalmente, na necessidade de solução de problemas de maiores dimensões, para os quais o tempo de processamento ou as ferramentas disponíveis não mais apresentem desempenho satisfatório. Por outro lado, não é objetivo do presente estudo a estruturação de um procedimento completo, que incorpore todas as propriedades da metaheurística Busca Tabu. Com isso exposto, na sequência é apresentada a metodologia que levou à elaboração de um 
procedimento simples, segmentado em duas principais fases, para a solução do problema proposto.

A estratégia para desenvolvimento de um procedimento baseado em Busca Tabu para a solução do problema de configuração de uma rede capacitada com restrição de cobertura teve como premissa uma importante propriedade da classe de problemas de localização conhecidos como não capacitados (Al-Sultan, Al-Fawzan, 1999).

Essa propriedade diz que os problemas de localização não capacitados podem matematicamente ser decompostos em dois subproblemas interdependentes: o problema de localização e o de alocação.

O primeiro diz respeito à determinação de quais nós candidatos serão abertos ou fechados. No modelo de programação linear apresentado no tópico anterior, corresponde à determinação de um vetor cujos componentes são as variáveis de decisão $X_{j}$. Nesta fase são utilizados os conceitos de Busca Tabu para obtenção do vetor solução.

A determinação de quais cidades cada central selecionada irá atender, corresponde ao problema de alocação, ou seja, para o vetor de componentes $X_{j}$ selecionado, no segundo subproblema é determinado o valor das variáveis $\mathrm{Y}_{\mathrm{ji}}$.

Ainda, segundo Al-Sultan e Al-Fawzan (1999), para qualquer subproblema de locação é possível obter-se uma solução ótima de alocação. Essa solução é obtida selecionando, para cada ponto a ser atendido, qual a central aberta que tem o menor custo para atendimento dessa demanda. 
No presente estudo, esse custo corresponde ao custo total de transporte, incluindo a transferência de material desde a origem até o representante selecionado, além dos valores de entrega e distribuição dentro da área de cobertura.

Conforme conclusão de Al-Sultan e Al-Fawzan (1999), a decomposição em dois subproblemas é uma estratégia eficaz na solução de problemas de localização não capacitados. Porém, o problema em questão é de localização capacitada, para o qual a simples alocação com base no critério de menor custo de ligação (no caso custo de transporte) pode ocasionar soluções que não atendam às restrições de capacidade estabelecidas, seja de limite mínimo de entregas, capacidade máxima de peso, ou ambas.

Diante disso, fez-se necessária a combinação da estratégia de subdivisão do problema (originária dos modelos não capacitados) com uma outra de refinamento da solução obtida, de forma a torná-la viável do ponto de vista das restrições de capacidade mínima e máxima do problema.

Esse refinamento consiste em modificar os valores originais, obtidos para as variáveis de alocação, na solução do segundo subproblema. Isso quer dizer que algumas ligações são desfeitas e outras são constituídas (muda-se de 1 para 0 , e vice-versa, o status de algumas variáveis $\mathrm{Y}_{\mathrm{ji}}$ ). Em ordem crescente, cada um dos movimentos possíveis é valorizado e, do menor para o maior, um a um é selecionado até que se encontre uma solução viável (no caso de haver uma).

Os movimentos possíveis são aqueles quando um nó candidato (que está com a capacidade máxima ultrapassada) "transfere" para outro (com capacidade ociosa), parte da demanda que 
estava sendo atendida por ele (ver figura 4.2). Da mesma forma, um candidato selecionado que na alocação original não tenha alcançado o limite mínimo de entregas, recebendo de um outro parte de sua demanda, também caracteriza um movimento possível. A valorização dos movimentos possíveis corresponde ao acréscimo de custo ao se mudar do candidato A para o B a alocação de determinado nó de demanda.

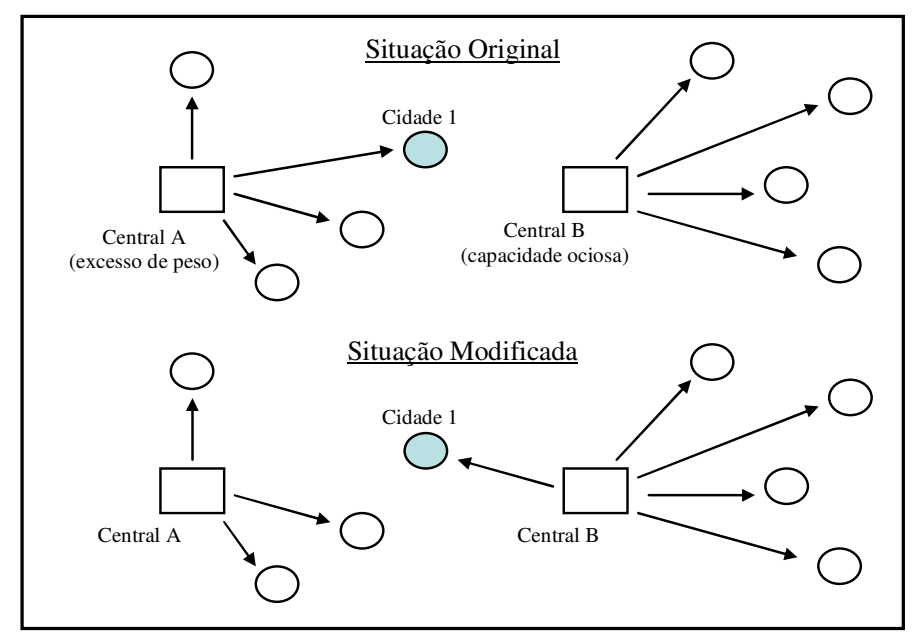

Figura 4.2 - Refinamento da alocação de cidades da solução original do procedimento

Diante do exposto, podemos dividir o procedimento para a solução do problema de configuração de uma rede capacitada com restrição de cobertura em duas fases:

- Fase 1: Determinação do vetor solução correspondente a quais centrais serão abertas aplicação de procedimento baseado no conceito de Busca Tabu, contemplando os dois subproblemas de locação e alocação.

- Fase 2: Refinamento da solução de alocação - adequação às restrições de capacidade (caso necessário).

Nos tópicos a seguir, cada uma das fases será melhor detalhada. 


\subsubsection{Determinação do vetor solução - Fase 1}

Esta primeira fase, conforme mostrado na figura 4.3 a seguir, corresponde à determinação de quais, dentre os locais candidatos, serão selecionados. Nesta fase são utilizados os conceitos de Busca Tabu para obtenção do status de cada componente do vetor solução. A fase pode ser dividida em inicialização e etapa principal.

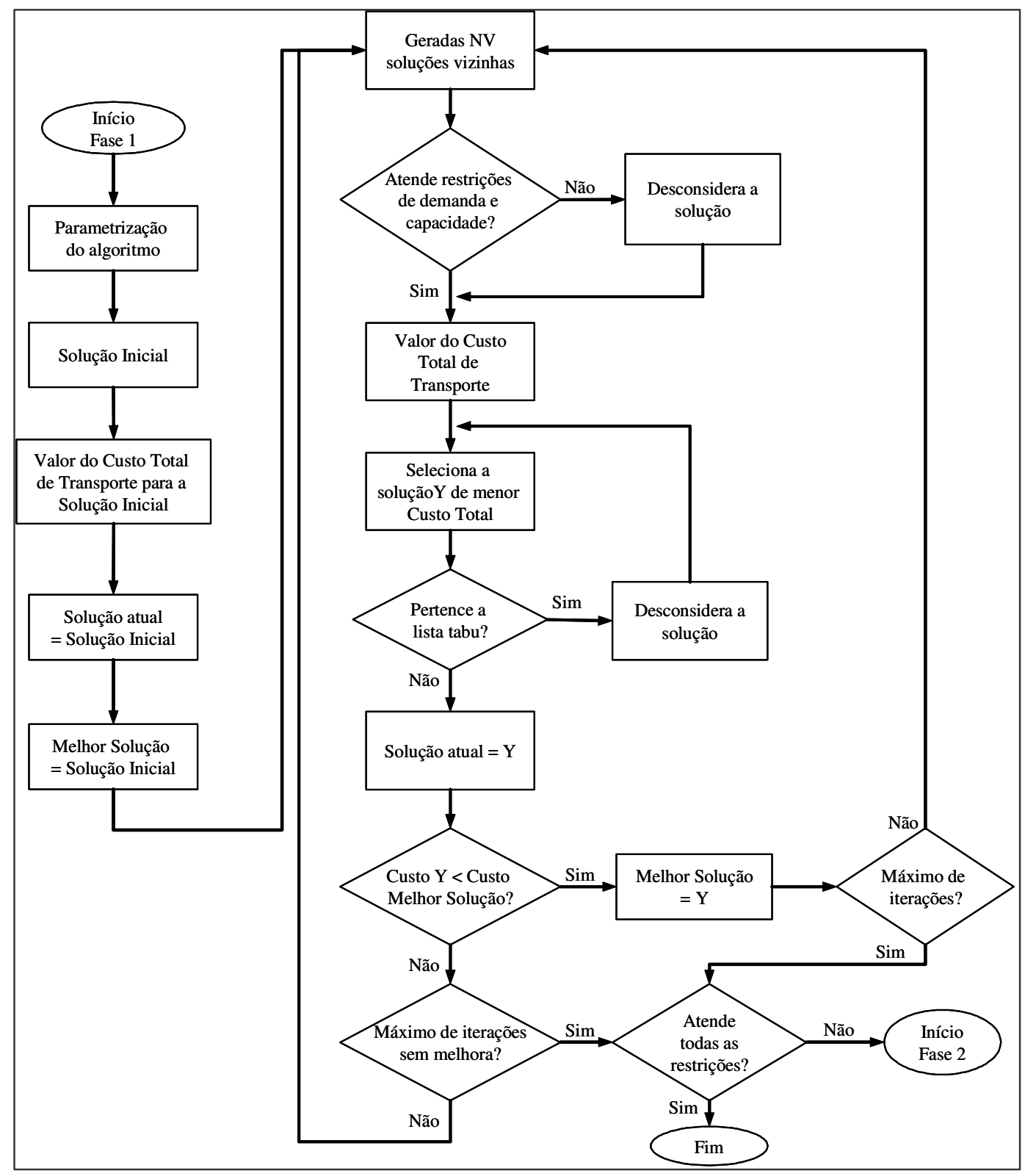

Figura 4.3 - Fluxograma da Fase 1 da Busca Tabu 


\section{$\underline{\text { I- Inicialização }}$}

1- Definição dos parâmetros do procedimento

a) Número de soluções aleatórias a serem geradas a partir da solução atual (NV);

b) Tamanho da lista tabu;

c) Critério de parada - número máximo de iterações e número de iterações sem que haja melhora no resultado global;

d) Probabilidade $\alpha$ de se alterar o status de um local candidato (abertura ou fechamento) no procedimento de geração de soluções vizinhas.

2- A solução inicial é gerada a partir de um procedimento ou heurística selecionada. Esta solução é um vetor em que cada componente corresponde a um nó da rede candidato à central, que pode assumir o valor 0 - se estiver fechado - ou 1 - se estiver aberto. Nesse estudo, adotou-se como solução inicial sempre todos os nós candidatos abertos, principalmente pelo fato dessa solução, por si só, já estar bem próxima da solução ótima para a maioria dos cenários analisados.

3- Com essa solução inicial é determinado o Custo Total de Transporte, a partir do procedimento descrito no tópico $\mathrm{V}$ a seguir.

4- Assume-se que a solução atual e a melhor solução global sejam igual à solução inicial encontrada, com o seu respectivo Custo Total de Transporte. 


\section{II- Etapa Principal}

1- São geradas NV soluções aleatórias a partir da solução atual (ver no próximo tópico o procedimento de geração de soluções vizinhas). Para cada uma dessas soluções, o Custo Total de Transporte é calculado (a partir do procedimento descrito no tópico V). A solução com menor custo total é selecionada, desde que atenda às restrições de atendimento de demanda e capacidade total.

Embora se tenha dito que as restrições seriam tratadas na etapa de refinamento do procedimento (fase 2), algumas condições já são verificadas para que se evite a tentativa de refinamento de soluções inviáveis. A primeira diz respeito ao atendimento da demanda. A solução é considerada como tendo obedecido a esse critério, desde que cada nó da rede seja atendido por uma única central. A outra restrição, na verdade complementar à primeira, diz que as centrais abertas devem ter capacidade total (em $\mathrm{kg}$ ) igual ou superior à demanda (também em $\mathrm{kg}$ ) total da rede em estudo.

2- Verifica-se se a solução selecionada pertence ou não à lista tabu. Se ela não pertencer, a solução atual é substituída por essa solução, que tem o status de cada um dos componentes de seu vetor armazenado na lista tabu.

3- Se o valor do Custo Total de Transporte dessa solução for maior que o menor Custo Total de Transporte já obtido, então é verificado se o número de iterações sem melhora no resultado atingiu o limite estabelecido no item 1c. Em caso afirmativo, encerra-se o procedimento. Se não, o contador de iterações sem melhora no resultado é atualizado e se repete a etapa principal desde o passo 1. Se o Custo Total de Transporte for o menor que o menor até então 
encontrado, esse passa a ser o menor Custo Total de Transporte e verifica-se se o máximo de iterações foi atingido. Em caso afirmativo, encerra-se a fase. Caso contrário é executado o passo 1 novamente (com o contador de iterações sem melhoria zerado).

4- Se a solução selecionada pertencer à lista tabu, seleciona-se outra solução gerada que apresente o menor Custo Total de Transporte e respeite as condições de cobertura e capacidade total, desconsiderando a solução anterior. Executa-se o procedimento a partir do passo 3 novamente.

5- Se a melhor solução atender a todas as restrições (incluindo as operacionais), o procedimento é encerrado sem a necessidade da segunda fase. Do contrário, executa-se a segunda fase.

$\underline{\text { III- Procedimento para geração de vizinhos a partir da solução atual }}$

Considera-se que $x_{i}$ é o i-ésimo componente do vetor solução $x$, com $1<\mathrm{i}<\mathrm{n}$, sendo $\mathrm{n}$ igual ao número de locais candidatos.

a) Definição da probabilidade $\alpha$ de mudança de status do local candidato.

b) Faz-se i $=1$

c) Um número aleatório $\beta$ (entre 0 e 1) é gerado em uma distribuição uniforme de média 0 e desvio 1.

d) Se $\beta>\alpha$, então troca-se o status de $x_{i}$ (se era 0 passa a ser 1 e vice-versa) e se $i=n$, encerra-se o procedimento.

e) Caso contrário, $\mathrm{i}=\mathrm{i}+1$ e o procedimento é repetido a partir do passo c. 
$\underline{\text { IV - Armazenamento na lista tabu }}$

Na lista tabu, a solução vizinha escolhida, ou seja, o status de cada um dos componentes do vetor solução, é armazenado durante o número de iterações definido no item $1 \mathrm{~b}$ do procedimento de inicialização.

\section{V - Cálculo do Custo Total de Transporte}

A função utilizada para cálculo do Custo Total de Transporte é a mesma função objetivo do modelo de programação linear:

$\mathrm{CT}=\sum_{J} \sum_{I} Y_{j i}\left(A_{i} C_{0 j}+D_{j i} K M_{j}+B_{i} C_{j}\right)$

As constantes e variáveis dessa equação estão detalhados no tópico 4.2.

Para sua resolução, faz-se necessário conhecer todas as variáveis de alocação $Y_{\mathrm{ji}}$. Uma vez resolvido o problema de locação (determinação do vetor solução, ou seja, quais centrais serão abertas), o problema de alocação é determinado calculando o custo total de transporte (desde a origem, passando pela central até chegar ao destino) para cada um dos nós de demanda da rede. Esse cálculo é feito para todas as centrais abertas pelo vetor solução e que atendam à restrição de cobertura, isto é, a distância entre a central e o nó seja menor ou igual à distância (em km) estabelecida. Para cada um dos nós, a central que oferecer o menor custo de transporte será selecionada e o valor da variável de alocação desse trecho será igual a um; por conseguinte, será igual a zero para todos os outros trechos entre esse mesmo nó e as demais centrais. Determinadas as variáveis de alocação, o valor do Custo Total de Transporte é calculado através da equação (4.2). 


\subsubsection{Refinamento da solução de alocação - Fase 2}

Conforme dito anteriormente, as soluções encontradas durante a execução da primeira fase do procedimento, não necessariamente atendem a todas as restrições estabelecidas no problema original. Apenas as restrições de cobertura e atendimento total da demanda é que precisam ser respeitadas durante a primeira fase. A explicação para tanto reside no fato de que o procedimento de alocação, baseado no menor custo de transporte, não leva em consideração nem o limite mínimo nem a capacidade máxima de cada uma das centrais selecionadas.

Como consequiência, as soluções obtidas podem precisar ser "ajustadas" com o objetivo de atender às restrições de capacidade do problema. Daí surge a necessidade da segunda fase do procedimento, chamada de refinamento da solução de alocação, que pode ser traduzida nos seguintes passos, conforme mostrado na figura 4.4 , a seguir.

1- As soluções geradas na fase 1 são ordenadas de forma crescente, de acordo com o valor do Custo Total de Transporte. A solução de menor custo é então selecionada.

2- São identificadas as centrais que não atingiram o limite mínimo de entregas e as que excederam a capacidade máxima de peso para essa particular solução. Naturalmente, as centrais do primeiro grupo são candidatas a receber um maior número de entregas para viabilizar sua utilização, enquanto que as do segundo grupo precisam se "desfazer" de alguns nós para que não ultrapassem o peso máximo permitido. Além dessas, as centrais que

atingiram o mínimo de entregas, porém não chegaram ao limite de peso, também são identificadas como potenciais "receptoras" de um maior número de entregas. 


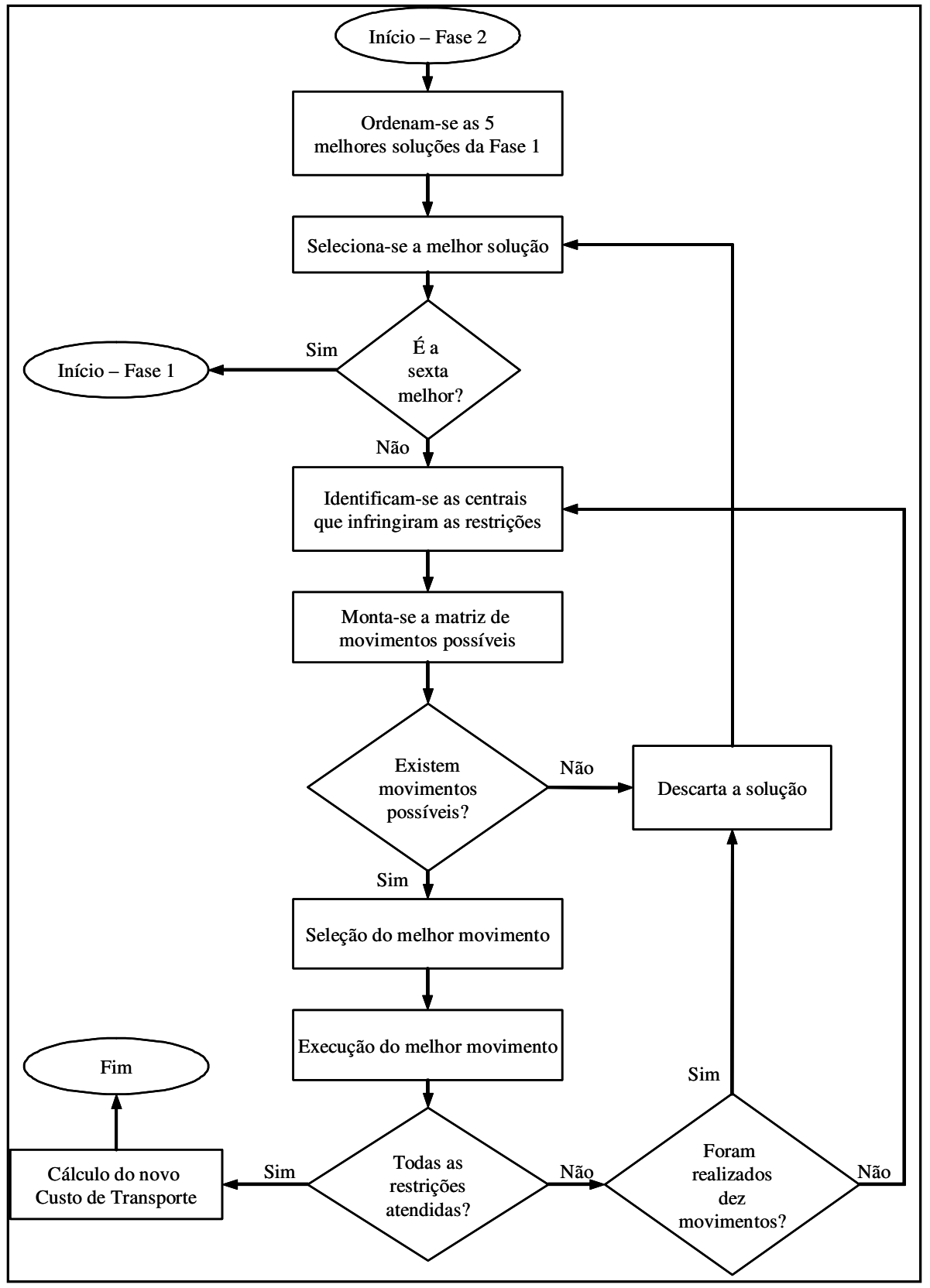

Figura 4.4 - Fluxograma da Fase 2 da Busca Tabu

3- Monta-se uma matriz de movimentos possíveis entre as centrais. Para cada uma das cidades alocadas a uma central que excedeu o peso permitido, são ordenadas (do menor para o maior custo de transporte), dentre as centrais que não atingiram o limite mínimo, ou ainda possuem capacidade ociosa de peso, as outras centrais capazes de atender a essa demanda. 
4- Para a escolha de qual é o melhor movimento dentre todos esses possíveis, busca-se minimizar o acréscimo de custo de transporte associado a cada alternativa. Então é calculado cada um desses acréscimos, e o movimento que apresentar o menor resultado é o escolhido. Esse acréscimo é simplesmente o custo de transporte da nova configuração (caso o movimento seja concretizado) menos o custo de transporte da atual alocação. Sabendo-se que a alocação original é baseada no critério de menor custo, o resultado dessa subtração é sempre positivo.

5- Com isso, tem-se um par de variáveis de alocação que terão os seus valores trocados. O nó deixará de ser atendido pela central a que originalmente estava alocado (o valor de $\mathrm{Y}_{\mathrm{ji}}$ muda de 1 para 0) e passará a ser alocado à nova central, configurando uma nova solução.

6- Executado o melhor movimento (e sempre um único movimento é executado por vez), fazse a verificação das restrições de capacidade. Se ambas forem atendidas, calcula-se a novo valor do Custo Total de Transporte e esse será o resultado do procedimento. Se alguma restrição ainda não estiver satisfeita, mantém-se a alocação modificada e executa-se o segundo melhor movimento, até que se esgotem os movimentos possíveis, ou sejam executados dez movimentos sem sucesso (critério de parada para evitar tempo excessivo de processamento), ou se encontre uma alocação que atenda a todas as restrições. Caso esta última condição não seja verdadeira, parte-se para a solução da fase 1 imediatamente superior (em temos do valor do Custo Total de Transporte) a se que estava buscando refinar e se repete a fase a partir do passo 2. Busca-se até a quinta melhor solução da fase 1 para a tentativa de refinamento (novamente utiliza-se neste ponto outro critério de parada). 
7- Se as cinco melhores soluções obtidas na fase 1 forem testadas e não se conseguir um refinamento capaz de atender a todas as restrições, cabe uma nova aplicação do procedimento, a partir da fase 1.

\subsection{Encaminhamento da aplicação de metodologia proposta}

Como foi dito logo na Introdução desse trabalho, um dos objetivos do presente estudo é o desenvolvimento e aplicação de uma metodologia para a análise e solução de problemas de distribuição de carga fracionada. Além disso, buscou-se desde o início viabilizar a implementação computacional dos modelos propostos em planilha eletrônica, o que seria uma forma de contribuição à utilização de ferramentas de pesquisa operacional no dia-a-dia das empresas do setor de transporte e logística, já que tais softwares possuem interface amigável a maioria dos usuários e estão presentes em grande parte dessas empresas.

Nessa linha, toda metodologia proposta nesse capítulo foi implementada em planilha eletrônica Excel da Microsoft. Desde o registro dos dados que constituem a rede a ser estudada, passando pelo cálculo da matriz de distância, incluindo o modelo de programação linear, o procedimento baseado em Busca Tabu, e até mesmo a representação gráfica dos resultados, tudo foi implementado - com sucesso - em planilha eletrônica, caracterizando um dos pontos de destaque do trabalho.

No que diz respeito à modelagem proposta, tanto a baseada em programação linear quanto a em Busca Tabu, cabe o detalhamento da utilização de ferramentas que viabilizaram a aplicação da metodologia. 
Para implementação e validação iniciais do modelo de programação linear selecionado, foi utilizado o suplemento Solver do Excel.

Com o Solver é possível localizar um valor ideal para uma fórmula em uma célula - chamada de célula de destino - em uma planilha. O Solver trabalha com um grupo de células relacionadas direta ou indiretamente com a fórmula na célula de destino. O Solver ajusta os valores nas células variáveis especificadas - chamadas de células ajustáveis - para produzir o resultado especificado por você na fórmula da célula de destino. Você pode aplicar restrições para restringir os valores que o Solver poderá usar no modelo e as restrições podem se referir as outras células que afetem a fórmula da célula de destino. Os problemas lineares e de inteiros usam o método simplex com limites sobre as variáveis e o método de desvio e limite, implementado por John Watson e Dan Fylstra, da Frontline Systems, Inc.

(Ajuda do Microsoft Office Excel 2003)

Na primeira fase de investigação sobre o comportamento do modelo de programação linear, alguns cenários de problemas de localização com dimensões reduzidas foram utilizados. Isso porque o suplemento Solver padrão que acompanha a planilha Excel tem como restrição o fato de resolver modelos com até duzentas variáveis de decisão, o que é pouco diante da natureza de tais problemas. Para se ter uma idéia do que isso representa em relação ao objeto do estudo, com o Solver padrão é possível de serem resolvidos, por exemplo, problemas com apenas vinte nós de demanda, e no máximo dez deles candidatos à central de desconsolidação.

Para superar tal obstáculo, foram pesquisadas alternativas ao Solver padrão. A própria empresa responsável pelo desenvolvimento do suplemento, comercializa extensões do Solver padrão (também compatíveis com o Excel), nas quais são implementados novos e mais velozes algoritmos para a solução de uma grande diversidade de problemas de natureza combinatória.

Uma dessas extensões é o Premium Solver Platform (PSP) for Excel. Ela inclui, entre outras funcionalidades, um algoritmo para solução de problemas de programação linear de larga 
escala, capaz de manipular até 8.000 variáveis de decisão (sendo 2.000 delas inteiras) e 8.000 restrições. Além do ganho em termos de dimensões do problema, o algoritmo utilizado para a solução de modelos inteiros (do tipo que está sendo proposto nesse trabalho), possibilita a obtenção de soluções até 100 vezes mais rápido que o Solver padrão. No mais, o PSP segue o mesmo padrão de funcionamento do Solver padrão presente no Excel.

Para a implementação e solução do modelo de programação linear proposto na metodologia desse estudo, foi utilizada uma versão trial (com licença para até quinze dias de uso) do Premium Solver Platform for Excel, disponível para download no endereço http://www.solver.com. Com isso, tornou-se viável a solução de problemas de dimensões inerentes a problemas reais de empresas de transporte e logística.

Em relação à programação linear, a solução encontrada na família dos suplementos Solver foi suficiente para viabilizar a utilização do modelo proposto. Quanto ao procedimento desenvolvido com base em Busca Tabu, seguindo a linha traçada na metodologia apresentada, buscou-se também sua implementação em planilha eletrônica. Por se tratar de um conjunto de rotinas a serem executadas de forma ordenada e, às vezes, repetidamente, foi identificada a necessidade de utilização de uma linguagem de programação que incorporasse essa série de procedimentos.

Diante disso, optou-se por codificar o procedimento baseado em Busca Tabu na linguagem de programação Visual Basic for Applications (VBA). O VBA é uma implementação do Visual Basic da Microsoft incorporada em todos os programas do Microsoft Office, bem como em outros aplicativos da Microsoft. Ele pode ser utilizado para controlar os aspectos relacionados 
à aplicação na qual está presente, incluindo a manipulação da interface do usuário, tais como menus, barras de ferramentas, formulários e caixas de diálogo.

Em $V B A$, a forma mais comum de trabalho é através das macros. Uma macro é um programa escrito ou gravado capaz de armazenar uma série de comandos no Excel para que possam ser utilizados posteriormente como um único comando. Com as macros, é possível automatizar tarefas complexas, tais como os procedimentos definidos na Busca Tabu. Portanto, a implementação desta heurística foi estruturada a partir da criação de macros no ambiente $V B A$ do Excel. Também a etapa de visualização dos resultados em mapas de alocação foi implementada em código $V B A$, possibilitando sua aplicação tanto para o caso do modelo de programação linear, quanto para a Busca Tabu.

A figura 4.5 abaixo ilustra o encaminhamento da metodologia de solução adotada.

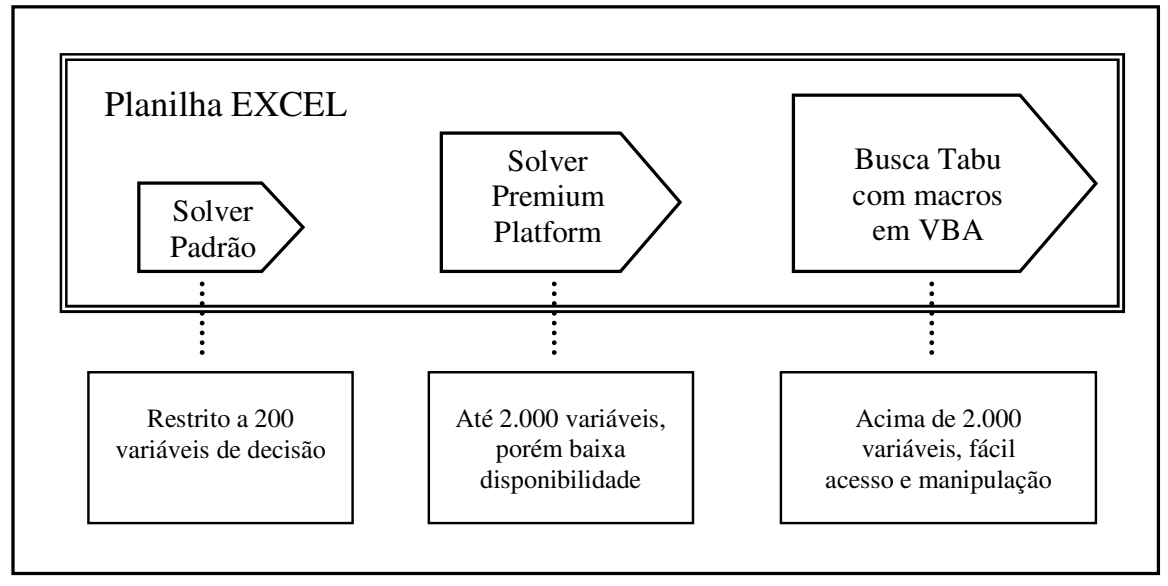

Figura 4.5 - Encaminhamento da metodologia de solução

Maiores detalhes sobre as implementações em Excel são apresentados no Apêndice A. 
A metodologia descrita nesse capítulo, com destaque para a comparação entre as soluções do modelo de programação linear selecionado e do procedimento baseado na Busca Tabu, tem como objetivo estabelecer uma seqüência de etapas para a solução do problema de localização objeto do estudo.

No próximo capítulo, sua aplicabilidade é colocada à prova em estudos de caso. Primeiramente, a solução é obtida com a utilização dos suplementos Solver do Microsoft Excel. Em seguida, a solução do problema de configuração de rede de distribuição capacitada, com restrição de cobertura, é investigada a partir da codificação em $V B A$ do procedimento baseado em Busca Tabu. Finalizando o capítulo, são apresentadas as comparações entre os dois enfoques de solução propostos. 


\section{APLICAÇÃO DA METODOLOGIA AO PROBLEMA EM QUESTÃO}

O problema foco do estudo de caso refere-se à distribuição de material promocional em pontos de venda de um dos mais representativos clientes da carteira de um operador logístico. A rede logística a ser avaliada é composta por um único centro de distribuição na cidade de São Paulo (operacionalizado pela empresa), origem de toda a carga, locais de entrega presentes em diferentes cidades do estado de São Paulo, e representantes regionais a serem utilizados como centrais de desconsolidação de carga.

Com o objetivo de analisar o comportamento do modelo selecionado e a qualidade da solução encontrada, um problema real foi escolhido para aplicação da metodologia proposta, ou seja, a utilização do modelo de programação linear selecionado e também do procedimento baseado na Busca Tabu.

\subsection{Aplicação da metodologia com o modelo de programação linear}

Este tópico apresenta inicialmente os resultados obtidos com a utilização dos suplementos Solver do Excel. Primeiramente, alguns testes de validação do modelo de programação linear foram feitos em problemas de dimensões reduzidas, utilizando-se o Solver padrão. Em seguida, já com suas dimensões reais, o problema em estudo foi resolvido com a utilização do suplemento Premium Solver Platform for Excel da Frontline Systems. 


\subsubsection{Estudo preliminar - utilização do Solver padrão}

Conforme dito anteriormente, um problema de menores dimensões foi selecionado para um estudo preliminar sobre a viabilidade do modelo proposto.

\section{Passo 1: Pontos da rede e nível de serviço}

Para esse estudo, a rede selecionada é composta por 14 cidades do estado de São Paulo, incluindo a capital São Paulo, origem das cargas. Os dados relacionados a cada uma das cidades que formam a rede de distribuição, incluindo a demanda em peso e número de entregas, encontram-se nas tabelas abaixo.

Tabela 5.1 - Cidades que compõem a rede do problema preliminar

\begin{tabular}{|c|c|c|c|c|c|c|c|}
\hline Nó & Cidade & Nó & Cidade & Nó & Cidade & Nó & Cidade \\
\hline $\mathbf{0}$ & São Paulo & 4 & Taubaté & 8 & Pres. Prudente & 12 & Franca \\
\hline 1 & Campinas & 5 & Bauru & 9 & Araçatuba & 13 & Assis \\
\hline 2 & Ribeirão Preto & 6 & S.J do Rio Preto & 10 & Piracicaba & & \\
\hline 3 & S.J dos Campos & 7 & Americana & 11 & Araraquara & & \\
\hline
\end{tabular}

Tabela 5.2 - Latitude, longitude e demanda dos nós da rede do problema preliminar

\begin{tabular}{lrrrrrrr}
\hline \multicolumn{1}{c}{ Nó } & $\mathbf{0}$ & $\mathbf{1}$ & $\mathbf{2}$ & $\mathbf{3}$ & $\mathbf{4}$ & $\mathbf{5}$ & \multicolumn{1}{c}{$\mathbf{6}$} \\
\hline Latitude & $-46,64$ & $-47,06$ & $-47,81$ & $-45,89$ & $-45,55$ & $-49,06$ & $-49,37$ \\
Longitude & $-23,54$ & $-22,90$ & $-21,17$ & $-23,17$ & $-23,02$ & $-22,31$ & $-20,82$ \\
Demanda de entregas & 7 & 3 & 1 & 1 & 1 & 1 & 1 \\
Demanda de peso $(\mathrm{kg})$ & 4880 & 840 & 1080 & 320 & 480 & 900 & 360 \\
\hline
\end{tabular}

\begin{tabular}{lrrrrrrr}
\hline \multicolumn{1}{c}{ Nó } & \multicolumn{1}{c}{$\mathbf{7}$} & $\mathbf{8}$ & $\mathbf{9}$ & $\mathbf{1 0}$ & $\mathbf{1 1}$ & $\mathbf{1 2}$ & \multicolumn{1}{c}{$\mathbf{1 3}$} \\
\hline Latitude & $-47,33$ & $-51,39$ & $-50,43$ & $-47,64$ & $-48,17$ & $-47,40$ & $-50,41$ \\
Longitude & $-22,74$ & $-22,12$ & $-21,21$ & $-22,72$ & $-21,79$ & $-20,54$ & $-22,66$ \\
Demanda de entregas & 1 & 1 & 1 & 1 & 1 & 1 & 1 \\
Demanda de peso $(\mathrm{kg})$ & 600 & 600 & 350 & 240 & 300 & 480 & 350 \\
\hline
\end{tabular}


Em se tratando de uma análise preliminar onde um dos objetivos é a validação do modelo proposto, alguns parâmetros (principalmente os relacionados a custos e restrições operacionais) foram variados de forma a obter um melhor entendimento de como esses dados influenciam a solução encontrada e o desempenho do modelo.

Quanto ao nível de serviço, em nosso estudo representado pela distância de cobertura a partir dos representantes, iniciou-se a análise com $100 \mathrm{~km}$. Com o objetivo de estudar os impactos de sua variação para o modelo, foram executadas rodadas variando essa distância de 50 em 50 até o limite de $600 \mathrm{~km}$.

\section{Passo 2: Cidades candidatas a representantes}

Nesse momento, todas as cidades da rede dispõem de representantes locais e, portanto, são candidatas a central de desconsolidação de carga.

\section{Passo 3: Custos de transferência e distribuição}

A tabela abaixo apresenta os custos de transferência entre a origem e cada uma das cidades candidata a representantes, as tarifas por entrega realizada e as taxas de rodagem para o atendimento às cidades a partir de uma central.

Tabela 5.3 - Custos de transporte de cada nó da rede do problema preliminar (continua)

\begin{tabular}{lrrrrrrr}
\hline \multicolumn{1}{c}{ Nó } & \multicolumn{1}{c}{$\mathbf{0}$} & \multicolumn{1}{c}{$\mathbf{1}$} & \multicolumn{1}{c}{$\mathbf{2}$} & \multicolumn{1}{c}{$\mathbf{3}$} & \multicolumn{1}{c}{$\mathbf{4}$} & \multicolumn{1}{c}{$\mathbf{5}$} & \multicolumn{1}{c}{$\mathbf{6}$} \\
\hline Transferência $(\mathrm{R} \$ / \mathrm{kg})$ & 0,00 & 0,49 & 1,55 & 0,49 & 0,70 & 1,63 & 2,20 \\
Entrega (R\$/entrega) & 25,00 & 30,00 & 35,00 & 30,00 & 40,00 & 35,00 & 30,00 \\
Rodagem $(\mathrm{R} \$ / \mathrm{km})$ & 0,25 & 0,30 & 0,35 & 0,30 & 0,40 & 0,35 & 0,30 \\
\hline
\end{tabular}


Tabela 5.3 - Custos de transporte de cada nó da rede do problema preliminar (conclusão)

\begin{tabular}{lrrrrrrr}
\hline \multicolumn{1}{c}{ Nó } & \multicolumn{1}{c}{$\mathbf{7}$} & $\mathbf{8}$ & \multicolumn{1}{c}{$\mathbf{9}$} & \multicolumn{1}{c}{$\mathbf{1 0}$} & \multicolumn{1}{c}{$\mathbf{1 1}$} & \multicolumn{1}{c}{$\mathbf{1 2}$} & \multicolumn{1}{c}{$\mathbf{1 3}$} \\
\hline Transferência (R\$/kg) & 0,66 & 2,78 & 2,69 & 0,83 & 1,39 & 1,94 & 2,17 \\
Entrega (R\$/entrega) & 40,00 & 40,00 & 40,00 & 35,00 & 35,00 & 40,00 & 40,00 \\
Rodagem (R $\$ / \mathrm{km})$ & 0,40 & 0,40 & 0,40 & 0,35 & 0,35 & 0,40 & 0,40 \\
\hline
\end{tabular}

\section{Passo 4: Matriz de Distância}

A partir da aplicação da fórmula (4.1), descrita no capítulo anterior, para cada par de pontos da rede em estudo, é obtida a matriz de distância teórica abaixo.

Tabela 5.4 - Matriz de distância teórica (em km) para o problema preliminar

\begin{tabular}{|c|c|c|c|c|c|c|c|c|c|c|c|c|c|c|}
\hline NÓ & $\mathbf{0}$ & $\mathbf{1}$ & $\mathbf{2}$ & $\mathbf{3}$ & $\mathbf{4}$ & $\mathbf{5}$ & $\mathbf{6}$ & $\mathbf{7}$ & $\mathbf{8}$ & $\mathbf{9}$ & $\mathbf{1 0}$ & $\mathbf{1 1}$ & $\mathbf{1 2}$ & $\mathbf{1 3}$ \\
\hline $\mathbf{0}$ & 0 & 83 & 290 & 87 & 125 & 283 & 414 & 114 & 512 & 468 & 138 & 251 & 343 & 398 \\
\hline $\mathbf{1}$ & 83 & 0 & 207 & 124 & 155 & 216 & 333 & 33 & 453 & 395 & 63 & 169 & 266 & 345 \\
\hline $\mathbf{2}$ & 290 & 207 & 0 & 298 & 310 & 181 & 168 & 181 & 385 & 272 & 173 & 78 & 82 & 315 \\
\hline $\mathbf{3}$ & 87 & 124 & 298 & 0 & 38 & 339 & 445 & 155 & 577 & 516 & 187 & 281 & 332 & 467 \\
\hline $\mathbf{4}$ & 125 & 155 & 310 & 38 & 0 & 368 & 464 & 184 & 607 & 541 & 217 & 302 & 336 & 499 \\
\hline $\mathbf{5}$ & 283 & 216 & 181 & 339 & 368 & 0 & 169 & 184 & 241 & 187 & 152 & 108 & 261 & 144 \\
\hline $\mathbf{6}$ & 414 & 333 & 168 & 445 & 464 & 169 & 0 & 300 & 254 & 117 & 277 & 165 & 208 & 231 \\
\hline $\mathbf{7}$ & 114 & 33 & 181 & 155 & 184 & 184 & 300 & 0 & 423 & 362 & 33 & 137 & 245 & 316 \\
\hline $\mathbf{8}$ & 512 & 453 & 385 & 577 & 607 & 241 & 254 & 423 & 0 & 142 & 391 & 334 & 449 & 117 \\
\hline $\mathbf{9}$ & 468 & 395 & 272 & 516 & 541 & 187 & 117 & 362 & 142 & 0 & 333 & 242 & 323 & 161 \\
\hline $\mathbf{1 0}$ & 138 & 63 & 173 & 187 & 217 & 152 & 277 & 33 & 391 & 333 & 0 & 117 & 244 & 284 \\
\hline $\mathbf{1 1}$ & 251 & 169 & 78 & 281 & 302 & 108 & 165 & 137 & 334 & 242 & 117 & 0 & 161 & 249 \\
\hline $\mathbf{1 2}$ & 343 & 266 & 82 & 332 & 336 & 261 & 208 & 245 & 449 & 323 & 244 & 161 & 0 & 390 \\
\hline $\mathbf{1 3}$ & 398 & 345 & 315 & 467 & 499 & 144 & 231 & 316 & 117 & 161 & 284 & 249 & 390 & 0 \\
\hline
\end{tabular}

Porém, sabe-se que a utilização da distância teórica no modelo pode distorcer os resultados.

Isso porque o caminho percorrido de um ponto a outro, na grande maioria dos casos, não corresponde exatamente a uma reta, mesmo que corrigida para o formato da Terra, como é o caso das distâncias da matriz acima. 
Com o intuito de minimizar essa distorção, alguns autores fazem uso de um coeficiente de correção de distância. Esse fator de circuito (sempre maior que 1) tem como objetivo justamente retratar as distorções à reta do caminho entre dois pontos.

No presente estudo, também foi utilizado o fator de circuito. A diferença é que foi aplicada uma metodologia baseada em regressão linear para chegar a esse número, ao invés da adoção de um determinado valor obtido da literatura. Com isso, se procurou determinar o fator mais apropriado para a rede em estudo, levando em consideração somente as cidades diretamente envolvidas no problema.

Para a aplicação da técnica da regressão linear, foi feito um levantamento das distâncias reais entre duas cidades disponíveis em guias rodoviários especializados. Os números obtidos são apresentados na tabela abaixo.

Tabela 5.5 - Matriz de distância real (em km) para o problema preliminar

\begin{tabular}{|c|c|c|c|c|c|c|c|c|c|c|c|c|c|c|}
\hline NÓ & $\mathbf{0}$ & $\mathbf{1}$ & $\mathbf{2}$ & $\mathbf{3}$ & $\mathbf{4}$ & $\mathbf{5}$ & $\mathbf{6}$ & $\mathbf{7}$ & $\mathbf{8}$ & $\mathbf{9}$ & $\mathbf{1 0}$ & $\mathbf{1 1}$ & $\mathbf{1 2}$ & $\mathbf{1 3}$ \\
\hline $\mathbf{0}$ & 0 & 98 & 310 & 97 & 140 & 325 & 440 & 132 & 556 & 537 & 165 & 277 & 388 & 433 \\
\hline $\mathbf{1}$ & 98 & 0 & 209 & 156 & 189 & 261 & 343 & 39 & 529 & 450 & 72 & 180 & 298 & 407 \\
\hline $\mathbf{2}$ & 310 & 209 & 0 & 369 & 402 & 219 & 185 & 179 & 448 & 328 & 189 & 81 & 89 & 372 \\
\hline $\mathbf{3}$ & 97 & 156 & 369 & 0 & 43 & 424 & 516 & 189 & 651 & 618 & 226 & 349 & 456 & 521 \\
\hline $\mathbf{4}$ & 140 & 189 & 402 & 43 & 0 & 468 & 560 & 234 & 696 & 663 & 271 & 394 & 489 & 566 \\
\hline $\mathbf{5}$ & 325 & 261 & 219 & 424 & 468 & 0 & 210 & 235 & 283 & 196 & 209 & 138 & 303 & 187 \\
\hline $\mathbf{6}$ & 440 & 343 & 185 & 516 & 560 & 210 & 0 & 337 & 293 & 158 & 323 & 166 & 221 & 287 \\
\hline $\mathbf{7}$ & 132 & 39 & 179 & 189 & 234 & 235 & 337 & 0 & 506 & 430 & 34 & 170 & 274 & 376 \\
\hline $\mathbf{8}$ & 556 & 529 & 448 & 651 & 696 & 283 & 293 & 506 & 0 & 181 & 472 & 414 & 499 & 131 \\
\hline $\mathbf{9}$ & 537 & 450 & 328 & 618 & 663 & 196 & 158 & 430 & 181 & 0 & 404 & 295 & 354 & 197 \\
\hline $\mathbf{1 0}$ & 165 & 72 & 189 & 226 & 271 & 209 & 323 & 34 & 472 & 404 & 0 & 156 & 276 & 342 \\
\hline $\mathbf{1 1}$ & 277 & 180 & 81 & 349 & 394 & 138 & 166 & 170 & 414 & 295 & 156 & 0 & 170 & 315 \\
\hline $\mathbf{1 2}$ & 388 & 298 & 89 & 456 & 489 & 303 & 221 & 274 & 499 & 354 & 276 & 170 & 0 & 452 \\
\hline $\mathbf{1 3}$ & 433 & 407 & 372 & 521 & 566 & 187 & 287 & 376 & 131 & 197 & 342 & 315 & 452 & 0 \\
\hline
\end{tabular}


Quando o problema tem dimensões reduzidas, é viável obter a matriz de distâncias reais acima e até dispensar o cálculo do fator de circuito. Isso porque as distâncias reais são obtidas diretamente do quadro de distâncias de guias rodoviários.

No entanto, o objetivo de apresentar o cálculo do fator de circuito é viabilizar a aplicação do modelo quando o número de pontos da rede for elevado e a obtenção de uma matriz como essa não for mais uma tarefa trivial. Em situações como essas, uma alternativa pode ser a obtenção de parte da matriz de distância real que possibilite o cálculo do fator de circuito e daí, a composição da matriz de distância corrigida.

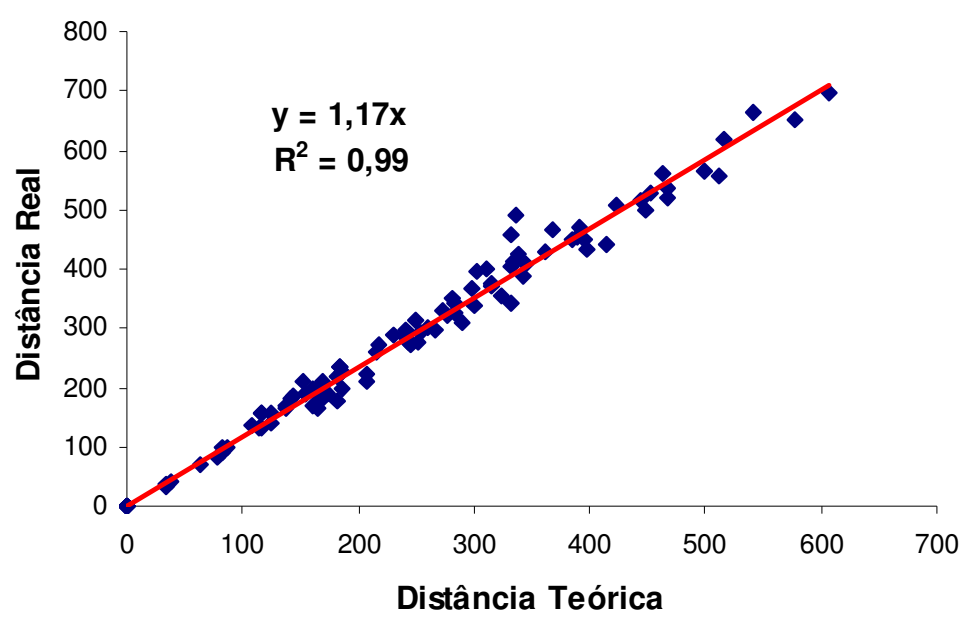

Figura 5.1 - Gráfico de correlação entre distância real e teórica

Para os dados do problema em estudo, a regressão linear chegou ao valor de 1,17 para o fator de correção, ou seja, as distâncias reais nesse caso são 17\% maiores que as teóricas. Com esse número é possível construir a matriz de distância corrigida, resultado da multiplicação da matriz real pelo fator encontrado. Um detalhe importante é que esse valor é exatamente o número referenciado na literatura como "bom valor" para o fator de circuito (Ballou, 1995). 


\section{Passo 5: Aplicação do modelo selecionado}

Conforme já dito nas seções anteriores, o principal objetivo dessa fase preliminar é a aplicação do modelo selecionado a um problema de menor escala para avaliação, tanto do comportamento do modelo, como da qualidade das soluções encontradas.

Diante disso, vários cenários foram preparados e o modelo foi aplicado a cada um deles. Para implementação da modelagem, foi utilizado o suplemento Solver padrão da planilha eletrônica Excel da Microsoft. Os resultados e principais interpretações são apresentados a seguir, detalhados no tópico referente a cada um dos cenários estudados. Essas etapas correspondem aos passos 7 e 8 da metodologia proposta. Nesse estudo preliminar, não foi levada em consideração a utilização do procedimento baseado em Busca Tabu (passo 6 da metodologia proposta).

\section{i) Relaxamento das restrições de mínimo de entregas e máximo de peso}

Para esse cenário, foram relaxadas as restrições operacionais dos representantes, ou seja, para a capacidade máxima de peso e o número mínimo de entregas, foram adotados respectivamente $12.000 \mathrm{~kg}$ e 1 para todos os candidatos. Assim, todos poderiam atender a todas as cidades ou somente à demanda do próprio local. Os resultados da aplicação computacional estão na tabela 5.6, a seguir. 
Tabela 5.6 - Resultado da aplicação do modelo ao cenário 1 do problema preliminar

\begin{tabular}{rrrrrrl}
\hline & $\begin{array}{c}\text { DC } \\
(\mathbf{k m})\end{array}$ & \multicolumn{1}{c}{$\begin{array}{c}\text { Transf. } \\
(\mathbf{R} \$)\end{array}$} & \multicolumn{1}{c}{$\begin{array}{c}\text { Distrib. } \\
(\mathbf{R} \$ \mathbf{)}\end{array}$} & Total $(\mathbf{R} \mathbf{})$ & $\begin{array}{c}\text { No. } \\
\text { Repres }\end{array}$ & \multicolumn{1}{c}{ Nós Selecionados } \\
\hline 1 & 100 & $9.343,90$ & 778,50 & $10.122,40$ & 10 & $0-2-4-5-6-7-8-9-11-13$ \\
2 & 150 & $8.066,50$ & 898,60 & $8.965,10$ & 7 & $0-2-6-9-10-11-13$ \\
3 & 200 & $6.755,90$ & $1.071,50$ & $7.827,40$ & 5 & $0-5-10-11-13$ \\
4 & 250 & $6.096,20$ & $1.209,40$ & $7.305,60$ & 4 & $0-7-11-13$ \\
5 & 300 & $5.072,60$ & $1.217,65$ & $6.290,25$ & 4 & $0-1-11-13$ \\
6 & 350 & $3.637,70$ & $1.305,00$ & $4.942,70$ & 3 & $0-1-13$ \\
7 & 400 & $3.309,50$ & $1.301,00$ & $4.610,50$ & 3 & $0-10-13$ \\
8 & 450 & $1.731,25$ & $1.460,15$ & $3.191,40$ & 2 & $0-11$ \\
9 & 500 & 981,75 & $1.546,60$ & $2.528,35$ & 2 & $0-10$ \\
10 & 550 & 693,00 & $1.529,45$ & 2.222 .45 & 2 & $0-10$ \\
11 & 600 & 0,00 & $1.524,50$ & $1.524,50$ & 1 & 0 \\
\hline
\end{tabular}

Pelo resultado acima, podemos concluir que:

a) São Paulo como origem das cargas aparece em todas as soluções; isso pode ser considerado como ponto positivo do modelo, visto que naturalmente a origem é uma boa opção de central de carga.

b) A idéia de equilíbrio entre nível de serviço e custos da operação ficou bem nítida à medida que o aumento da distância de cobertura, ou seja, o relaxamento do nível de serviço corresponde à diminuição nos custos de entrega.

c) Outro resultado esperado comprovado pelo modelo é a relação direta entre nível de cobertura e número de representantes necessários. 


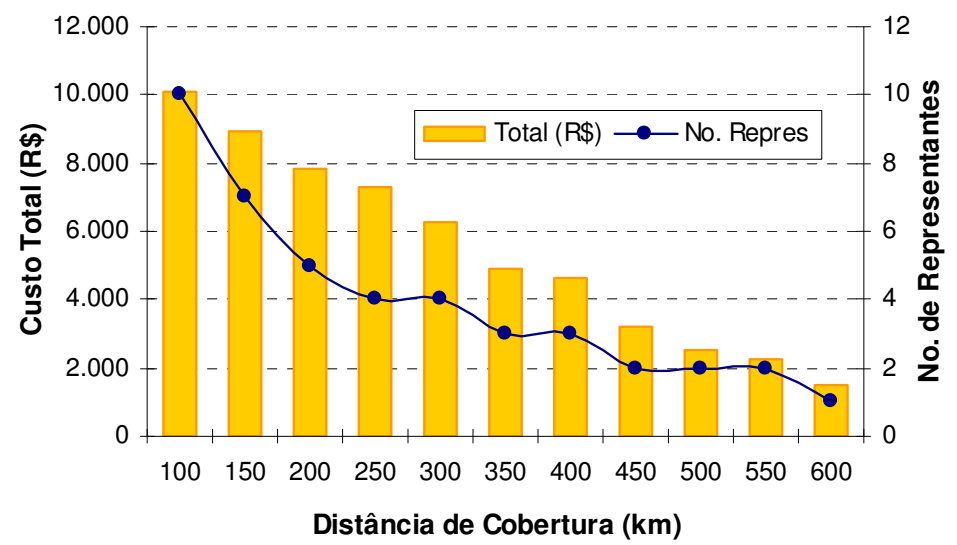

Figura 5.2 - Gráfico de relação entre cobertura, custo e representantes no cenário 1

d) Um aspecto que merece atenção é o fato de que o custo de transferência prevalece sobre o de distribuição no intervalo de 100 a 450 km da distância de cobertura. Isso quer dizer que do ponto de vista de custos, essa etapa do transporte está prevalecendo sobre a distribuição para a grande maioria dos cenários estudados.

e) Ainda em relação ao tópico anterior, uma distorção do modelo ocorre na última rodada quando a opção de configuração com uma só central na origem acaba por ser, dentre todas as outras, a melhor em termos de custo total. Do ponto de vista prático, essas soluções com baixo nível de serviço (grande distância de cobertura) não se mostram viáveis. Mas no estudo estão sendo consideradas para justamente permitir avaliar a eficácia do modelo.

\section{ii) Inclusão das restrições de mínimo de entregas e máximo de peso}

O cenário de restrições operacionais tem como objetivo traduzir realmente as dificuldades que podem ser encontradas na viabilidade de alguma solução como àquelas obtidas no tópico anterior. 
A primeira restrição visa a garantir que o recurso de distribuição (principalmente relacionado à frota) presente em cada representante seja levado em consideração quando da alocação de carga a esse representante. Isso porque o nível de serviço (traduzido em distância de cobertura), para que seja cumprido, prevê entregas imediatas assim que a carga chegue ao representante. Uma possível falta de veículo para entrega poderia comprometer a operação. Essa restrição é traduzida em capacidade máxima de atendimento (em $\mathrm{kg}$ ) de cada local candidato.

Por outro lado, é conhecido que toda atividade econômica exige um mínimo de volume para que se torne viável. O segundo grupo de restrições, de forma simples, incorpora justamente essa idéia ao modelo, ao garantir que no mínimo uma quantidade de entregas será alocada ao mesmo representante de forma a viabilizar a sua utilização.

Assim, para as rodadas seguintes do modelo, os dados abaixo estão sendo considerados:

Tabela 5.7 - Restrições operacionais dos nós do problema preliminar

\begin{tabular}{cccccccc}
\hline Nó & $\mathbf{0}$ & $\mathbf{1}$ & $\mathbf{2}$ & $\mathbf{3}$ & $\mathbf{4}$ & $\mathbf{5}$ & $\mathbf{6}$ \\
\hline Mínimo de entregas & 7 & 2 & 2 & 2 & 2 & 2 & 2 \\
Máximo de peso $(\mathrm{kg})$ & 12.000 & 1.500 & 1.500 & 1.500 & 1.500 & 1.500 & 1.500 \\
\hline & & & & & & & \\
\hline Nó & $\mathbf{7}$ & $\mathbf{8}$ & $\mathbf{9}$ & $\mathbf{1 0}$ & $\mathbf{1 1}$ & $\mathbf{1 2}$ & $\mathbf{1 3}$ \\
\hline Mínimo de entregas & 2 & 2 & 2 & 2 & 2 & 2 & 2 \\
Máximo de peso (kg) & 1.500 & 1.500 & 1.500 & 1.500 & 1.500 & 1.500 & 1.500 \\
\hline
\end{tabular}

Os resultados são mostrados na tabela 5.8, a seguir. 
Tabela 5.8 - Resultados da aplicação do modelo para o cenário 2

\begin{tabular}{lcccccl}
\hline & $\begin{array}{c}\text { DC } \\
(\mathbf{k m})\end{array}$ & \multicolumn{1}{c}{$\begin{array}{c}\text { Transf. } \\
(\mathbf{R} \$)\end{array}$} & \multicolumn{1}{c}{$\begin{array}{c}\text { Distrib. } \\
(\mathbf{R} \$ \mathbf{)}\end{array}$} & Total $(\mathbf{R} \$ \mathbf{)}$ & $\begin{array}{c}\text { No. } \\
\text { Repres }\end{array}$ & \multicolumn{1}{c}{ Locais } \\
\hline 1 & 100 & - & - & - & - & Não existe solução viável \\
2 & 150 & - & - & - & - & Não existe solução viável \\
3 & 200 & $6.755,90$ & $1.071,50$ & $7.827,40$ & 5 & $0-5-10-11-13$ \\
4 & 250 & $6.472,40$ & $1.167,70$ & $7.640,10$ & 5 & $0-7-10-11-13$ \\
5 & 300 & $6.181,40$ & $1.202,55$ & $7.383,95$ & 6 & $0-1-7-10-11-13$ \\
6 & 350 & $3.705,50$ & $1.310,60$ & $5.016,10$ & 3 & $0-10-13$ \\
7 & 400 & $3.309,50$ & $1.301,00$ & $4.610,50$ & 3 & $0-10-13$ \\
8 & 450 & $1.731,25$ & $1.460,15$ & $3.191,40$ & 2 & $0-11$ \\
9 & 500 & 981,75 & $1.546,60$ & $2.528,35$ & 2 & $0-10$ \\
10 & 550 & 693,00 & $1.529,45$ & $2.222,45$ & 2 & $0-10$ \\
11 & 600 & 0,00 & $1.524,50$ & $1.524,50$ & 1 & 0 \\
\hline
\end{tabular}

A combinação das restrições de cobertura e operacionais produz uma faixa inicial de inviabilidade para valores baixos de distância de cobertura. Esse fato é mais fácil de ser entendido se olharmos os resultados anteriores e percebermos que para esses valores de cobertura, são necessários de 7 a 10 representantes, o que violaria a restrição de mínimo de entregas, já que para a maioria deles apenas uma entrega seria destinada.

O resultado para as distâncias de cobertura de $200 \mathrm{~km}$ e de 400 a $600 \mathrm{~km}$ é o mesmo obtido nas rodadas anteriores, nas quais não eram levadas em consideração as restrições operacionais. O que se pode concluir é que nesses casos essas restrições nada influenciaram nas soluções indicadas pelo modelo.

Das 11 rodadas executadas nesse mesmo cenário, apenas com a variação da distância de cobertura, percebemos que além da inviabilidade ocasionada pela combinação das restrições nas duas primeiras rodadas, apenas em outros três casos o conjunto de restrições operacionais ocasionou mudança na solução (rodadas 4, 5 e 6, respectivamente 250, 300 e 350 km de distância de cobertura). 
Nos três casos acima, como era esperado, as soluções obtidas são piores em relação ao custo total quando comparadas com as mesmas soluções do cenário sem restrição. Na prática, realmente restrições desse tipo na maioria das vezes ocasionam aumento de despesas.

Para valores da distância de cobertura de 250 e 300 km, o número de representantes é maior que o encontrado anteriormente. Justamente para esses dois casos a variação de custos é maior entre as soluções dos dois cenários.

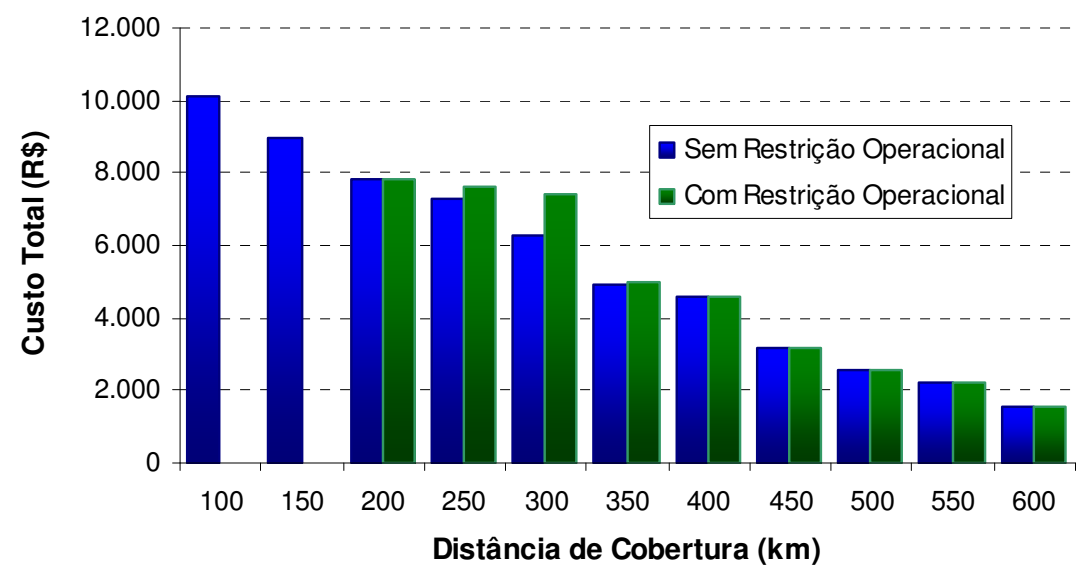

Figura 5.3 - Gráfico de relação entre cobertura e custos dos cenários 1 e 2

Comparando as duas soluções de $300 \mathrm{~km}$ de distância de cobertura, fica mais clara a forma como as restrições operacionais determinam a configuração da rede. O resultado imediato é o aumento no número de representantes necessários para atender às restrições (de 4 para 6) e o aumento no custo total de distribuição em mais de $17 \%$.

\subsubsection{Estudo de caso - utilização do Premium Solver Platform}

O estudo preliminar descrito em detalhes no tópico anterior, serviu para fundamentar a utilização do modelo de programação linear. Porém, como já foi dito, a ferramenta que estava 
sendo utilizada para resolver o modelo - no caso o Solver padrão do Excel - possui a restrição de manipulação de até no máximo 200 variáveis de decisão.

Diante disso, em seu lugar passou-se a utilizar o Premium Solver Platform for Excel, um outro suplemento comercializado pelo Frontline System, que permite trabalhar, em programação linear, com problemas de até 8.000 variáveis de decisão, sendo até 2.000 delas variáveis inteiras, como aquelas do modelo em questão.

A seguir descrevemos cada passo da metodologia proposta aplicada ao problema real, sem redução do número de nós.

\section{Passo 1: Pontos da rede e nível de serviço}

A rede selecionada para o estudo é composta por 98 cidades do estado de São Paulo, incluindo a capital São Paulo, que continua sendo a origem das cargas. A tabela 5.9 apresenta os dados relacionados a cada uma das cidades que formam a rede de distribuição, incluindo a demanda em peso e número de entregas.

Tabela 5.9 - Dados da rede do problema real (continua)

\begin{tabular}{|c|c|c|c|c|c|}
\hline \multirow[b]{2}{*}{ Nó } & \multirow[b]{2}{*}{ Nome da Cidade } & \multirow[b]{2}{*}{ Latitude } & \multirow[b]{2}{*}{ Longitude } & \multicolumn{2}{|c|}{ Demanda } \\
\hline & & & & Peso $(\mathrm{kg})$ & Entregas \\
\hline $\mathbf{0}$ & SAO PAULO & $-46,64$ & $-23,54$ & 5550 & 111 \\
\hline 1 & CAMPINAS & $-47,06$ & $-22,90$ & 600 & 12 \\
\hline 2 & BARUERI & $-46,87$ & $-23,51$ & 100 & 2 \\
\hline 3 & RIBEIRAO PRETO & $-47,81$ & $-21,17$ & 450 & 9 \\
\hline 4 & SAO JOSE DOS CAMPOS & $-45,89$ & $-23,17$ & 300 & 6 \\
\hline 5 & SANTOS & $-46,33$ & $-23,96$ & 250 & 5 \\
\hline 6 & OSASCO & $-46,79$ & $-23,53$ & 100 & 2 \\
\hline 7 & GUARULHOS & $-46,53$ & $-23,46$ & 300 & 6 \\
\hline 8 & TAUBATE & $-45,55$ & $-23,02$ & 50 & 1 \\
\hline 9 & JUNDIAI & $-46,88$ & $-23,19$ & 250 & 5 \\
\hline 10 & SANTO ANDRE & $-46,54$ & $-23,66$ & 200 & 4 \\
\hline 11 & SOROCABA & $-47,45$ & $-23,50$ & 150 & 3 \\
\hline
\end{tabular}


Tabela 5.9 - Dados da rede do problema real (continuação)

\begin{tabular}{|c|c|c|c|c|c|}
\hline \multirow[b]{2}{*}{ Nó } & \multirow[b]{2}{*}{ Nome da Cidade } & \multirow[b]{2}{*}{ Latitude } & \multirow[b]{2}{*}{ Longitude } & \multicolumn{2}{|c|}{ Demanda } \\
\hline & & & & Peso (kg) & Entregas \\
\hline 12 & BAURU & $-49,06$ & $-22,31$ & 100 & 2 \\
\hline 13 & SAO JOSE DO RIO PRETO & $-49,37$ & $-20,82$ & 150 & 3 \\
\hline 14 & AMERICANA & $-47,33$ & $-22,74$ & 50 & 1 \\
\hline 15 & SAO BERNARDO DO CAMPO & $-46,56$ & $-23,69$ & 300 & 6 \\
\hline 16 & LIMEIRA & $-47,40$ & $-22,56$ & 100 & 2 \\
\hline 17 & TABOAO DA SERRA & $-46,79$ & $-23,62$ & 50 & 1 \\
\hline 18 & PRESIDENTE PRUDENTE & $-51,39$ & $-22,12$ & 100 & 2 \\
\hline 19 & MARILIA & $-49,94$ & $-22,21$ & 50 & 1 \\
\hline 20 & ARACATUBA & $-50,43$ & $-21,21$ & 50 & 1 \\
\hline 21 & PIRACICABA & $-47,64$ & $-22,72$ & 100 & 2 \\
\hline 22 & DIADEMA & $-46,62$ & $-23,69$ & 100 & 2 \\
\hline 23 & SAO CARLOS & $-47,89$ & $-22,02$ & 100 & 2 \\
\hline 24 & MOGI DAS CRUZES & $-46,19$ & $-23,52$ & 50 & 1 \\
\hline 25 & ATIBAIA & $-46,55$ & $-23,12$ & 50 & 1 \\
\hline 26 & MOGI-MIRIM & $-46,95$ & $-22,43$ & 50 & 1 \\
\hline 27 & ITAPETININGA & $-48,05$ & $-23,59$ & 50 & 1 \\
\hline 28 & MOGI-GUACU & $-46,94$ & $-22,37$ & 100 & 2 \\
\hline 29 & BARRETOS & $-48,57$ & $-20,55$ & 50 & 1 \\
\hline 30 & INDAIATUBA & $-47,22$ & $-23,09$ & 50 & 1 \\
\hline 31 & GUARUJA & $-46,25$ & $-23,99$ & 100 & 2 \\
\hline 32 & SUZANO & $-46,31$ & $-23,54$ & 50 & 1 \\
\hline 33 & VOTORANTIM & $-47,44$ & $-23,54$ & 50 & 1 \\
\hline 34 & SAO VICENTE & $-46,39$ & $-23,96$ & 50 & 1 \\
\hline 35 & ARARAQUARA & $-48,17$ & $-21,79$ & 50 & 1 \\
\hline 36 & CAMPOS DO JORDAO & $-45,59$ & $-22,74$ & 50 & 1 \\
\hline 37 & BEBEDOURO & $-48,47$ & $-20,94$ & 50 & 1 \\
\hline 38 & HORTOLANDIA & $-47,22$ & $-22,86$ & 50 & 1 \\
\hline 39 & SAO CAETANO DO SUL & $-46,55$ & $-23,62$ & 100 & 2 \\
\hline 40 & BRAGANCA PAULISTA & $-46,54$ & $-22,95$ & 50 & 1 \\
\hline 41 & FRANCA & $-47,40$ & $-20,54$ & 100 & 2 \\
\hline 42 & ASSIS & $-50,41$ & $-22,66$ & 50 & 1 \\
\hline 43 & SUMARE & $-47,27$ & $-22,82$ & 100 & 2 \\
\hline 44 & CUBATAO & $-46,42$ & $-23,89$ & 150 & 3 \\
\hline 45 & GUARATINGUETA & $-45,19$ & $-22,81$ & 100 & 2 \\
\hline 46 & BOTUCATU & $-48,44$ & $-22,88$ & 100 & 2 \\
\hline 47 & JACAREI & $-45,96$ & $-23,30$ & 50 & 1 \\
\hline 48 & MIRASSOL & $-49,52$ & $-20,82$ & 50 & 1 \\
\hline 49 & ITU & $-47,29$ & $-23,26$ & 50 & 1 \\
\hline 50 & VALINHOS & $-46,99$ & $-22,97$ & 50 & 1 \\
\hline 51 & SERTAOZINHO & $-47,99$ & $-21,14$ & 50 & 1 \\
\hline 52 & SAO JOAO DA BOA VISTA & $-46,79$ & $-21,97$ & 50 & 1 \\
\hline 53 & RIO CLARO & $-47,56$ & $-22,41$ & 50 & 1 \\
\hline 54 & SAO ROQUE & $-47,13$ & $-23,52$ & 50 & 1 \\
\hline 55 & OLIMPIA & $-48,91$ & $-20,74$ & 50 & 1 \\
\hline 56 & JAU & $-48,55$ & $-22,29$ & 50 & 1 \\
\hline 57 & LORENA & $-45,12$ & $-22,73$ & 50 & 1 \\
\hline 58 & PINDAMONHANGABA & $-45,46$ & $-22,92$ & 50 & 1 \\
\hline 59 & MAUA & $-46,46$ & $-23,67$ & 100 & 2 \\
\hline 60 & CATANDUVA & $-48,97$ & $-21,14$ & 100 & 2 \\
\hline 61 & BIRIGUI & $-50,34$ & $-21,29$ & 50 & 1 \\
\hline 62 & PIRASSUNUNGA & $-47,42$ & $-21,99$ & 50 & 1 \\
\hline 63 & SANTA BARBARA D OESTE & $-47,41$ & $-22,75$ & 50 & 1 \\
\hline 64 & JAGUARIUNA & $-46,98$ & $-22,70$ & 50 & 1 \\
\hline 65 & CACAPAVA & $-45,70$ & $-23,10$ & 50 & 1 \\
\hline
\end{tabular}


Tabela 5.9 - Dados da rede do problema real (conclusão)

\begin{tabular}{|c|c|c|c|c|c|}
\hline \multirow[b]{2}{*}{ Nó } & \multirow[b]{2}{*}{ Nome da Cidade } & \multirow[b]{2}{*}{ Latitude } & \multirow[b]{2}{*}{ Longitude } & \multicolumn{2}{|c|}{ Demanda } \\
\hline & & & & Peso (kg) & Entregas \\
\hline 66 & LINS & $-49,74$ & $-21,67$ & 100 & 2 \\
\hline 67 & CASA BRANCA & $-47,09$ & $-21,77$ & 50 & 1 \\
\hline 68 & SAO JOAQUIM DA BARRA & $-47,85$ & $-20,58$ & 50 & 1 \\
\hline 69 & SALTO & $-47,29$ & $-23,20$ & 50 & 1 \\
\hline 70 & ARARAS & $-47,38$ & $-22,35$ & 50 & 1 \\
\hline 71 & AMPARO & $-46,76$ & $-22,70$ & 50 & 1 \\
\hline 72 & PIRACAIA & $-46,35$ & $-23,05$ & 50 & 1 \\
\hline 73 & TANABI & $-49,64$ & $-20,62$ & 50 & 1 \\
\hline 74 & NOVA ODESSA & $-47,29$ & $-22,77$ & 50 & 1 \\
\hline 75 & TIETE & $-47,71$ & $-23,10$ & 50 & 1 \\
\hline 76 & ITATIBA & $-46,84$ & $-23,00$ & 50 & 1 \\
\hline 77 & JALES & $-50,54$ & $-20,27$ & 50 & 1 \\
\hline 78 & PIRAJU & $-49,38$ & $-23,19$ & 50 & 1 \\
\hline 79 & CRUZEIRO & $-44,96$ & $-22,57$ & 50 & 1 \\
\hline 80 & SAO PEDRO & $-47,91$ & $-22,54$ & 50 & 1 \\
\hline 81 & ORLANDIA & $-47,89$ & $-20,72$ & 50 & 1 \\
\hline 82 & APARECIDA & $-45,22$ & $-22,84$ & 50 & 1 \\
\hline 83 & SAO JOSE DO RIO PARDO & $-46,89$ & $-21,59$ & 50 & 1 \\
\hline 84 & VOTUPORANGA & $-49,97$ & $-20,42$ & 50 & 1 \\
\hline 85 & AVARE & $-48,92$ & $-23,09$ & 50 & 1 \\
\hline 86 & PRAIA GRANDE & $-46,40$ & $-24,00$ & 50 & 1 \\
\hline 87 & FERNANDOPOLIS & $-50,24$ & $-20,28$ & 50 & 1 \\
\hline 88 & JABOTICABAL & $-48,32$ & $-21,25$ & 50 & 1 \\
\hline 89 & GUAIRA & $-48,31$ & $-20,32$ & 50 & 1 \\
\hline 90 & BATATAIS & $-47,58$ & $-20,89$ & 50 & 1 \\
\hline 91 & LEME & $-47,39$ & $-22,18$ & 50 & 1 \\
\hline 92 & MOCOCA & $-47,00$ & $-21,47$ & 50 & 1 \\
\hline 93 & TUPA & $-50,51$ & $-21,93$ & 50 & 1 \\
\hline 94 & MONTE ALTO & $-48,49$ & $-21,26$ & 50 & 1 \\
\hline 95 & RIBEIRAO PIRES & $-46,41$ & $-23,71$ & 50 & 1 \\
\hline 96 & IPERO & $-47,69$ & $-23,35$ & 50 & 1 \\
\hline 97 & PAULINIA & $-47,15$ & $-22,76$ & 50 & 1 \\
\hline
\end{tabular}

\section{Passo 2: Cidades candidatas a representantes}

Em se tratando de um problema real, as cidades que foram consideradas como candidatas às centrais de desconsolidação de carga foram aquelas nas quais o operador logístico já possui representantes locais de distribuição cadastrados e ativos. Essas cidades estão na tabela 5.10 e a representação da rede a ser estudada, com destaque para essas cidades, é apresentada na figura abaixo. 


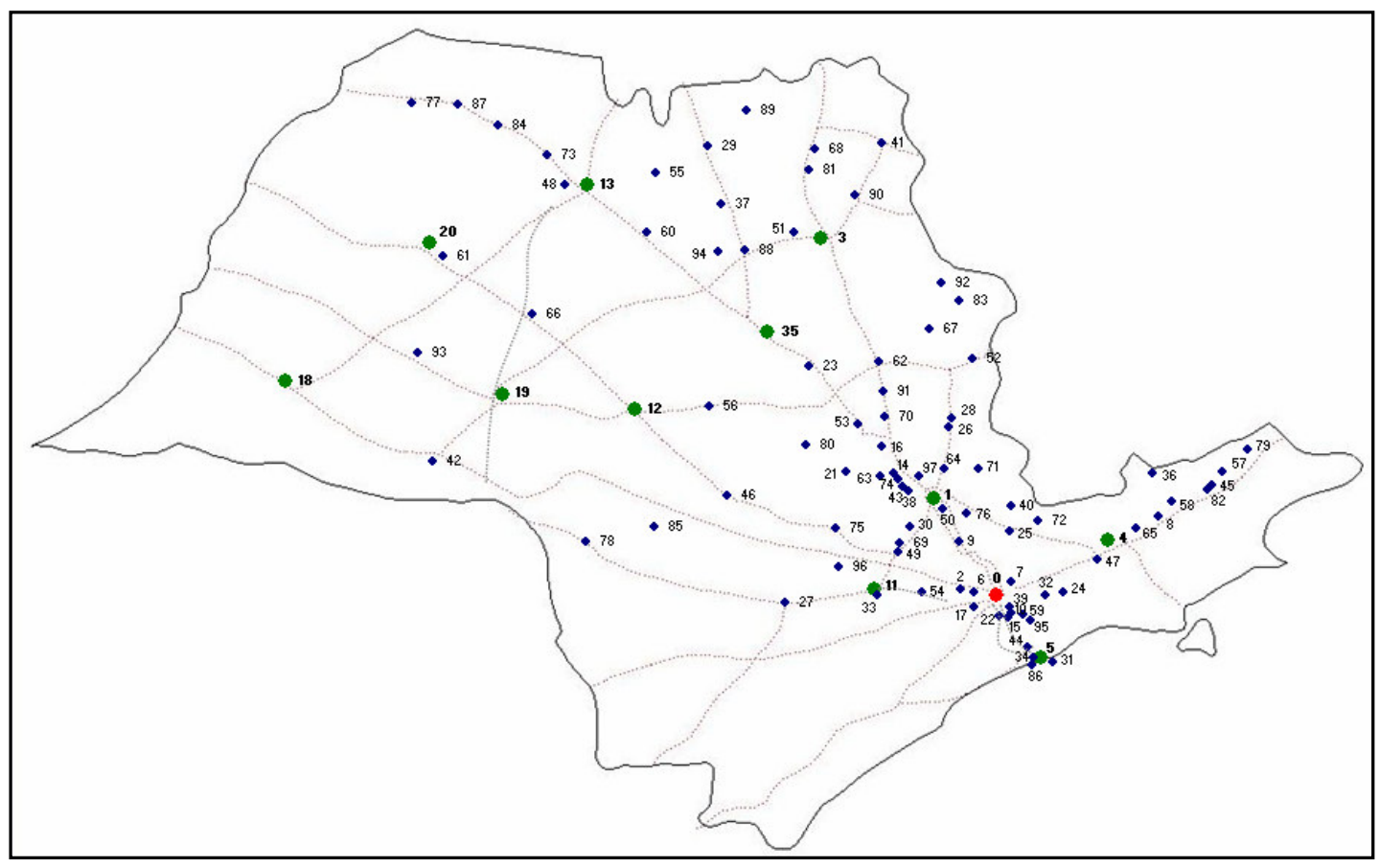

Figura 5.4 - Rede do problema real estudado, com destaque as candidatas às centrais

\section{Passo 3: Custos de transferência e distribuição}

Os custos de transferência entre a origem e cada um das cidades candidata à central, as tarifas por entrega realizada e as taxas de rodagem para o atendimento às cidades a partir de uma central, também constam na tabela 5.10.

Tabela 5.10 - Dados das cidades candidatas a central de desconsolidação (representantes)

\begin{tabular}{|c|c|c|c|c|c|c|}
\hline \multirow[b]{2}{*}{ Nó } & \multirow[b]{2}{*}{ Nome da Cidade } & \multicolumn{3}{|c|}{ Custos de Transporte } & \multicolumn{2}{|c|}{ Restrições Operacionais } \\
\hline & & $\begin{array}{c}\text { Transfer. } \\
(\mathrm{R} \$ / \mathrm{kg})\end{array}$ & $\begin{array}{c}\text { Entrega } \\
(\mathbf{R} \$ / \text { entrega })\end{array}$ & $\begin{array}{c}\begin{array}{c}\text { Rodagem } \\
(\mathrm{R} \$ / \mathbf{k m})\end{array} \\
\end{array}$ & Peso (kg) & Entregas \\
\hline $\mathbf{0}$ & SAO PAULO & 0,00 & 14,75 & 0,50 & 12000 & 5 \\
\hline 1 & CAMPINAS & 1,00 & 13,50 & 0,47 & 4000 & 5 \\
\hline 3 & RIBEIRAO PRETO & 1,30 & 16,00 & 0,50 & 800 & 5 \\
\hline 4 & SAO JOSE DOS CAMPOS & 1,00 & 14,75 & 0,50 & 400 & 5 \\
\hline 5 & SANTOS & 1,00 & 14,75 & 0,50 & 400 & 5 \\
\hline 11 & SOROCABA & 1,00 & 14,75 & 0,50 & 400 & 5 \\
\hline 12 & BAURU & 1,30 & 13,50 & 0,43 & 400 & 5 \\
\hline 13 & SAO JOSE DO RIO PRETO & 1,30 & 17,25 & 0,57 & 400 & 5 \\
\hline 18 & PRESIDENTE PRUDENTE & 1,30 & 13,00 & 0,40 & 400 & 5 \\
\hline 19 & MARILIA & 1,30 & 13,50 & 0,43 & 400 & 5 \\
\hline 20 & ARACATUBA & 1,30 & 13,00 & 0,40 & 400 & 5 \\
\hline 35 & ARARAQUARA & 1,30 & 16,00 & 0,50 & 400 & 5 \\
\hline
\end{tabular}




\section{Passo 4: Matriz de distância}

Da mesma forma como descrito no estudo preliminar, para determinação da matriz real de distância entre cada par (cidade e candidata a central) da rede em estudo, utilizou-se a correção, através de um fator de circuito, das distâncias teóricas obtidas a partir da aplicação da fórmula (4.1) apresentada no capítulo anterior.

Considerando que a rede estudada no problema real pertence à mesma região daquela analisada no estudo preliminar, convencionou-se utilizar o mesmo fator de correção encontrado naquele estudo. Portanto, as distâncias teóricas obtidas foram multiplicadas por 1,17 para determinação da matriz de distâncias reais abaixo, utilizada no modelo.

Tabela 5.11 - Matriz de distâncias reais para o problema real (continua)

\begin{tabular}{|c|c|c|c|c|c|c|c|c|c|c|c|c|}
\hline NÓ & $\mathbf{0}$ & $\mathbf{1}$ & $\mathbf{3}$ & $\mathbf{4}$ & $\mathbf{5}$ & $\mathbf{1 1}$ & $\mathbf{1 2}$ & $\mathbf{1 3}$ & $\mathbf{1 8}$ & $\mathbf{1 9}$ & $\mathbf{2 0}$ & $\mathbf{3 5}$ \\
\hline $\mathbf{0}$ & 0 & 97 & 339 & 102 & 64 & 98 & 331 & 484 & 599 & 433 & 548 & 294 \\
\hline $\mathbf{1}$ & 97 & 0 & 242 & 145 & 161 & 91 & 253 & 390 & 530 & 358 & 462 & 198 \\
\hline $\mathbf{2}$ & 29 & 82 & 324 & 125 & 87 & 69 & 304 & 462 & 571 & 405 & 522 & 273 \\
\hline $\mathbf{3}$ & 339 & 242 & 0 & 349 & 402 & 305 & 212 & 197 & 450 & 291 & 318 & 91 \\
\hline $\mathbf{4}$ & 102 & 145 & 349 & 0 & 115 & 192 & 397 & 521 & 675 & 503 & 604 & 329 \\
\hline $\mathbf{5}$ & 64 & 161 & 402 & 115 & 0 & 146 & 390 & 549 & 651 & 488 & 608 & 358 \\
\hline $\mathbf{6}$ & 19 & 87 & 330 & 117 & 78 & 80 & 315 & 470 & 580 & 415 & 531 & 281 \\
\hline $\mathbf{7}$ & 16 & 96 & 335 & 85 & 69 & 110 & 337 & 484 & 607 & 440 & 552 & 293 \\
\hline $\mathbf{8}$ & 146 & 181 & 363 & 44 & 153 & 235 & 431 & 543 & 710 & 537 & 633 & 353 \\
\hline $\mathbf{9}$ & 55 & 42 & 284 & 119 & 119 & 80 & 284 & 431 & 558 & 388 & 498 & 239 \\
\hline $\mathbf{1 0}$ & 19 & 116 & 358 & 99 & 46 & 111 & 349 & 503 & 614 & 449 & 566 & 312 \\
\hline $\mathbf{1 1}$ & 98 & 91 & 305 & 192 & 146 & 0 & 247 & 419 & 504 & 342 & 466 & 239 \\
\hline $\mathbf{1 2}$ & 331 & 253 & 212 & 397 & 390 & 247 & 0 & 198 & 282 & 108 & 219 & 126 \\
\hline $\mathbf{1 3}$ & 484 & 390 & 197 & 521 & 549 & 419 & 198 & 0 & 297 & 193 & 137 & 193 \\
\hline $\mathbf{1 4}$ & 133 & 39 & 212 & 181 & 198 & 101 & 215 & 351 & 495 & 322 & 424 & 160 \\
\hline $\mathbf{1 5}$ & 21 & 118 & 360 & 104 & 44 & 110 & 349 & 504 & 613 & 448 & 566 & 314 \\
\hline $\mathbf{1 6}$ & 158 & 61 & 187 & 199 & 222 & 123 & 201 & 329 & 483 & 309 & 406 & 137 \\
\hline $\mathbf{1 7}$ & 21 & 99 & 342 & 123 & 69 & 81 & 321 & 480 & 585 & 420 & 539 & 290 \\
\hline $\mathbf{1 8}$ & 599 & 530 & 450 & 675 & 651 & 504 & 282 & 297 & 0 & 174 & 166 & 391 \\
\hline $\mathbf{1 9}$ & 433 & 358 & 291 & 503 & 488 & 342 & 108 & 193 & 174 & 0 & 143 & 220 \\
\hline $\mathbf{2 0}$ & 548 & 462 & 318 & 604 & 608 & 466 & 219 & 137 & 166 & 143 & 0 & 283 \\
\hline $\mathbf{2 1}$ & 161 & 74 & 202 & 219 & 225 & 104 & 178 & 324 & 457 & 284 & 390 & 137 \\
\hline $\mathbf{2 2}$ & 19 & 115 & 357 & 110 & 49 & 102 & 343 & 500 & 606 & 442 & 560 & 309 \\
\hline $\mathbf{2 3}$ & 249 & 152 & 110 & 284 & 314 & 200 & 146 & 239 & 422 & 249 & 325 & 46 \\
\hline $\mathbf{2 4}$ & 54 & 131 & 363 & 57 & 60 & 151 & 378 & 521 & 649 & 481 & 592 & 328 \\
\hline $\mathbf{2 5}$ & 56 & 67 & 295 & 80 & 112 & 119 & 318 & 453 & 596 & 424 & 529 & 261 \\
& & & & & & & & & & & \\
\hline
\end{tabular}


Tabela 5.11 - Matriz de distâncias reais para o problema real (continuação)

\begin{tabular}{|c|c|c|c|c|c|c|c|c|c|c|c|c|}
\hline NÓ & 0 & 1 & 3 & 4 & 5 & 11 & 12 & 13 & 18 & 19 & 20 & 35 \\
\hline 26 & 150 & 63 & 193 & 161 & 213 & 152 & 254 & 359 & 535 & 360 & 448 & 168 \\
\hline 27 & 170 & 149 & 316 & 264 & 211 & 73 & 206 & 394 & 443 & 289 & 421 & 234 \\
\hline 28 & 157 & 71 & 187 & 164 & 219 & 159 & 255 & 357 & 537 & 362 & 448 & 167 \\
\hline 29 & 453 & 356 & 123 & 470 & 518 & 406 & 236 & 104 & 398 & 273 & 241 & 167 \\
\hline 30 & 91 & 30 & 259 & 160 & 154 & 61 & 243 & 393 & 516 & 346 & 457 & 204 \\
\hline 31 & 74 & 171 & 411 & 115 & 11 & 157 & 400 & 558 & 661 & 498 & 618 & 367 \\
\hline 32 & 39 & 122 & 357 & 69 & 55 & 137 & 366 & 511 & 636 & 469 & 581 & 319 \\
\hline 33 & 96 & 95 & 311 & 191 & 142 & 6 & 252 & 425 & 509 & 346 & 472 & 245 \\
\hline 34 & 62 & 159 & 400 & 118 & 7 & 140 & 385 & 544 & 645 & 482 & 603 & 353 \\
\hline 35 & 294 & 198 & 91 & 329 & 358 & 239 & 126 & 193 & 391 & 220 & 283 & 0 \\
\hline 36 & 164 & 178 & 336 & 67 & 183 & 245 & 420 & 521 & 702 & 528 & 617 & 335 \\
\hline 37 & 404 & 307 & 87 & 426 & 469 & 355 & 191 & 111 & 385 & 242 & 240 & 116 \\
\hline 38 & 113 & 19 & 230 & 165 & 178 & 89 & 232 & 371 & 510 & 338 & 442 & 180 \\
\hline 39 & 14 & 111 & 352 & 98 & 50 & 109 & 345 & 498 & 612 & 446 & 562 & 308 \\
\hline 40 & 77 & 62 & 277 & 83 & 133 & 131 & 314 & 441 & 592 & 420 & 521 & 248 \\
\hline 41 & 401 & 311 & 96 & 388 & 463 & 386 & 305 & 243 & 525 & 377 & 378 & 188 \\
\hline 42 & 466 & 404 & 369 & 546 & 515 & 370 & 168 & 270 & 137 & 81 & 188 & 291 \\
\hline 43 & 121 & 27 & 223 & 172 & 185 & 91 & 225 & 364 & 503 & 331 & 435 & 173 \\
\hline 44 & 51 & 149 & 391 & 113 & 14 & 133 & 377 & 535 & 638 & 475 & 594 & 344 \\
\hline 45 & 198 & 225 & 381 & 96 & 202 & 285 & 469 & 569 & 750 & 577 & 666 & 383 \\
\hline 46 & 232 & 166 & 235 & 308 & 288 & 143 & 105 & 291 & 367 & 200 & 324 & 146 \\
\hline 47 & 87 & 142 & 356 & 19 & 96 & 180 & 393 & 523 & 669 & 498 & 603 & 331 \\
\hline 48 & 496 & 402 & 213 & 535 & 560 & 428 & 202 & 18 & 283 & 188 & 122 & 207 \\
\hline 49 & 87 & 54 & 278 & 168 & 146 & 37 & 245 & 405 & 514 & 346 & 462 & 219 \\
\hline 50 & 85 & 12 & 254 & 135 & 151 & 89 & 262 & 401 & 539 & 367 & 474 & 209 \\
\hline 51 & 353 & 256 & 22 & 366 & 418 & 315 & 200 & 173 & 431 & 274 & 296 & 88 \\
\hline 52 & 206 & 125 & 160 & 191 & 264 & 215 & 276 & 346 & 555 & 381 & 450 & 168 \\
\hline 53 & 185 & 88 & 164 & 223 & 249 & 143 & 181 & 302 & 462 & 288 & 380 & 109 \\
\hline 54 & 60 & 82 & 316 & 156 & 111 & 39 & 280 & 443 & 542 & 378 & 498 & 257 \\
\hline 55 & 456 & 360 & 145 & 483 & 521 & 400 & 206 & 57 & 350 & 229 & 194 & 164 \\
\hline 56 & 282 & 197 & 171 & 340 & 343 & 205 & 61 & 215 & 342 & 167 & 267 & 80 \\
\hline 57 & 209 & 233 & 381 & 109 & 216 & 297 & 476 & 571 & 757 & 584 & 670 & 387 \\
\hline 58 & 163 & 192 & 363 & 61 & 171 & 250 & 440 & 546 & 720 & 546 & 639 & 358 \\
\hline 59 & 27 & 123 & 363 & 94 & 41 & 121 & 358 & 510 & 624 & 459 & 574 & 319 \\
\hline 60 & 421 & 325 & 142 & 456 & 484 & 358 & 153 & 64 & 319 & 183 & 177 & 129 \\
\hline 61 & 534 & 448 & 308 & 590 & 593 & 450 & 204 & 132 & 167 & 129 & 15 & 270 \\
\hline 62 & 222 & 126 & 116 & 240 & 287 & 197 & 201 & 282 & 479 & 305 & 378 & 95 \\
\hline 63 & 138 & 47 & 211 & 191 & 202 & 97 & 206 & 346 & 486 & 312 & 417 & 156 \\
\hline 64 & 117 & 27 & 222 & 145 & 180 & 118 & 254 & 379 & 535 & 362 & 459 & 186 \\
\hline 65 & 125 & 164 & 357 & 23 & 135 & 215 & 415 & 534 & 694 & 522 & 620 & 343 \\
\hline 66 & 445 & 360 & 243 & 503 & 505 & 363 & 117 & 119 & 207 & 74 & 103 & 190 \\
\hline 67 & 236 & 147 & 117 & 233 & 298 & 229 & 248 & 304 & 521 & 349 & 411 & 131 \\
\hline 68 & 413 & 318 & 78 & 413 & 476 & 384 & 268 & 188 & 473 & 330 & 323 & 163 \\
\hline 69 & 89 & 48 & 271 & 167 & 150 & 44 & 242 & 399 & 512 & 344 & 459 & 212 \\
\hline 70 & 179 & 82 & 161 & 209 & 243 & 150 & 201 & 312 & 483 & 309 & 397 & 121 \\
\hline 71 & 110 & 44 & 235 & 122 & 171 & 133 & 281 & 400 & 562 & 388 & 483 & 207 \\
\hline 72 & 73 & 87 & 301 & 59 & 118 & 144 & 338 & 466 & 617 & 445 & 546 & 274 \\
\hline 73 & 525 & 431 & 234 & 562 & 589 & 459 & 230 & 41 & 288 & 209 & 122 & 234 \\
\hline 74 & 128 & 33 & 218 & 177 & 192 & 97 & 221 & 358 & 500 & 326 & 429 & 166 \\
\hline 75 & 140 & 82 & 252 & 219 & 198 & 60 & 192 & 358 & 460 & 293 & 410 & 179 \\
\hline 76 & 74 & 29 & 266 & 116 & 138 & 98 & 282 & 418 & 558 & 387 & 491 & 226 \\
\hline 77 & 635 & 543 & 353 & 677 & 698 & 562 & 321 & 159 & 262 & 263 & 123 & 349 \\
\hline 78 & 331 & 281 & 324 & 419 & 377 & 234 & 122 & 309 & 277 & 144 & 287 & 233 \\
\hline
\end{tabular}


Tabela 5.11 - Matriz de distâncias reais para o problema real (conclusão)

\begin{tabular}{|c|c|c|c|c|c|c|c|c|c|c|c|c|}
\hline NÓ & $\mathbf{0}$ & $\mathbf{1}$ & $\mathbf{3}$ & $\mathbf{4}$ & $\mathbf{5}$ & $\mathbf{1 1}$ & $\mathbf{1 2}$ & $\mathbf{1 3}$ & $\mathbf{1 8}$ & $\mathbf{1 9}$ & $\mathbf{2 0}$ & $\mathbf{3 5}$ \\
\hline $\mathbf{7 9}$ & 238 & 255 & 390 & 136 & 243 & 323 & 494 & 580 & 776 & 601 & 683 & 400 \\
\hline $\mathbf{8 0}$ & 200 & 112 & 179 & 256 & 263 & 136 & 142 & 285 & 422 & 248 & 350 & 103 \\
\hline $\mathbf{8 1}$ & 397 & 302 & 60 & 400 & 461 & 366 & 250 & 181 & 462 & 316 & 315 & 144 \\
\hline $\mathbf{8 2}$ & 192 & 220 & 379 & 90 & 197 & 281 & 466 & 566 & 746 & 573 & 662 & 380 \\
\hline $\mathbf{8 3}$ & 256 & 172 & 124 & 239 & 315 & 257 & 278 & 318 & 548 & 378 & 432 & 158 \\
\hline $\mathbf{8 4}$ & 572 & 479 & 281 & 610 & 635 & 503 & 269 & 89 & 280 & 233 & 116 & 282 \\
\hline $\mathbf{8 5}$ & 280 & 225 & 283 & 364 & 329 & 184 & 103 & 301 & 322 & 168 & 305 & 192 \\
\hline $\mathbf{8 6}$ & 67 & 163 & 405 & 124 & 11 & 142 & 386 & 548 & 645 & 483 & 605 & 358 \\
\hline $\mathbf{8 7}$ & 607 & 515 & 318 & 647 & 670 & 537 & 300 & 126 & 276 & 253 & 122 & 318 \\
\hline $\mathbf{8 8}$ & 360 & 263 & 63 & 385 & 425 & 310 & 164 & 140 & 387 & 232 & 255 & 73 \\
\hline $\mathbf{8 9}$ & 466 & 369 & 126 & 473 & 530 & 427 & 275 & 145 & 441 & 316 & 283 & 192 \\
\hline $\mathbf{9 0}$ & 364 & 270 & 46 & 362 & 427 & 340 & 256 & 218 & 488 & 333 & 347 & 137 \\
\hline $\mathbf{9 1}$ & 198 & 102 & 142 & 221 & 263 & 172 & 201 & 300 & 482 & 308 & 388 & 108 \\
\hline $\mathbf{9 2}$ & 274 & 187 & 104 & 260 & 333 & 270 & 271 & 300 & 536 & 367 & 417 & 147 \\
\hline $\mathbf{9 3}$ & 510 & 434 & 342 & 578 & 565 & 419 & 181 & 200 & 109 & 77 & 95 & 283 \\
\hline $\mathbf{9 4}$ & 372 & 275 & 84 & 401 & 436 & 317 & 153 & 122 & 367 & 214 & 235 & 80 \\
\hline $\mathbf{9 5}$ & 33 & 130 & 370 & 94 & 34 & 128 & 365 & 518 & 631 & 466 & 583 & 328 \\
\hline $\mathbf{9 6}$ & 128 & 95 & 283 & 216 & 179 & 34 & 213 & 387 & 472 & 309 & 432 & 212 \\
\hline $\mathbf{9 7}$ & 119 & 22 & 221 & 161 & 184 & 103 & 236 & 369 & 516 & 343 & 443 & 176 \\
\hline
\end{tabular}

\section{Passo 5: Aplicação do modelo selecionado}

Nesta etapa, da mesma forma como foi feito no estudo preliminar, dois principais cenários foram analisados: com e sem as restrições de limite mínimo e capacidade máxima de peso nas centrais. Os limites mínimos de entrega e as capacidades máximas de cada central foram apresentados na tabela 5.10. No cenário com as restrições relaxadas, as centrais podem realizar uma única entrega e também atender a toda a demanda de distribuição.

Os resultados da aplicação computacional estão na tabela 5.12, a seguir. 
Tabela 5.12 - Resultados do modelo de programação linear para o problema real

\begin{tabular}{|c|c|c|c|c|c|c|c|}
\hline & Cenário & $\begin{array}{c}\text { DC } \\
(\mathbf{k m})\end{array}$ & $\begin{array}{c}\text { Transf. } \\
\text { (R\$) }\end{array}$ & $\begin{array}{l}\text { Distrib. } \\
\text { (R\$) }\end{array}$ & Total $(\mathbf{R} \$)$ & $\begin{array}{c}\text { No. } \\
\text { Repres }\end{array}$ & $\begin{array}{c}\text { Centrais localizadas } \\
\text { nas cidades }\end{array}$ \\
\hline 1 & sem restrições & 150 & $5.480,00$ & $7.447,36$ & $12.927,36$ & 10 & $\begin{array}{l}0-1-3-4-12-13- \\
18-19-20-35\end{array}$ \\
\hline \multirow{2}{*}{2} & sem restrições & 200 & $4.225,00$ & $8.004,03$ & $12.229,03$ & 9 & $\begin{array}{l}0-3-4-12-13-18 \\
-19-20-35\end{array}$ \\
\hline & com restrições & 200 & $4.040,00$ & $8.430,41$ & $12.470,41$ & 8 & $\begin{array}{l}0-3-4-12-13-19 \\
-20-35\end{array}$ \\
\hline \multirow{2}{*}{3} & sem restrições & 300 & $3.055,00$ & $8.772,75$ & $11.827,75$ & 8 & $\begin{array}{l}0-3-12-13-18- \\
19-20-35\end{array}$ \\
\hline & com restrições & 300 & $2.990,00$ & $8.965,14$ & $11.955,14$ & 7 & $\begin{array}{l}0-3-12-13-19- \\
20-35\end{array}$ \\
\hline \multirow{2}{*}{4} & sem restrições & 400 & $2.405,00$ & $9.263,64$ & $11.668,64$ & 7 & $\begin{array}{l}0-12-13-18-19- \\
20-35\end{array}$ \\
\hline & com restrições & 400 & $2.405,00$ & $9.393,51$ & $11.798,51$ & 6 & $\begin{array}{l}0-12-13-19-20- \\
35\end{array}$ \\
\hline
\end{tabular}

O tempo médio de processamento do Solver para as rodadas e cenários descritos na tabela 5.12 foi de três segundos, em um notebook AMD 2800 1.60GHz, com 384 MB de memória RAM.

Conforme já observado no estudo preliminar, a combinação das restrições de cobertura e operacionais, no caso do problema real também produz uma faixa inicial de inviabilidade para 150 km de distância de cobertura.

Em todos os casos, com exceção da primeira rodada, a inclusão das restrições operacionais ocasionou aumento no valor da função objetivo. Esse já era um resultado esperado, inclusive sendo obtido no estudo de caso preliminar. Da mesma forma, o relaxamento do nível de serviço, representado pelo aumento da distância de cobertura, tem relação indireta com o número de representantes, para ambos os cenários. $\mathrm{O}$ gráfico abaixo ilustra esse comportamento. 


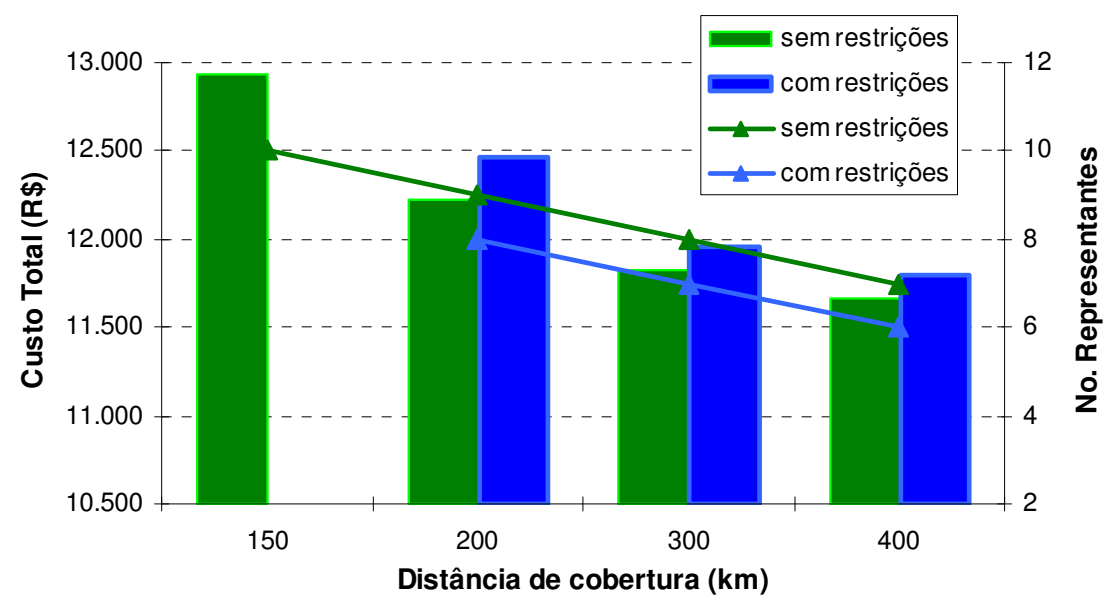

Figura 5.5 - Relação entre cobertura, custos e representantes

A aplicação do modelo ao problema real manteve a relação de equilíbrio entre nível de serviço oferecido (representado pela distância de cobertura) e custos da operação, à medida que com o aumento da distância, ou seja, com o relaxamento do nível de serviço, o custo total de transporte também diminui.

A cidade de São Paulo (nó 0), como origem das cargas, continua aparecendo em todas as soluções, o que também é um resultado esperado, uma vez que a origem é sempre uma boa opção de ponto de partida para a distribuição.

Segundo os dados da tabela 5.12, a diferença (em porcentagem) do valor da função objetivo entre os dois cenários de $300 \mathrm{~km}$ de distância de cobertura, é de apenas 1\%. Isso mostra que a inclusão das restrições não proporciona grande mudança na configuração da rede de distribuição em termos de custo de transporte.

A influência das restrições operacionais na configuração da rede é melhor visualizada a partir dos mapas de alocação, como mostrado a seguir. 


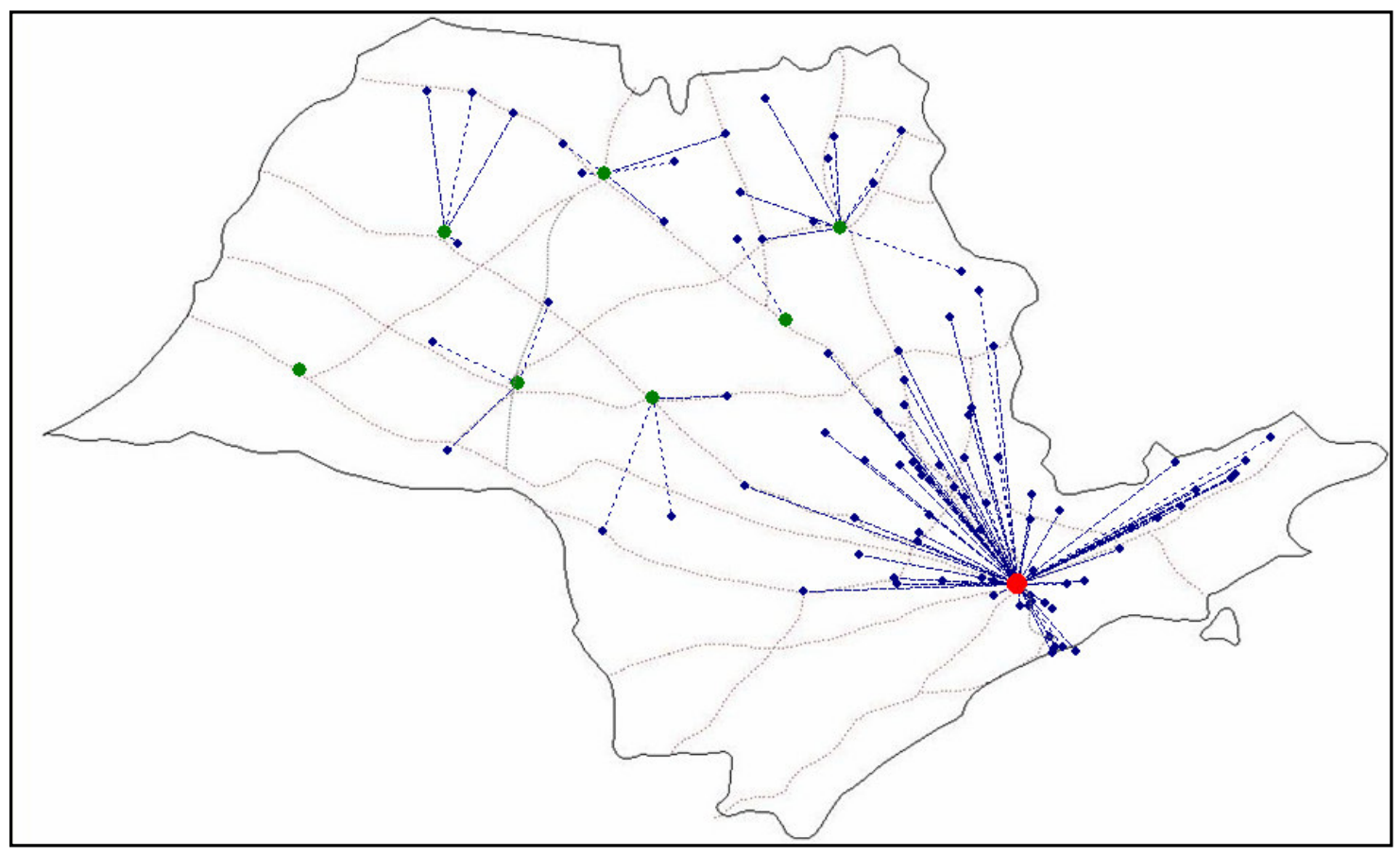

Figura 5.6 - Solução para 300 km de cobertura, sem restrições operacionais

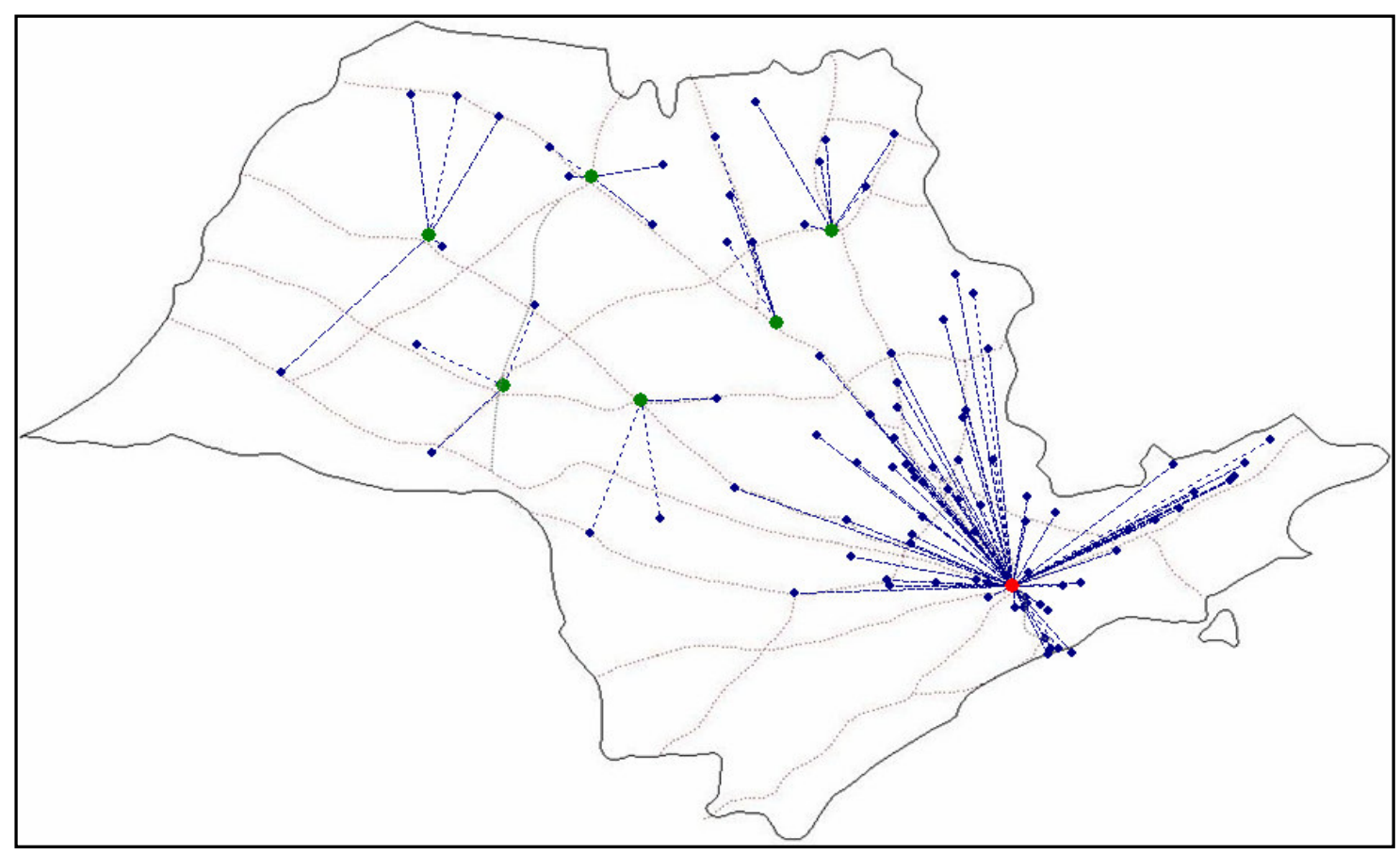

Figura 5.7 - Solução para 300 km de cobertura, com restrições operacionais 
A principal diferença diz respeito à cidade 18 (Presidente Prudente) candidata à central de desconsolidação de carga. No cenário sem restrições, essa cidade é selecionada, porém só atenderia à sua própria demanda. Com isso, quando a restrição de limite mínimo de entregas é inserida, sua abertura deixa de ser viável e a demanda passa a ser atendida pela central em Araçatuba (20).

A outra diferença está na alocação das cidades à central em Araraquara. Novamente, para atender às restrições de limite mínimo de entregas, mais cidades passam a ser atendidas por essa central, em relação à alocação original da solução sem restrições operacionais.

\subsection{Aplicação da metodologia com o procedimento baseado em Busca Tabu}

Seguindo a metodologia adotada, o sexto passo corresponde à aplicação do procedimento desenvolvido com base em Busca Tabu ao problema real objeto do estudo.

Conforme detalhado no tópico 4.3, que trata da estrutura da heurística, o procedimento desenvolvido baseia-se em alguns parâmetros de entrada, a saber: solução inicial, número de soluções vizinhas geradas a cada iteração, probabilidade de mudança de status dos componentes do vetor solução, comprimento da lista tabu e critérios de parada (número máximo de iterações e número máximo de iterações sem melhora no valor da função objetivo).

Em relação à solução inicial, optou-se não utilizar qualquer heurística mais elaborada. A solução para inicialização do procedimento foi adotada com sendo aquela em que todas as cidades candidatas às centrais estão abertas. Isso devido à própria natureza do problema, visto 
que essa solução está próxima da melhor possível, principalmente para valores mais baixos de distância de cobertura.

Quanto aos demais parâmetros, alguns testes foram realizados variando-se um ou mais parâmetros, com o objetivo de obter a melhor combinação entre eles. Para a heurística, essa melhor combinação corresponde à obtenção de boas soluções, mas sem "esforço" computacional excessivo, ou seja, dentro de um tempo de processamento razoável.

Para exemplificar a relação entre esses parâmetros, quando se aumenta o número de vizinhos gerados a cada iteração, ou a probabilidade de mudança de status, ou o comprimento da lista tabu, ou o número máximo de iterações, a qualidade da solução melhora, porém se gasta mais tempo com a execução do procedimento. Portanto, há um trade-off a ser levado em consideração.

Com base nos resultados dessa análise, e também no trabalho de Al-Sultan e Al-Fawzan (1999), foram definidos os seguintes intervalos para os parâmetros do procedimento:

a) Número de vizinhos $=5$ vezes o número de locais candidatos (no caso do problema em estudo, $\mathrm{NV}=60$ )

b) Probabilidade de mudança $\alpha \varepsilon[0,8 ; 0,9]$

c) Comprimento da lista tabu $=10$

d) Iterações sem melhora / número máximo de iterações: [10;20] / 50

Com o objetivo de comparar os resultados com aqueles obtidos com a aplicação do modelo de programação linear, os mesmos cenários (com e sem restrições operacionais) foram 
considerados na aplicação computacional, que tem os resultados apresentados na tabela 5.13 abaixo.

Tabela 5.13 - Resultados do procedimento Busca Tabu para o problema real

\begin{tabular}{|c|c|c|c|c|c|c|c|}
\hline & Cenário & $\begin{array}{c}\text { DC } \\
(\mathbf{k m})\end{array}$ & $\begin{array}{c}\text { Transf. } \\
\text { (R\$) }\end{array}$ & $\begin{array}{c}\text { Distrib. } \\
(\mathbf{R} \$)\end{array}$ & Total (R\$) & $\begin{array}{c}\text { No. } \\
\text { Repres }\end{array}$ & $\begin{array}{c}\text { Centrais localizadas } \\
\text { nas cidades }\end{array}$ \\
\hline 1 & sem restrições & 150 & $5.480,00$ & $7.447,36$ & $12.927,36$ & 10 & $\begin{array}{l}0-1-3-4-12-13- \\
18-19-20-35\end{array}$ \\
\hline \multirow{2}{*}{2} & sem restrições & 200 & $4.225,00$ & $8.004,03$ & $12.229,03$ & 9 & $\begin{array}{l}0-3-4-12-13-18 \\
-19-20-35\end{array}$ \\
\hline & com restrições & 200 & --- & --- & --- & --- & $\begin{array}{l}\text { Não obteve solução } \\
\text { viável }\end{array}$ \\
\hline \multirow{2}{*}{3} & sem restrições & 300 & $3.055,00$ & $8.772,75$ & $11.827,75$ & 8 & $\begin{array}{l}0-3-12-13-18- \\
19-20-35\end{array}$ \\
\hline & com restrições & 300 & $2.990,00$ & $9.037,31$ & $12.027,31$ & 7 & $\begin{array}{l}0-3-12-13-19- \\
20-35\end{array}$ \\
\hline \multirow{2}{*}{4} & sem restrições & 400 & $2.405,00$ & $9.263,64$ & $11.668,64$ & 7 & $\begin{array}{l}0-12-13-18-19- \\
20-35\end{array}$ \\
\hline & com restrições & 400 & $2.405,00$ & $9.421,80$ & $11.826,80$ & 6 & $\begin{array}{l}0-12-13-19-20- \\
35\end{array}$ \\
\hline
\end{tabular}

Os resultados apresentados na tabela acima correspondem a melhor rodada de aplicação da Busca Tabu para os cenários pré-determinados. Seu desempenho, assim como a comparação com as soluções ótimas da programação linear, será analisado no próximo tópico.

A figura 5.8 exemplifica uma das soluções obtidas com a aplicação do procedimento Busca Tabu. Para esse cenário destacado, a metaheurística levou ao mesmo resultado do modelo em programação linear.

\subsection{Comparação entre os resultados da programação linear e da Busca Tabu}

O sétimo passo da metodologia proposta refere-se à comparação dos resultados, sob o ponto de vista dos dois enfoques abordados: programação linear e Busca Tabu. 


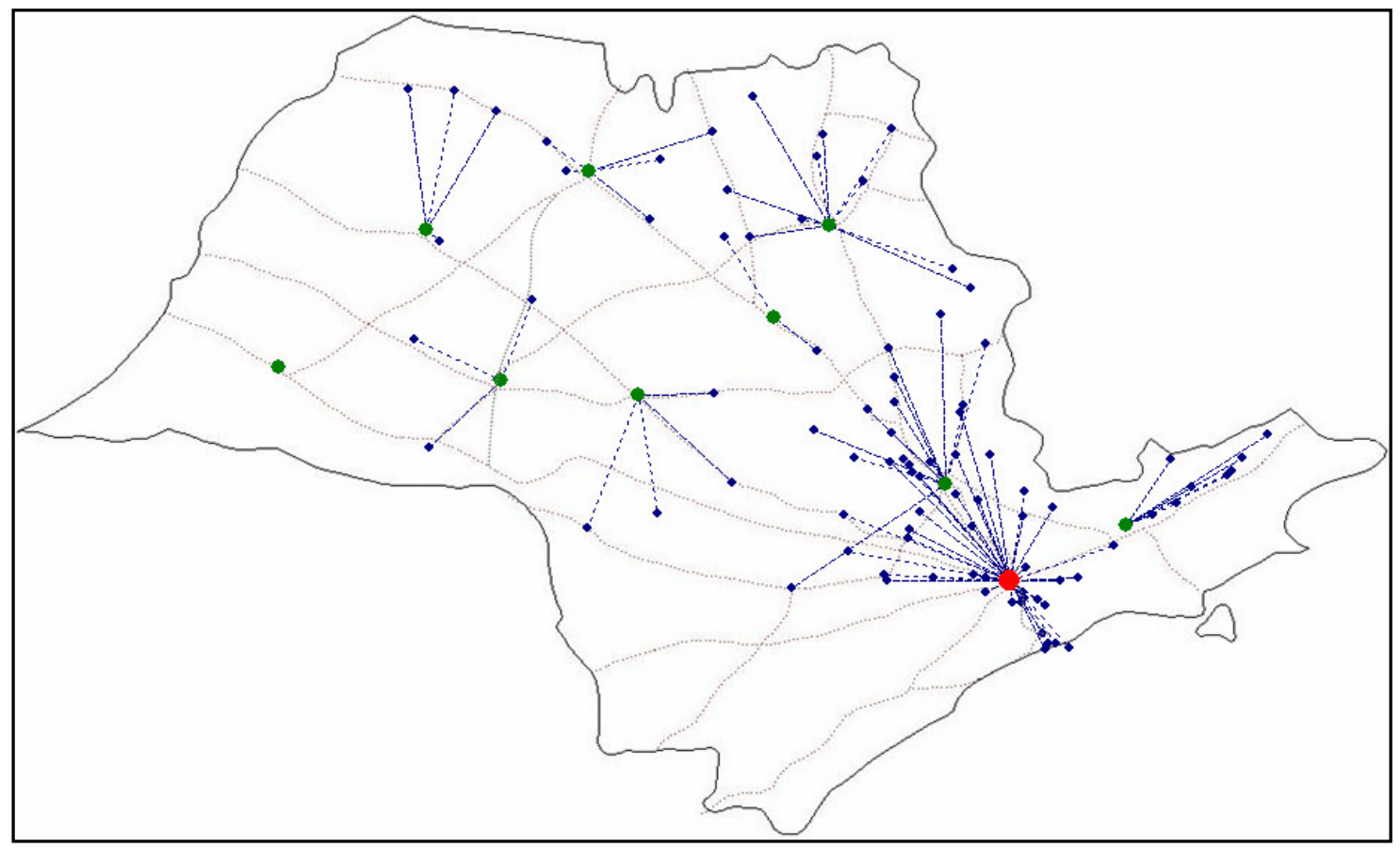

Figura 5.8 - Solução para 150 km de cobertura, sem restrições operacionais

No cenário sem restrições operacionais, o melhor resultado do procedimento Busca Tabu, para cada uma das distâncias de cobertura analisada, é o mesmo obtido com a aplicação do modelo de programação linear. Para esse cenário, somente a primeira fase do procedimento é utilizada, não havendo necessidade de refinamento da solução encontrada, pois não há restrições de capacidade.

Quando essas restrições de limite mínimo de entregas e máximo de peso são incorporadas, se faz necessária à utilização também da fase de refinamento. Nesses casos, as soluções obtidas com o procedimento já apresentam uma diferença em relação às soluções ótimas. Porém, essas diferenças, em termos percentuais, estão muito próximas das melhores soluções, conforme mostrado na tabela 5.14 abaixo. 
Tabela 5.14 - Comparação entre os resultados da programação linear e da Busca Tabu

\begin{tabular}{|c|c|c|c|c|c|}
\hline & Cenário & $\begin{array}{c}\mathrm{DC} \\
(\mathbf{k m})\end{array}$ & $\begin{array}{l}\text { Custo Total (R\$) } \\
\text { Prog. Linear }\end{array}$ & $\begin{array}{c}\text { Custo Total }(\mathbf{R} \$) \\
\text { Busca Tabu }\end{array}$ & $\Delta \%$ \\
\hline \multirow{2}{*}{1} & sem restrições & 150 & $12.927,36$ & $12.927,36$ & $0,00 \%$ \\
\hline & com restrições & 150 & \multicolumn{2}{|c|}{ não existe solução viável } & --- \\
\hline \multirow{2}{*}{2} & sem restrições & 200 & $12.229,03$ & $12.229,03$ & $0,00 \%$ \\
\hline & com restrições & 200 & $12.470,41$ & não obteve solução & --- \\
\hline \multirow{2}{*}{3} & sem restrições & 300 & $11.827,75$ & $11.827,75$ & $0,00 \%$ \\
\hline & com restrições & 300 & $11.955,14$ & $12.027,31$ & $0,60 \%$ \\
\hline \multirow{2}{*}{4} & sem restrições & 400 & $11.668,64$ & $11.668,64$ & $0,00 \%$ \\
\hline & com restrições & 400 & $11.798,51$ & $11.826,80$ & $0,24 \%$ \\
\hline
\end{tabular}

$\Delta \%$ : diferença (em porcentagem) do melhor resultado da programação linear e da Busca Tabu para os cenários analisados.

Por se tratar de uma série de procedimentos estruturados, não existe, por parte da Busca Tabu, a garantia de que as soluções obtidas são as ótimas para o problema em estudo. As melhores soluções registradas na tabela acima são encontradas após algumas rodadas de aplicação do procedimento. Para ilustrar esse comportamento, na tabela 5.15 são apresentados alguns resultados que nos permitem avaliar a eficiência do procedimento.

A análise dos dados dessa tabela leva-nos a crer que o procedimento Busca Tabu apresentou um bom desempenho no que diz respeito à qualidade das soluções obtidas.

No cenário sem restrições operacionais, em algumas das rodadas executadas, a Busca Tabu chegou à mesma solução ótima da programação linear. Nos demais casos, com exceção da rodada com 200 km de distância de cobertura, a solução obtida pela metaheurística está muito próxima da ótima. 
A partir da aplicação em 10 rodadas para cada um dos cenários indicados, a pior solução obtida foi apenas $2,64 \%$ mais "cara" (em termos de valor da função objetivo) que a solução ótima correspondente, sendo que na média essa diferença está próxima de $1 \%$.

Tabela 5.15 - Desempenho da Busca Tabu para os diferentes cenários do problema real

\begin{tabular}{|c|c|c|c|c|c|c|c|c|c|c|}
\hline & Restrito & $\begin{array}{c}\text { DC } \\
(\mathbf{k m})\end{array}$ & $\mathbf{N}$ & $\alpha$ & NV & $\begin{array}{l}\text { Critério } \\
\text { Parada }\end{array}$ & $\begin{array}{l}\text { Tempo } \\
\text { Médio } \\
\text { (mm:ss) }\end{array}$ & $\begin{array}{c}\text { Solução } \\
\text { Ótima }\end{array}$ & $\Delta \%$ & $\begin{array}{c}\text { [Mín; Máx] } \\
\text { (\%) }\end{array}$ \\
\hline 1 & Não & 150 & 10 & 0,8 & 60 & $20 / 50$ & $08: 52$ & 5 de 10 & 0,58 & {$[0 ; 2,20]$} \\
\hline \multirow{2}{*}{2} & Não & 200 & 10 & 0,8 & 60 & $20 / 50$ & $10: 53$ & 3 de 10 & 0,77 & {$[0 ; 2,58]$} \\
\hline & Sim & 200 & 10 & 0,8 & 60 & $20 / 50$ & \multicolumn{4}{|c|}{ Não obteve solução viável } \\
\hline \multirow{2}{*}{3} & Não & 300 & 10 & 0,8 & 60 & $20 / 50$ & 08:06 & 2 de 10 & 0,59 & {$[0 ; 1,26]$} \\
\hline & Sim & 300 & 10 & 0,8 & 60 & $20 / 50$ & $10: 32$ & 0 de 10 & 0,60 & {$[0,60]$} \\
\hline \multirow{2}{*}{4} & Não & 400 & 10 & 0,8 & 60 & $20 / 50$ & $10: 09$ & 2 de 10 & 0,76 & {$[0 ; 1,36]$} \\
\hline & Sim & 400 & 10 & 0,8 & 60 & $20 / 50$ & $13: 17$ & 0 de 10 & 1,27 & {$[0,24 ; 2,64]$} \\
\hline
\end{tabular}

Restrito: se não, cenário sem as restrições operacionais; se sim, com as restrições de mínimo de entregas e máximo de peso.

DC $(\mathrm{km})$ : distância de cobertura.

$\mathrm{N}$ : o número de vezes em que o procedimento foi aplicado.

$\alpha$ : parâmetro de probabilidade de mudança de status do componente do vetor solução.

NV: número de soluções vizinhas aleatórias geradas a cada iteração do procedimento.

Critério de Parada: número de iterações sem melhora / número total de iterações.

Tempo Médio: tempo médio (em minutos e segundos) gasto na execução do procedimento em um notebook Compaq, processador AMD 2800 1.6GHz, com 384MB de memória RAM.

Solução Ótima: do total de rodadas, quantas vezes o procedimento obteve a melhor solução possível.

$\Delta \%$ : variação percentual entre a média das soluções encontradas pelo procedimento e a solução ótima dada pelo modelo de programação linear.

[Mín; Máx] (\%): em percentual, qual a menor e a maior diferença entre as soluções geradas pela Busca Tabu e a solução ótima.

A ressalva fica por conta do tempo de processamento. Nesse ponto, a Busca Tabu não se mostra tão eficiente, à medida que cada rodada de sua aplicação dura em média 10 minutos, contra apenas três segundos do modelo em programação linear resolvido através do Solver.

Para ilustrar a diferença entre as soluções obtidas via programação linear e Busca Tabu, a seguir são apresentados os mapas de alocação para ambas as soluções em um mesmo cenário. 


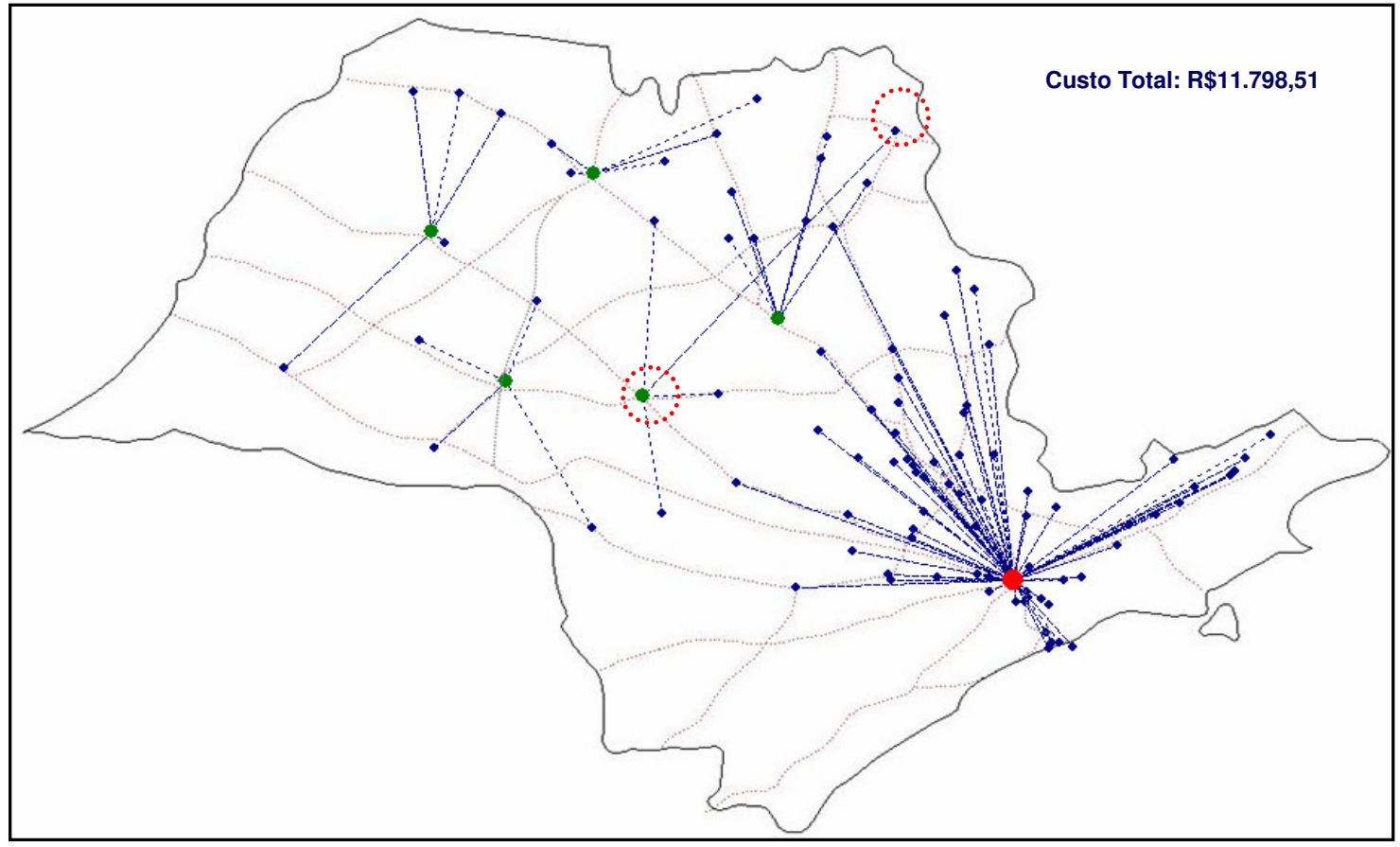

Figura 5.9 - Solução da PL para 400 km de cobertura, com restrições operacionais

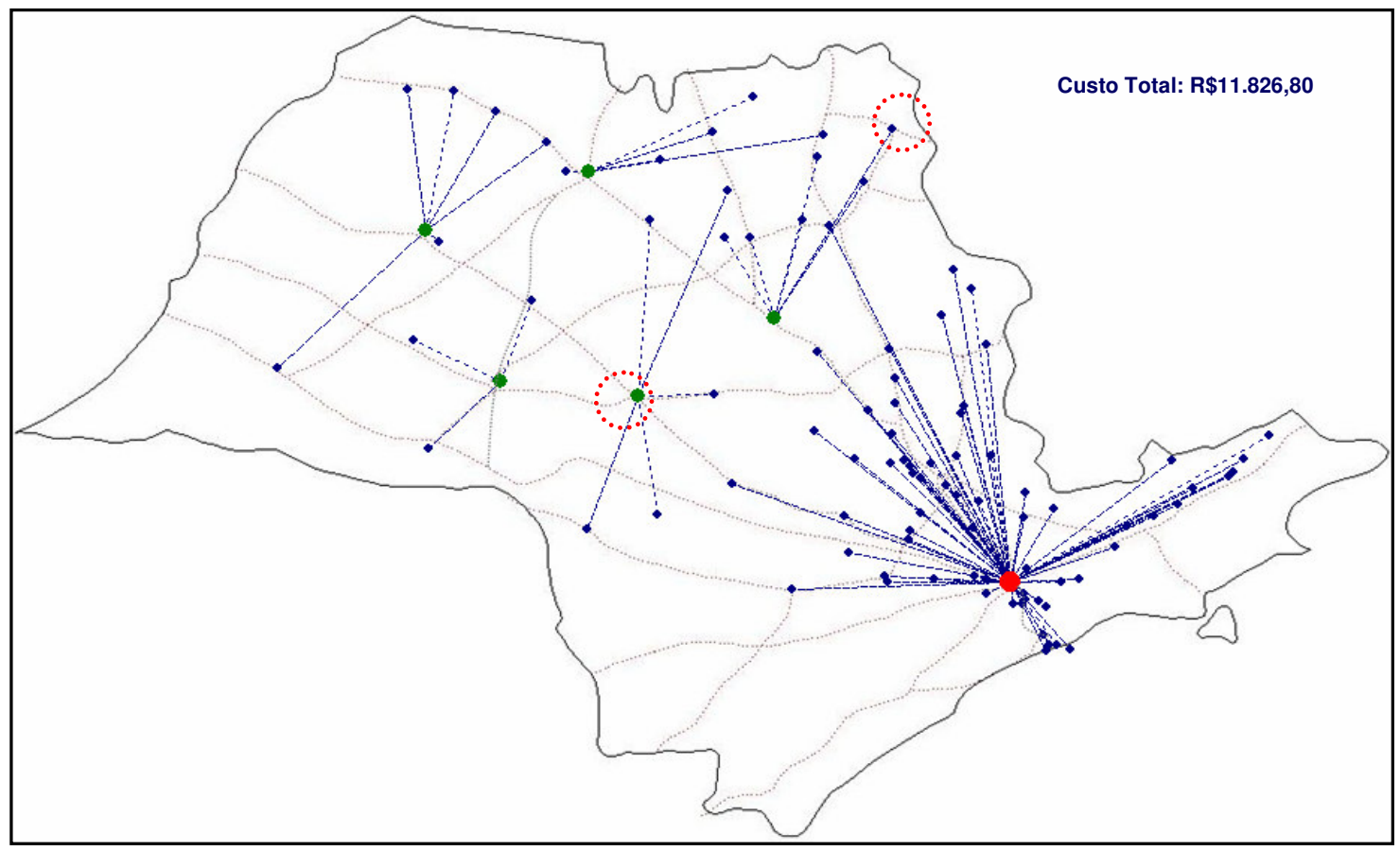

Figura 5.10 - Solução da BT para 400 km de cobertura, com restrições operacionais 
Pelas figuras acima, percebe-se que a alocação de apenas algumas cidades difere entre as soluções. Essa diferença é ocasionada pela fase de refinamento da Busca Tabu, na escolha entre os movimentos possíveis entre as centrais.

Do ponto de vista prático, a solução da metaheurística parece até mais viável, principalmente no que diz respeito à alocação das cidades à central Bauru (12). Na solução original da programação linear, a cidade de Franca (41) está alocada a essa central, o que já não ocorre na solução refinada da Busca Tabu (em destaque nas figuras 5.9 e 5.10).

\subsection{Considerações finais sobre a aplicação da metodologia}

Diante do exposto nesse capítulo, da comparação entre as soluções obtidas pelos dois métodos, podemos afirmar que ambos obtiveram resultados satisfatórios. Em particular, o procedimento baseado em Busca Tabu comprovou ser uma boa alternativa à programação linear, caso não seja possível aplicá-la ao problema, por exemplo, pela indisponibilidade do suplemento Premium Solver Platform (PSP), ou outra ferramenta que viabilize a implementação do modelo. 


\section{CONCLUSÕES E RECOMENDAÇÕES}

A metodologia adotada para a solução do problema de configuração de uma rede de distribuição capacitada, com restrição de cobertura, mostrou-se satisfatória, tanto do ponto de vista de resultados, quanto da viabilidade das soluções encontradas, a partir de sua aplicação em alguns cenários de um problema real de distribuição.

A modelagem teve como principal objetivo incorporar ao máximo as características reais do problema objeto do estudo. Assim, o tradicional modelo de localização, com função objetivo de minimização de custos das ligações entre os nós da rede, teve sua função modificada, com a inclusão de novas parcelas que representam com maior fidelidade a estrutura de custos de transporte.

Nessa mesma linha, como forma de tratar no modelo questões relacionadas à prestação do serviço de transporte, foi feita a associação entre nível de serviço e distância de cobertura, sendo este conceito também incorporado à modelagem. Dessa forma, o atendimento ficou diretamente ligado, além do aspecto custo, também à proximidade da central ao ponto de demanda. Com isso, as chances de cumprimento dos prazos de entrega aumentam, à medida que a distância a ser percorrida na etapa de distribuição está limitada pela distância de cobertura, um dos parâmetros do modelo.

A modelagem incorporando o conceito de distância de cobertura ao modelo de mínimo custo mostrou-se possível, embora o conjunto resultante de restrições originado dessa combinação seja bastante rígido e, até certo ponto, difícil de ser respeitado. Tanto que para alguns cenários não foi possível encontrar solução viável. 
No entanto, a associação da distância de cobertura ao nível de serviço, e a variação desse parâmetro nos diversos cenários de aplicação do modelo, permitiram a análise de alguns trade-offs muito importantes na tomada de decisões. Entre eles podemos citar o nível de serviço versus o número de representantes necessários e nível de serviço versus custo total da operação.

Ainda no que diz respeito à fidelidade da modelagem proposta ao problema real, dois grupos de restrições foram adicionados. O primeiro - peso máximo a ser distribuído por cada central candidata - retratou a disponibilidade do recurso frota de distribuição alocada em cada uma das potenciais centrais de desconsolidação de carga. O segundo grupo de restrições - limite mínimo de entregas - conferiu ao modelo o aspecto de viabilidade econômica, à medida que exigiu um volume mínimo de movimentação a ser alocada em determinada central para que esta pudesse ser utilizada.

Uma outra contribuição do presente estudo está na estruturação de um procedimento capacitado baseado em Busca Tabu, algo encontrado em apenas um trabalho da literatura pesquisada.

O fato de tanto o modelo de programação linear quanto o procedimento Busca Tabu terem sido implementados e resolvidos em planilha eletrônica, se constitui em um facilitador à sua utilização e um ponto de destaque da metodologia adotada.

Principalmente no que diz respeito às alternativas de solução propostas, tanto a modelagem em programação linear, quanto a Busca Tabu se mostraram viáveis de serem aplicadas ao problema de natureza tática descrito nesse trabalho. 
A utilização dos suplementos Solver do Excel tornou possível a solução do modelo de programação linear de forma conveniente, tanto do ponto de vista de qualidade da solução, quanto de tempo computacional para sua obtenção.

Já em relação à Busca Tabu, a sua implementação em Excel não foi tão eficiente sob o aspecto tempo computacional, em relação às soluções obtidas. No entanto, buscou-se resolvêlo em planilha eletrônica como forma de superar uma limitação de programação do próprio autor.

Contudo, não se pode afirmar que esse tempo inviabilize a utilização do procedimento elaborado, ainda mais se considerado seu aspecto tático. Isso porque sua utilização deverá estar associada à tomada de decisões para as quais normalmente se dispõe de tal tempo, por se tratar de atividade de planejamento de distribuição.

A implementação de uma macro no Excel que, a partir dos dados de latitude e longitude das cidades da rede em estudo, permite plotar em um gráfico (que tem como plano de fundo a malha rodoviária da região estudada) a solução de alocação obtida, seja da aplicação do modelo de programação linear, ou da Busca Tabu, possibilitando ao tomador de decisões um melhor entendimento acerca dos resultados obtidos; portanto, outro ponto positivo da metodologia adotada.

Como recomendações de continuidade desse trabalho, a codificação da metaheurística Busca Tabu em uma linguagem de programação mais apropriada, por exemplo, C++, poderá resultar na diminuição do seu tempo de processamento, melhorando, pois, sua eficiência. 
Além disso, a incorporação de rotinas mais elaboradas à sua estrutura, tais como memória de longo prazo, estratégias de diversificação e intensificação do espaço de busca, bem como a variabilidade de alguns parâmetros (como o comprimento da lista tabu), são questões importantes a serem consideradas com o objetivo de melhoria do desempenho da metaheurística.

Em termos da metodologia sugerida, sua aplicação em redes de abrangência nacional, envolvendo também o modal de transporte aéreo, seria uma das possibilidades de extensão do estudo ora descrito. A partir da adaptação da estrutura de custos de transporte de transferência, o modelo proposto pode se prestar para a configuração de uma rede de distribuição multimodal.

Esse trabalho não teve como pretensão esgotar o assunto referente aos problemas de localização e configuração de redes de distribuição. O objetivo foi, a partir da implementação de um modelo de programação linear inteira e de um procedimento simples com base em Busca Tabu, contribuir para a pesquisa e utilização de ferramentas de pesquisa operacional na solução de problemas de planejamento de distribuição de carga fracionada em sistemas como o do estado de São Paulo. 


\section{REFERÊNCIAS BIBLIOGRÁFICAS}

AL-SULTAN, K.S.; AL-FAWZAN, M.A. A tabu search approach to the uncapacitated facility location problem. Annals of Operations Research, v. 86, p. 91-103, 1999.

BALLOU, R. H. Gerenciamento da cadeia de suprimentos: planejamento, organização e logística empresarial. 4. ed. Porto Alegre: Bookman, 2001.

BRANDEAU, M.L.; CHIU, S.S. An overview of some representative location problem. Management Science, v. 35, p. 645-674, 1989.

CARMONA, T. Programação de planilhas em VBA. São Paulo: Digerati Books, 2006.

CHURCH, R.; MEADOWS, M. Location modeling utilizing maximum service distance criteria. Geographical Analysis, v. 11, p. 358-373, 1979.

CHURCH, R.; REVELLE, C.; The maximal covering location problem. Regional Science Association, v. 32, p. 101-118, 1974.

CRUZ, C.; RIBEIRO, U. Metodologia científica: teoria e prática. Rio de Janeiro: Axcel Books, 2003.

DASKIN, M. S. Network and discrete location: models, algorithms, and applications. New York: John Wiley \& Sons, Inc, 1995.

DASKIN, M. S. et. al. Facility location in supply chain design. Illinois: Northwestern University, 2003. Disponível em < http://www.lehigh.edu/ rtb3/facil-loc-sc.pdf $>$. Acesso em: 16 out. 2004.

FYLSTRA, D. et al. Design and use of the Microsoft Excel Solver. Interfaces, v. 28, n. 5, p. 29-55, 1998.

GENDREAU, M. An introduction to tabu search. Universidade de Montreal, Montreal, Canadá, 2002.

GENDRON, B.; et al. A Tabu search with slope scaling for the multicommodity capacitated location problem with balancing requirements. Annals of Operations Research, v. 122, p. 193-217, 2003. 
GIANNIKOS, I.; NICKEL, S. (Orgs.) Some personal views on the current state and the future of location analysis. European Journal of Operational Research, v. 104, p. 269-287, 1998.

GLOVER, F. Tabu search - Part I. ORSA Journal on Computing, v. 1, n. 3, p. 190-206, 1989.

. Tabu search - Part II. ORSA Journal on Computing, v. 2, n. 1, p. 4-32, 1990a.

. Tabu search: a tutorial. Interfaces, v. 20, n. 4, p. 74-94, 1990 b.

GLOVER, F.; LAGUNA, M. Tabu Search, Boston: Kluwer Academic Publishers, 1997.

GUMUS, M.; BOOKBINDER, J. H. (2004) Cross-docking and its implications in locationdistribution systems. Journal of Business Logistics, v. 25, n. 2, 2004.

HAKIMI, S.L. Optimal locations of switching centers and the absolute centers and the medians of a graph. Operations Research, v. 12, p. 450-459, 1964.

LACERDA, L. Considerações sobre o estudo de localização de instalações. Rio de Janeiro, 1998. Disponível em: <http://www.cel.coppead.ufrj.br>. Acesso em: 25 jul. 2004.

LACERDA, L.; VASCONCELLOS, R. S. Utilização de planilhas eletrônicas como interface para modelagem de problemas de programação matemática. Rio de Janeiro, 1996. Disponível em: <http://www.cel.coppead.ufrj.br >. Acesso em: 25 jul. 2004.

MICHEL, L.; VAN HENTENRYCK, P. A simple tabu search for warehouse location. European Journal on Operations Research, v. 157, p. 576-591, 2004.

MUTARELLI, F. Modelagem de redes de distribuição aplicada ao caso de uma editora de revistas. Dissertação (Mestrado) - Escola Politécnica, Universidade de São Paulo, São Paulo, 2004.

OSMAN, I. H.; LAPORTE, G. Metaheuristcs: a bibliography. Annals of Operations Research, v. 63, p. 513-623, 1996.

OWEN, S. H.; DASKIN, M. S. Strategic facility location: a review. European Journal of Operational Research, v. 111, p. 423-447, 1998. 
PIRLOT, M. General local search methods. European Journal of Operational Research, v. 92, p. 493-511, 1996.

PIZZOLATO, N. D. Localização de escolas públicas: síntese de algumas linhas de experiências no Brasil. Pesquisa Operacional, v. 24, n. 1, p. 111-131, 2004.

ROLLAND, E.; et al. An efficient tabu search procedure for the p-median problem. European Journal of Operational Research, v. 96, p. 329-342, 1996.

SILVA, M. R. Uma contribuição ao problema de localização de terminais de consolidação no transporte de carga parcelada. Dissertação (Mestrado) - Escola Politécnica, Universidade de São Paulo, São Paulo, 2004.

SILVA, M. R.; CUNHA, C. B. Configuração de redes do tipo hub-and-spoke para o transporte rodoviário de carga parcelada no Brasil utilizando algoritmos genéticos. Revista Transportes, v. 12, p. 23-31, 2004.

SUN, M.; McKEOWN, P. G. Tabu search applied to the general fixed charge problem. Annals of Operations Research, v. 41, p. 405-420, 1993.

TONDO, C. M. Um modelo matemático para a localização estratégica de terminais de contêineres no interior: aplicação ao estado de São Paulo. Tese (Doutorado) - Escola Politécnica, Universidade de São Paulo, São Paulo, 1992.

TUZUN, D.; BURKE, L. I. A two-phase tabu search approach to the location routing problem. European Journal of Operational Research, v. 116, p. 87-99, 1999.

VALLIM, A. R. Localização de centros de distribuição de carga: contribuições à modelagem matemática. Tese (Doutorado) - Escola Politécnica, Universidade de São Paulo, São Paulo, 2004.

VOSS, S. Meta-heuristcs: the state of the art. Local Search for Planning and Scheduling, LNAI 2148, p. 1-23. Berlin: Springer-Verlag, 2001. 


\section{APÊNDICE A - IMPLEMENTAÇÕES EM EXCEL}

O objetivo deste apêndice é apresentar alguns detalhes e características das implementações do modelo de programação linear, do procedimento Busca Tabu e também do aplicativo para geração dos mapas de alocação das soluções obtidas em ambos os métodos, todos no ambiente de planilha eletrônica do Microsoft Excel.

\section{A.1 Suplemento Solver do Excel}

Para viabilizar a solução do modelo de programação linear, foi utilizado o suplemento Solver, primeiramente em sua versão padrão, que acompanha a planilha eletrônica Excel. Porém, devido à restrição do número de variáveis de decisão que o programa é capaz de manipular (até 200), buscou-se uma versão complementar do suplemento, o Premium Solver Platform (PSP), da empresa Frontline System, para a solução do modelo em problemas de maior dimensão.

Segundo Flystra et. al (1998), desde a sua introdução em 1991, o Solver tornou-se o mais distribuído, e geralmente mais utilizado, sistema com o propósito de modelagem e otimização. Ainda segundo os autores, de 80 a 90\% dos 35 milhões de usuários desse tipo de software, utilizam o Solver padrão que acompanha o Excel.

A utilização do suplemento parte do princípio de que o modelo já se encontra estruturado em planilha eletrônica, ou seja, a equação da função objetivo, as variáveis de decisão e as restrições já possuem células reservadas na planilha. Com isso, os parâmetros e opções do Solver são preenchidos para que seus algoritmos sejam processados. 
A interface com o usuário não é muito diferente no caso do PSP. Além do aumento no número de variáveis que podem ser manipuladas, as demais configurações permanecem as mesmas, com o acréscimo de algumas informações nas caixas de diálogo.

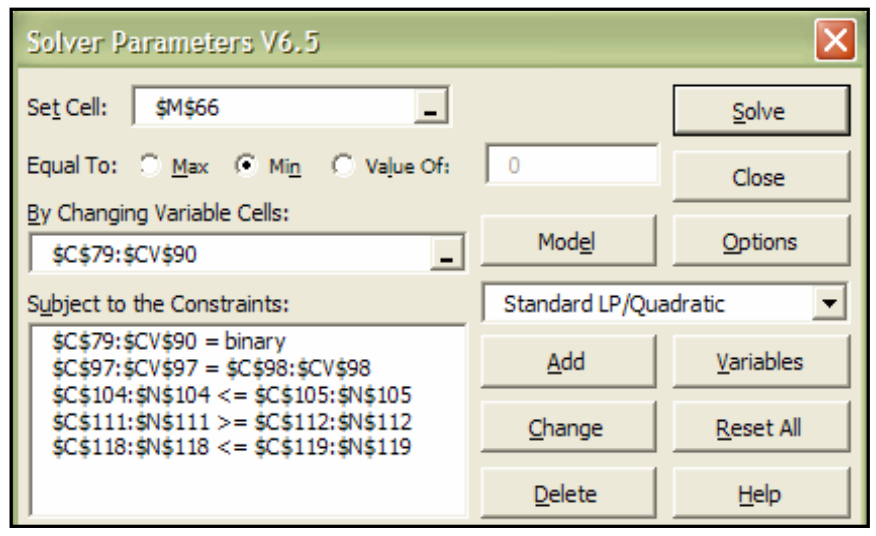

Figura A.1 - Tela de parâmetros do PSP

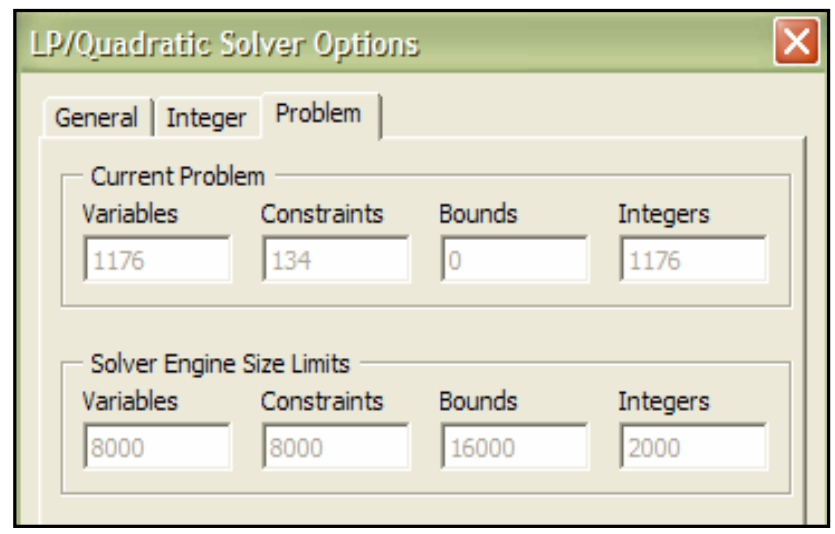

Figura A.2 - Tela de opções do PSP

\section{A.2 Codificação da Busca Tabu em Visual Basic for Application}

Em relação ao procedimento elaborado com base nos conceitos da metaheurística Busca Tabu, foi utilizada a linguagem de programação Visual Basic for Application (VBA), conforme descrito no tópico 4.4, que trata do encaminhamento da metodologia proposta para implementação do procedimento. 
O programa foi estruturado em duas grandes macros, que correspondem exatamente às duas principais fases do procedimento. A primeira é a que define quais, dentre os locais candidatos, serão selecionados como centrais de desconsolidação de carga. Trata-se da macro Busca Tabu. A outra é a macro Refinamento, que diz respeito à realocação das cidades com o objetivo de atender a todas as restrições de capacidade.

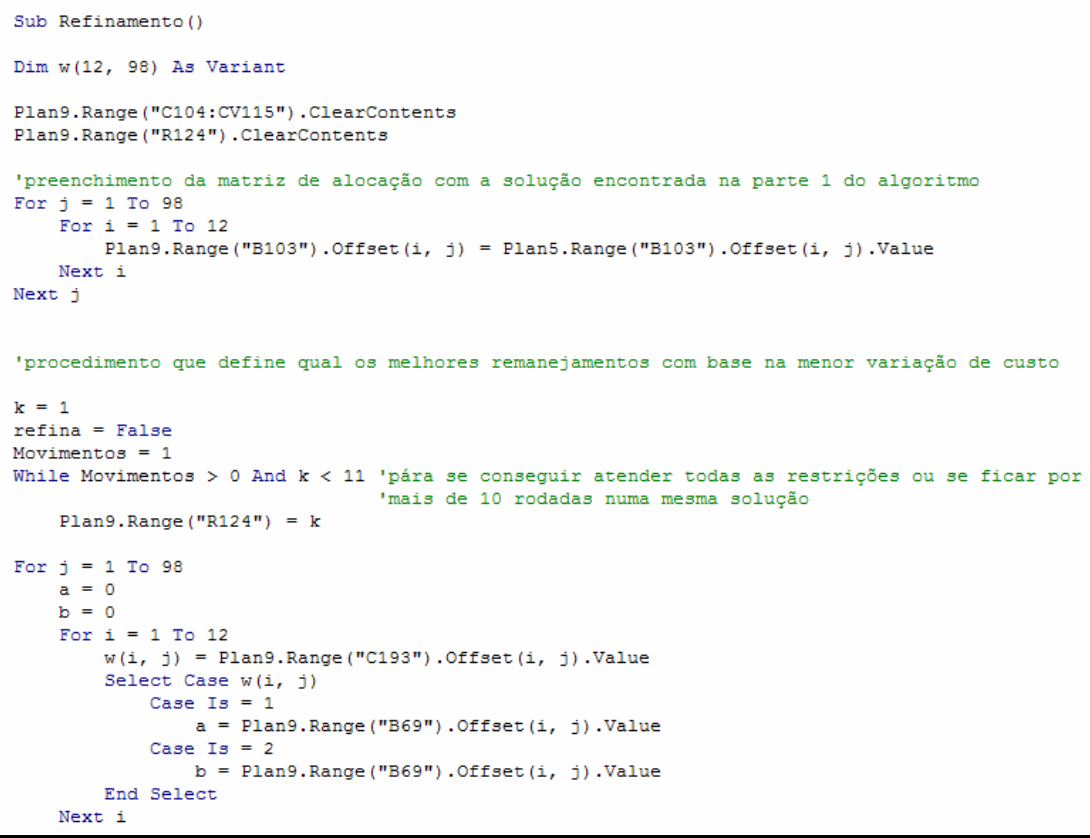

Figura A.3 - Trecho da macro Refinamento codificada em VBA

A fim de que fosse possível acompanhar as iterações do procedimento, os resultados intermediários (tais como as soluções vizinhas geradas, os vetores armazenados na lista tabu e as etapas de refinamento) são gravados nas planilhas. Foi desenvolvida também uma interface que funciona como "Menu Principal" do programa, que serve tanto para iniciar o procedimento de ambas as fases, quanto para acompanhar seu andamento. Através de caixas de mensagem, o programa informa o término da primeira fase, o início do refinamento e se foi encontrada ou não uma solução viável ao término dessa fase. 


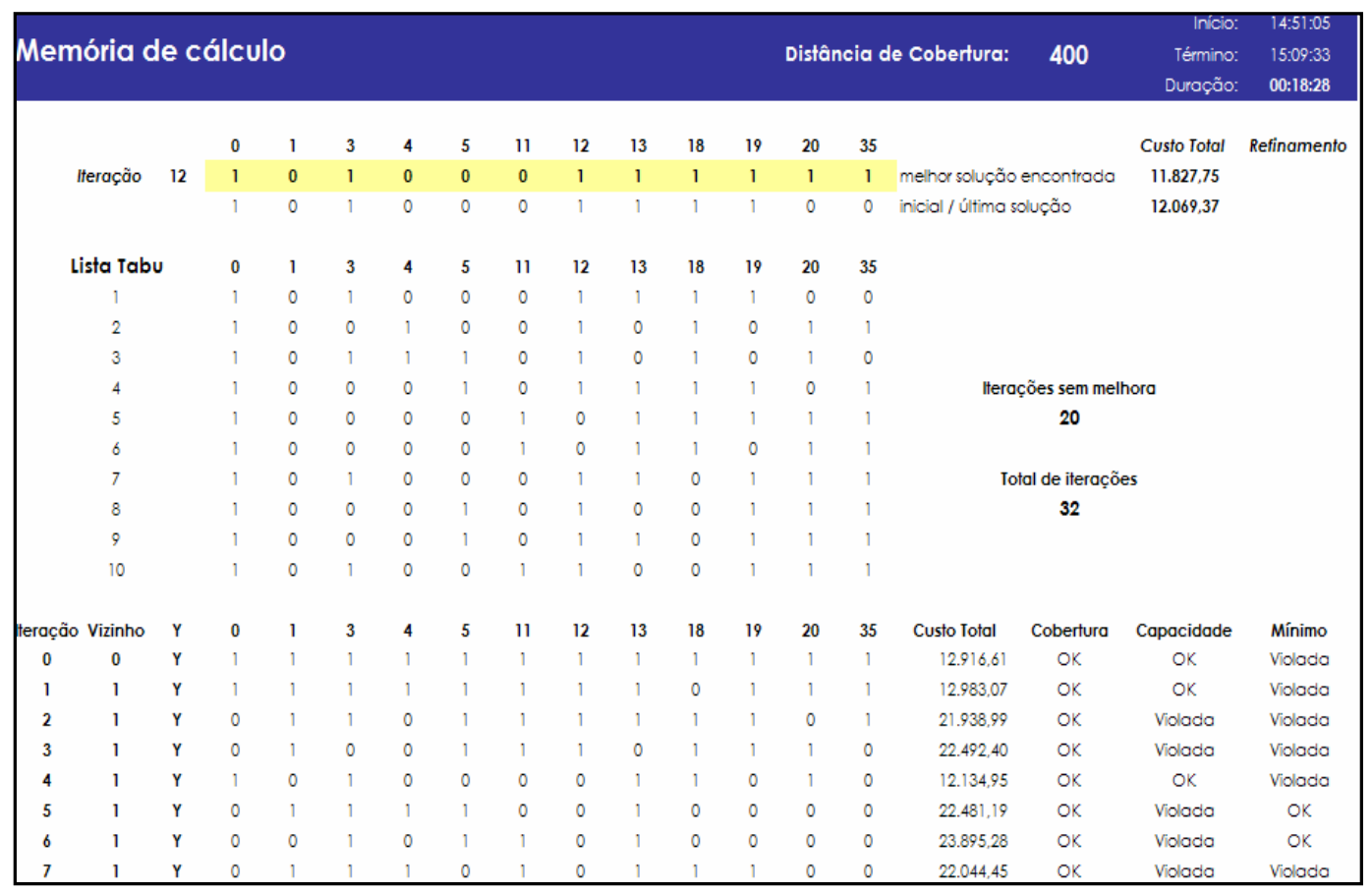

Figura A.4 - Planilha de registro dos resultados intermediários da Busca Tabu

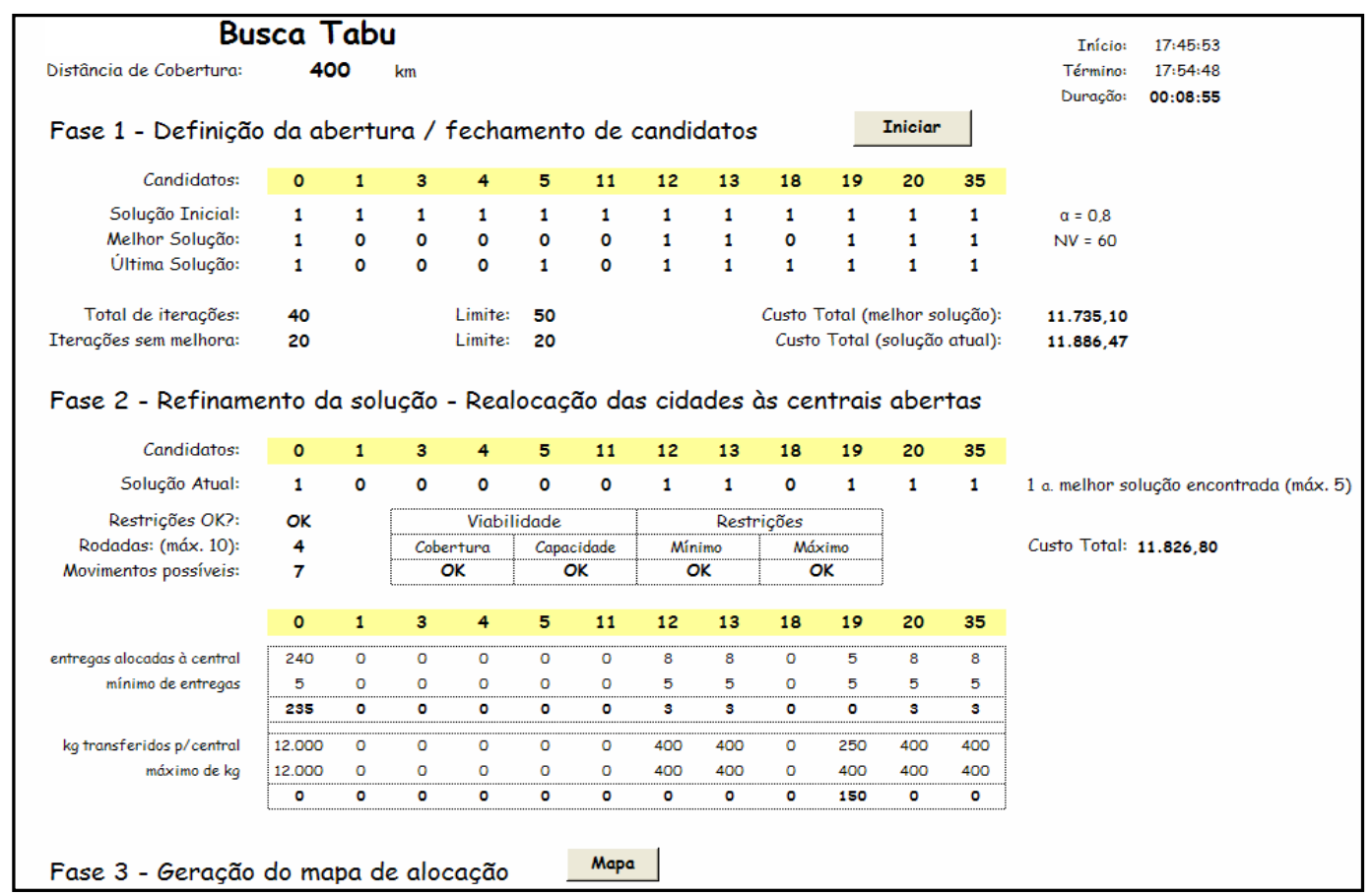

Figura A.5 - Planilha de acompanhamento das iterações do procedimento 


\section{A.3 Geração de mapas de alocação}

Embora os métodos propostos tenham apresentado desempenho satisfatório na solução do problema de configuração de rede estudado, as soluções obtidas, em termos de variáveis de decisão muitas vezes não possibilitam seu pleno entendimento. Isso porque se tratam de matrizes de alocação, onde são identificados quais arcos da rede (ligações entre nós) devem ser utilizados.

\begin{tabular}{|c|c|c|c|c|c|c|c|c|c|c|c|c|c|c|c|}
\hline \multicolumn{16}{|c|}{ VARIÁVEL DE DECISÃO: se a central atende ou não a cidade $(0=$ não; $1=\operatorname{sim})$} \\
\hline Nó' & NOME DO NÓ & 0 & 1 & 2 & 3 & 4 & 5 & 6 & 7 & 8 & 9 & 10 & 11 & 12 & 13 \\
\hline 0 & SAO PAULO & 1 & 1 & 1 & 0 & 1 & 1 & 1 & 1 & 1 & 1 & 1 & 1 & 0 & 0 \\
\hline 1 & CAMPINAS & 0 & 0 & 0 & 0 & 0 & 0 & 0 & 0 & 0 & 0 & 0 & 0 & 0 & 0 \\
\hline 3 & RIBEIRAO PRETO & 0 & 0 & 0 & 1 & 0 & 0 & 0 & 0 & 0 & 0 & 0 & 0 & 0 & 0 \\
\hline 4 & SAO JOSE DOS CAMPOS & 0 & 0 & 0 & 0 & 0 & 0 & 0 & 0 & 0 & 0 & 0 & 0 & 0 & 0 \\
\hline 5 & SANTOS & 0 & 0 & 0 & 0 & 0 & 0 & 0 & 0 & 0 & 0 & 0 & 0 & 0 & 0 \\
\hline 11 & SOROCABA & 0 & 0 & 0 & 0 & 0 & 0 & 0 & 0 & 0 & 0 & 0 & 0 & 0 & 0 \\
\hline 12 & BAURU & 0 & 0 & 0 & 0 & 0 & 0 & 0 & 0 & 0 & 0 & 0 & 0 & 1 & 0 \\
\hline 13 & SAO JOSE DO RIO PRETO & 0 & 0 & 0 & 0 & 0 & 0 & 0 & 0 & 0 & 0 & 0 & 0 & 0 & 1 \\
\hline 18 & PRESIDENTE PRUDENTE & 0 & 0 & 0 & 0 & 0 & 0 & 0 & 0 & 0 & 0 & 0 & 0 & 0 & 0 \\
\hline 19 & MARILIA & 0 & 0 & 0 & 0 & 0 & 0 & 0 & 0 & 0 & 0 & 0 & 0 & 0 & 0 \\
\hline 20 & ARACATUBA & 0 & 0 & 0 & 0 & 0 & 0 & 0 & 0 & 0 & 0 & 0 & 0 & 0 & 0 \\
\hline 35 & ARARAQUARA & 0 & 0 & 0 & 0 & 0 & 0 & 0 & 0 & 0 & 0 & 0 & 0 & 0 & 0 \\
\hline & & 1 & 1 & 1 & 1 & 1 & 1 & 1 & 1 & 1 & 1 & 1 & 1 & 1 & 1 \\
\hline
\end{tabular}

Figura A.6 - Planilha com parte da matriz de alocação (variáveis de decisão)

Para superar essa limitação, foi desenvolvida, ainda em ambiente Excel, uma macro codificada em $V B A$ que, a partir da matriz de alocação obtida em qualquer um dos dois métodos, ilustra a solução em um mapa.

Esse mapa é um gráfico cartesiano em que cada ponto corresponde a uma cidade da rede, com suas coordenadas dadas em latitude e longitude do centro da cidade. Do resultado da alocação, são plotados também os arcos que ligam as centrais a cada um dos pontos atendidos 
por ela. A transformação em mapa é conseguida com a utilização, como plano de fundo do gráfico, de uma figura com o contorno do estado de SP e suas principais rodovias.

Ao final do procedimento Busca Tabu, por exemplo, a partir do clique em um botão na planilha de acompanhamento das iterações, um mapa com a ilustração da solução (como o da figura abaixo) é gerado.

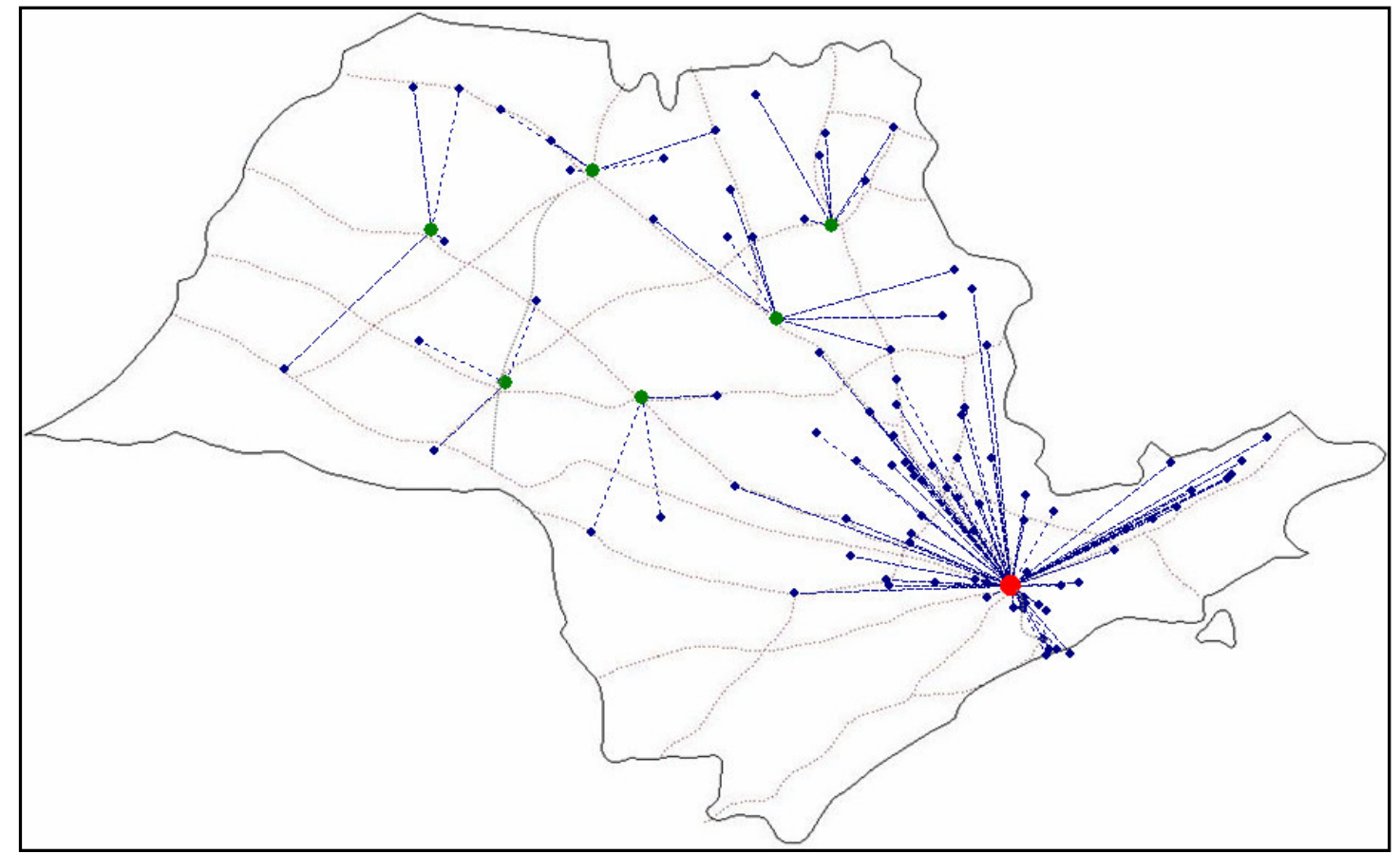

Figura A.7 - Exemplo de mapa de alocação gerado através de gráfico no Excel 